\title{
LA CONTRATACIÓN A TRAVÉS DE PLATAFORMAS INTERMEDIARIAS EN LÍNEA
}

\section{CONTRACT THROUGH ONLINE INTERMEDIARY PLATFORMS}

\author{
Matilde Cuena Casas \\ Catedrática de Derecho Civil \\ Universidad Complutense \\ Vicepresidenta de la Fundación Hay Derecho \\ ORCID ID: 0000-0001-8980-1186
}

Recibido: 17.06.2020 / Aceptado: 03.07.2020

DOI: https://doi.org/10.20318/cdt.2020.5612

Resumen: Las plataformas intermediarias en línea se han convertido en protagonistas del desarrollo del mercado digital y generan retos normativos importantes. Las nuevas tecnologías han favorecido nuevas formas de intercambio en las que el operador de la plataforma adopta una posición especial y compleja. El trabajo se centra en el análisis de las plataformas que, siendo prestadores de servicios de la sociedad de la información, actúan como intermediarias (también en sentido material), favoreciendo las transacciones entre los usuarios de la plataforma que pueden ser iguales (peer to peer, P2P, Consumer to Consumer, C2C) o entre empresarios (Business to Business, B2B), o entre empresario y consumidor (Business to Consumer, B2C). Se genera una relación contractual compleja: contrato celebrado por los usuarios con la plataforma que les permite el acceso para poder lograr la interacción y, posteriormente, el contrato celebrado entre los usuarios.

El objeto del presente trabajo es el diagnóstico y propuesta de solución de los problemas que suscita la contratación a través de plataformas intermediarias en línea. Tenemos nuevos operadores que no encajan exactamente en los modelos regulados en la legislación de comercio electrónico lo que plantea problemas para determinar su responsabilidad en las transacciones realizadas por los usuarios a través de las plataformas.

La "horizontalidad" de las relaciones jurídicas entre pares que se producen en un mercado multilateral es la que genera retos normativos. El acervo comunitario en materia de protección de los consumidores está basado en un modelo de distribución en cadena: fabricante, mayorista, minorista y consumidor en una escala vertical. El desequilibrio entre las posiciones de las partes cuando el empresario es proveedor y el adquirente consumidor (B2C), sirvió de justificación para el diseño de un sistema contractual de protección del consumidor, propio de la contratación en masa. La economía de la plataforma deja obsoleto este esquema porque los bienes y servicios se intercambian entre pares y los particulares actúan como proveedores (prosumidores). Y en este caso ¿Cuál es la parte débil que hay que proteger?

En la primera parte del trabajo se analiza el fenómeno de la contratación a través de plataformas intermediarias en línea, tradicionalmente vinculado a la denominada "economía colaborativa". Después

\footnotetext{
* Trabajo realizado en el marco del Proyecto de investigación (DER 2017-83321-P) sobre "Tutela de los consumidores y clientes de servicios FinTech", financiado por el Ministerio de Ciencia, Innovación y Universidades y del que soy investigadora principal. El trabajo forma parte de las actividades realizadas como miembro del Instituto de Derecho Europeo e integración regional (IDEIR). Universidad Complutense.

Este trabajo desarrolla y profundiza en ideas expuestas en mi monografía, Las FinTech de préstamos o crowdlending. La contratación a través de plataformas intermediarias en línea, Ed. Reus. Madrid, 2019.
} 
de las necesarias precisiones conceptuales se enumeran las características generales al mismo tiempo que se diagnostican los problemas que esta modalidad de contratación ocasiona. Los sistemas de reputación online y los problemas que ocasionan las reseñas falsas, la fijación de precios personalizados son algunos de los temas tratados.

La segunda parte del trabajo se centra en los problemas que genera la estructura triangular de la contratación a través de plataformas. Se analiza la relación entre los usuarios y el operador de la plataforma, los derechos y obligaciones de las partes, así como los contratos entre los usuarios entre sí en los que el operador de la plataforma no es parte, pero interviene de forma activa. El trabajo concluye con unas propuestas de reforma legales que favorezcan la transparencia en esta modalidad de contratación y aclaren el régimen de responsabilidad del operador de la plataforma.

Palabras clave: economía colaborativa, plataformas intermediarias en línea, prosumidores, responsabilidad civil operador de la plataforma.

Abstract: Online intermediary platforms have become major players in the development of the digital marketplace and raise important regulatory challenges. Technological progress

This article focus on the analysis of platforms which are information society service providers and act as intermediaries (also in the material sense) enabling transactions between all kind of platform users: consumers (peer to peer, P2P, Consumer to Consumer, C2C) or entrepreneurs (Business to Business, B2B). A complex contractual relationship is generated: the contract concluded by the users with the platform that allows them access in order to achieve the interaction and, subsequently, the contract concluded between the users.

The purpose of this paper is to diagnose and propose solutions to problems arising from contracting through online intermediary platforms. We have new operators who do not exactly fit into the models regulated in e-commerce legislation, which poses problems in determining their responsibility for the transactions carried out by users through the platforms.

The "horizontality" of the legal relationships between peers in a multilateral market that creates regulatory challenges. The Community acquis on consumer protection is based on a chain distribution model: manufacturer, wholesaler, retailer and consumer on a vertical scale. The imbalance between the positions of the parties when the entrepreneur is a supplier and the purchaser a consumer (B2C), served as a justification for the design of a contractual system of consumer protection, typical of mass contracting. The economics of the platform makes this scheme obsolete because goods and services are exchanged between peers and individuals act as suppliers (prosumers). And in this case, what's the weak part to protect?

The first part of the paper analyses the phenomenon of recruitment through online intermediary platforms, traditionally linked to the so-called "collaborative economy". After the necessary conceptual clarifications, the general characteristics are listed, at the same time as the problems that this contracting modality causes are diagnosed. Online reputation systems and the problems caused by false reviews, custom pricing are some of the topics discussed.

The second part of the article analyses the problems that the triangular structure of this kind of way of contract. It analyses the relationship between users and the platform operator, the rights and obligations of the parties, as well as contracts between users among themselves to which the platform operator is not a party, but is actively involved. The paper concludes with proposals for legal reform to promote transparency in this type of contract and clarify the liability regime of the platform operator.

Keywords: collaborative economy, online intermediary platforms, prosumer, civil liability of the platform operator.

Sumario: I. Economía colaborativa versus economía de la plataforma. 1. Descripción del fenómeno. 2. Precisión terminológica. De la economía colaborativa a la economía de la plataforma. II. Características de la contratación a través de plataformas intermediarias en línea. 1. Son mercados multilaterales. 2. Diversidad de usuarios que intervienen a través de plataformas. 3. El carácter instrumental de las plataformas intermediarias en línea. 3.1. Clasificación de las plataformas intermediarias en línea en función de su modelo de negocio. 3.2.2 Criterios para determinar el rol de la 
plataforma. En particular, la postura del TJUE en el caso Uber y el caso Airbnb. 4. Las plataformas intermediarias en línea como prestadoras de servicio de la sociedad de la información. Consecuencias. 4.1. No sujeción a autorización previa. 4.2. Plataformas intermediarias en línea y prestador de servicio de intermediación de la sociedad de la información. La responsabilidad del operador de la plataforma. 5. Mecanismos para la valoración de bienes y servicios. Los sistemas de reputación online. V. Régimen jurídico aplicable en la contratación a través de plataformas intermediarias en línea. 1. La relación entre el operador de la plataforma y los usuarios. 1.1. Naturaleza de la relación jurídica entre los usuarios y el operador de la plataforma. Contrato de mediación electrónica. 1.2. Derechos y obligaciones de las partes. 2. Régimen jurídico aplicable a los contratos celebrados entre los usuarios a través de plataformas intermediarias en línea. En particular, la posición jurídica del prosumidor. VI. Recapitulación. Retos jurídicos que plantea la "economía de la plataforma".

\section{La economía colaborativa versus economía de la plataforma}

\section{Descripción del fenómeno}

1. La digitalización de la economía fruto de los importantes avances tecnológicos de los últimos años, ha facilitado que emerja un nuevo modelo de mercado que está teniendo un crecimiento progresivo y constante, que queda englobado en lo que se ha denominado la economía colaborativa (sharing economy) o también denominada economía bajo demanda o consumo colaborativo: un conjunto heterogéneo $\mathrm{y}$ rápidamente cambiante de modos de producción y consumo por el que los agentes comparten, de forma innovadora, activos, bienes o servicios infrautilizados, a cambio o no de un valor monetario, valiéndose para ello de plataformas sociales digitales y, en particular, de internet ${ }^{1}$. Su impacto y desarrollo está siendo extraordinario a nivel mundial ${ }^{2}$, y parece que se cumple la conclusión que ya se vaticinó en 2011 que consideraba que la economía colaborativa era una de las 10 ideas que cambiarían el mundo ${ }^{3}$.

2. Paradójicamente, la tecnología, la irrupción del mercado digital ha permitido volver a formas ancestrales de intercambio de bienes y servicios, muchas veces a través del trueque, rememorando la economía de hace milenios ${ }^{4}$. A través de plataformas digitales ${ }^{5}$ los particulares pueden obtener de otro

${ }^{1}$ Comisión Nacional de los mercados y la competencia (CNMC)“Los nuevos modelos de prestación de servicios y la economía colaborativa”, $2016 \mathrm{https} / /$ docs.google.com/document/d/1n65MjUaTmRLuZCqTIlqyWvobVqreR-iAzsz1mhxy2y0/ edit (Consultado el 25 de febrero de 2020), p. 17.

En 2015 el Diccionario Oxford incluyó la locución «sharing economy» entre sus neologismos, definiéndola como "un sistema económico en el que bienes o servicios son compartidos entre particulares, de forma gratuita o a cambio de una suma de dinero, normalmente a través de internet". https://www.oxfordlearnersdictionaries.com/definition/english/sharing-economy (Consultado el 20 de mayo de 2020).

${ }^{2}$ Según el informe elaborado por R.VAUGHAN y R. DAVERIO "Assessing the size and presence of the collaborative economy in Europe", abril, 2016, PWC, sobre la base de los datos de plataformas dedicadas a alojamiento, transporte, finanzas, servicio doméstico y servicios profesionales, el crecimiento del sector en Europa en 2015 ha sido espectacular. Se generaron ingresos por valor de 4.000 millones de euros y se hicieron 28.000 millones de transacciones. El incremento es notable si se compara con los datos de 2013 (1000 millones de ingresos) y 2014 (1.800 millones de euros). https://www.pwc.es/es/publicaciones/digital/evaluacion-economia-colaborativa-europa.pdf (Consultado el 3 de marzo de 2020).

${ }^{3}$ B. Whals, “Today's Smart Choice: Don't Own. Share”, Revista Time 2011. http://content.time.com/time/specials/packages/article/0,28804,2059521_2059717,00.html (Consultado el 15 de mayo2020).

${ }^{4}$ D. García-Ochoa Mayor y D. Narvaez Barba "Economía colaborativa y financiación”, Diario LA LEY, no 8807 , de 20 de julio de 2016, No 8807, 20 de julio de 2016, p.2 (Smarteca).

${ }^{5}$ La tecnología ha favorecido la economía colaborativa, sin duda, pero no se puede restringir su concepto a aquella se produce online. Así lo ha señalado el Consejo Económico y Social Europeo (CESE), en el Dictamen sobre la «Comunicación de la Comisión al Parlamento Europeo, al Consejo, al Comité Económico y Social Europeo y al Comité de las Regiones - Una Agenda Europea para la economía colaborativa», COM (2016) 356 final], (2017/C 075/06). Se sugiere a la Comisión que acote el concepto de economía colaborativa evitando sesgos que la equiparen con la economía digital. Efectivamente, existen movimientos de economía colaborativa offline: los bancos del tiempo (se intercambian habilidades de los miembros de un grupo sin utilizar dinero. Solo se contabilizan las horas de servicio prestado y realizado), los grupos de consumo, o los coworkings son claros ejemplos de esta economía colaborativa offline. 
particular todo tipo de bienes y servicios de forma rápida, desde cualquier país del mundo y con una importante reducción de costes de transacción y de búsqueda, lográndose una monetización de recursos infrautilizados y reduciéndose las asimetrías informativas y el riesgo de selección adversa ${ }^{6}$. Como veremos, los sistemas de reputación diseñados por las plataformas tratan de generar un entorno de confianza que favorezca la contratación. Ante tasas altas de desempleo fruto de la crisis financiera de 2008, las necesidades de consumo se cubren compartiendo, alquilando, prestando bienes, en lugar de comprarlos (consumo colaborativo $)^{7}$. Los ciudadanos desconfían de un sistema que se ha construido basado en el sobreendeudamiento ${ }^{8}$ para fomentar el consumo y con él el crecimiento económico. Ese modelo ha fracasado y buena prueba de ello ha sido precisamente la crisis financiera de 2008. La desconfianza hacia el sistema financiero ha favorecido que, gracias a la tecnología, los ciudadanos puedan atender sus demandas de bienes y servicios sin recurrir al endeudamiento a través del sistema bancario. En este sentido, debe destacarse que el impulso de la economía colaborativa no es sino consecuencia, entre otros factores, de fallos regulatorios. Un mercado de crédito diseñado a favor de los acreedores con el objeto de abaratar el coste del crédito, acompañado de un régimen de insolvencia personal que dificulta la recuperación del deudor ${ }^{9}$, hace que, a pesar de las reformas emprendidas para tratar de paliar estos fallos, el ciudadano comience a desconfiar de los sistemas de financiación tradicionales.

3. La falsa recuperación de la crisis de 2008 se ha puesto de manifiesto en la subsiguiente a la emergencia sanitaria por la pandemia por Covid-19 que estamos padeciendo. Ese nivel de deuda privada fruto del sobreendeudamiento masivo de particulares y empresas que se evidenció en 2008, tuvo mucho que ver con el incremento de la deuda pública ${ }^{10}$. Hemos pasado de un endeudamiento público que no llegaba al $40 \%$ del PIB en $2008^{11}$ al $99 \%$ en el primer trimestre de $2020^{12}$. La deuda pública se disparó por la necesaria cobertura social que el Estado debe proporcionar para evitar situaciones de exclusión social de los ciudadanos, a lo que hay que sumar las cantidades empleadas en el rescate al sistema financiero. A ello se une la pérdida de ingresos públicos por economía sumergida. Cuando se ha producido la actual crisis sanitaria el Estado ha tenido que aumentar más el gasto público, pero careciendo de margen para hacerlo lo que nos coloca en un escenario más severo que en 2008. Por ello, si la recuperación económica post -pandemia no es en "uve asimétrica" sino en "L", la crisis económica será profunda y estructural. Pero la causa no estará solo en la paralización de la actividad económica por la pandemia por virus Covid-19, sino en el sobreendeudamiento masivo subyacente de particulares, empresas y Estados. Por lo tanto, las razones que impulsaron a la economía colaborativa en 2008 se reproducen en la actualidad tras la nueva crisis económica a la que nos enfrentamos.

${ }^{6}$ Vid. explicación detallada sobre los efectos de las asimetrías de información en G. DomenECH PASCUAL"La regulación de la economía colaborativa. El caso Uber contra taxi”, Revista CEFLEGAL, n 175-17, 2015, p. 61-104.

${ }^{7}$ El Comité Económico y Social Europeo (CESE) en su dictamen «Consumo colaborativo o participativo: un modelo de sostenibilidad para el siglo XXI» (Dictamen de iniciativa) 2014/C 177/01), 11 de junio de 2014, destaca que la economía colaborativa "supone una solución a la crisis económica y financiera en la medida que posibilita el intercambio en casos de necesidad". "El consumo colaborativo o participativo puede suponer un comportamiento resiliente frente a la actual situación económica y financiera, y puede ofrecer respuestas a las incertidumbres crecientes que provoca la crisis económica. Puede representar una oportunidad para retomar la senda de un desarrollo sostenible en lo económico, humano en lo social, y armónico con el planeta en lo medioambiental". http://eur-lex.europa.eu/legal-content/ES/TXT/PDF/?uri=CELEX:52013IE2788\&from $=$ ES (Consultado el 26 de febrero de 2018).

${ }^{8}$ R. Botsman, y R. Rogers “What's Mine Is Yours: The Rise of Collaborative Consumption”, Harper Collins, p. 21.

${ }^{9}$ España ha sido de los países de la UE que más ha tardado en regular un régimen de insolvencia personal que incorpore un régimen de segunda oportunidad para las personas físicas insolventes. Hasta la promulgación de la Ley 25/2015, de 28 de julio, de mecanismo de segunda oportunidad, reducción de carga financiera y otras medidas de orden social, la persona física insolvente, tras la liquidación de su patrimonio en el proceso concursal, se veía lastrada por el pasivo pendiente, sin posibilidad de recuperación, por la aplicación prácticamente indiscriminada del art. 1911 CC. Vid. M. CuENA CASAS "La exoneración del pasivo insatisfecho", en Prats Albentosa, L., Comentarios a la Ley de mecanismo de segunda oportunidad”, Thomson Aranzadi, 2016, pp. 61-161.

${ }^{10}$ Así se pone de relieve en el estudio llevado a cabo por S. Mibaye, M. Moreno Badía, K. Chae, "Bailing out the people? When Private debt becomes public", IMF Working paper 18/141. International Monetary Fund, 2018, p. 5, explican cómo España es un claro ejemplo de conversión de deuda privada en pública. https://www.imf.org/en/Publications/WP/ Issues/2018/06/21/Bailing-Out-the-People-When-Private-Debt-Becomes-Public-45904 (Consultado el 15 de mayo de 2020).

${ }^{11} \mathrm{https}$ ://datosmacro.expansion.com/deuda/espana?anio=2008 (Consultado el 5 de mayo de 2020).

$12 \mathrm{https} / / /$ datosmacro.expansion.com/deuda/espana (Consultado el 5 de mayo de 2020). 
4. Lo cierto y verdadero es que ya sea por razón de la crisis económica o por el factor tecnológico, asistimos a un cambio de mentalidad de los ciudadanos ${ }^{13}$ sobre la forma de relacionarse económica y socialmente ${ }^{14}$, en donde empieza a prevalecer la relación entre "pares" (peer to peer): intercambio de bienes (muchos de ellos, infrautilizados) y servicios entre iguales mediante regalo, trueque o incluyendo una contraprestación monetaria. Si tradicionalmente el intercambio económico se basa en una relación vertical entre el suministrador del bien o servicio (generalmente una empresa) y un demandante (consumidor o empresario), la economía colaborativa genera un mercado horizontal, entre iguales (peers), gracias al uso de plataformas digitales que son prestadores de servicios de la sociedad de la información. Con la economía colaborativa se obtienen ingresos o y se disfrutan de servicios a los que se tienen acceso en condiciones más favorables que en el marco del modelo tradicional de intercambio ${ }^{15}$.

5. Sin duda las nuevas tecnologías de la comunicación han sido un factor clave para estas formas de intercambio. A través de estas plataformas los usuarios adoptan una posición activa, se generan comunidades de usuarios, cambio de paradigma en el uso de internet que se engloba en el término Web 2.0, que surgió para referirse a nuevos sitios web caracterizados por la participación colaborativa de los usuarios. El término engloba las aplicaciones ${ }^{16}$ que permiten interactuar y colaborar a los usuarios quienes pueden generar su propio contenido en la red, generando una comunidad virtual ${ }^{17}$. Ello a diferencia de los sitios web tradicionales en los que se producía una intermediación meramente técnica y los usuarios adoptaban una posición pasiva limitándose a visualizar el contenido de una página web, modelo denominado Web. 1.0. Las plataformas de economía colaborativa ${ }^{18}$, son una manifestación de una nueva generación en la historia de internet donde los usuarios se intercambian información, contenidos, bienes y servicios, adoptando una posición activa, aprovechando la inteligencia colectiva.

${ }^{13}$ Resulta muy gráfico el ejemplo propuesto por Brian Chesky, fundador de la plataforma de alojamiento Airbnb. "En Estados Unidos existen aproximadamente unos 80 millones de taladros domésticos, cada uno de los cuales tiene un uso medio de unos 13 minutos a lo largo de su vida útil. Siendo esto así, ¿realmente necesitamos tener un taladro en propiedad? ¿no resultaría económicamente más rentable pagar por su uso cuando realmente necesitemos ese utensilio? ¿Y si trasladamos lo anterior al campo de la movilidad? Un coche se pasa de media más de un 95\% de su tiempo estacionado. Sólo en España existen 29 millones de coches, de los cuales 5 millones apenas salen del garaje. Adicionalmente, en España se calculan unos 100 millones de asientos de coche vacíos al día. ¿Estamos siendo realmente eficientes en la asignación de los recursos existentes y en el respeto al medio ambiente?" https://www.youtube.com/watch?v=KINsjz4K_34 (Consultado el 20 de abril de 2020).

${ }^{14}$ Este cambio de mentalidad es especialmente acusado en España. Como se ha puesto de relieve en el INFORME NIELSEN, "Compartir en sociedad", 2013, más de la mitad de los españoles (53\%) estaría dispuesto a compartir o alquilar bienes personales. Esta cifra supera en nueve puntos a la media europea registrada en el $44 \%$. Según el mismo estudio, se observa que en los países donde la crisis financiera ha impactado con mayor virulencia existe mayor predisposición a compartir o a alquilar. Ello evidencia que, aunque otros factores hayan podido coadyuvar a la aparición de este fenómeno, la crisis financiera ha sido uno de los más determinantes junto con los avances tecnológicos. http://www.nielsen.com/es/es/press-room/2014/la-crisis-lleva-amas-de-la-mitad-de-los-espanoles-a-querer-comp.html (Consultado el 13 de mayo de 2020).

${ }^{15}$ Como se señala en el Dictamen del Consejo Económico y Social Europeo (CESE), la clave no es el intercambio entre pares, "sino que lo que adquiere relevancia social y económica a partir del decenio de 2000, con el uso de internet y las redes sociales, no es una práctica recíproca de intercambio, sino más bien un «comportamiento prosocial no recíproco» o, más exactamente, «el acto y el proceso de distribuir lo que es nuestro con otros para su uso o el acto y el proceso de recibir o tomar alguna cosa de otros para nuestro uso». Por esta razón, la economía colaborativa se inspira en varias corrientes de pensamiento que van desde el libre acceso gratuito y universal al conocimiento a la economía de la funcionalidad o a la economía del don (gift economy), centrada en el trueque sin ánimo de lucro. A diferencia de la pura economía del trueque, la economía colaborativa se basa en una idea de contraprestación monetaria o no monetaria".

Dictamen del Comité Económico y Social Europeo sobre el tema «La economía colaborativa y la autorregulación» (Dictamen exploratorio) (2016/C 303/05). https://eur-lex.europa.eu/legal-content/ES/TXT/PDF/?uri=CELEX:52016AE0933\&from $=$ ES (Consultado el 20 de mayo de 2020).

${ }^{16}$ Como señala R. Truman "What is web 2.0? B\&T Weekly,2007, $p$. 18, esta nueva generación de internet a que se hace referencia con el término Web 2.0 se caracteriza por que los sitios web son plataformas, una interface rica y fácil de usar; se pone énfasis en la comunidad y la interacción; promueve a los usuarios como codesarrolladores, se pretende aprovechar la inteligencia colectiva; $y$, la audiencia decide lo que es importante.

${ }_{17}$ T. O'REILLY, "What is web 2.0: Design patterns and business models for the next generation of software". International Journal of Digital Economics No. 65, 2007, pp. 17-37. https://mpra.ub.uni-muenchen.de/4580/ (Consultado el 13 de mayo de 2020).

${ }^{18}$ M. PACHeCo JimÉnEz"La Web 2.0 como instrumento esencial de la economía colaborativa: auge de negocios de dudosa legalidad. Revista CESCO de Derecho de consumo, n 17, 2016, p. 2. 
6. Como he señalado, el consumo colaborativo supone un cambio de paradigma, una reacción ante el hiperconsumo basado en deseos inducidos y creados artificialmente que ha provocado la acumulación de bienes que, en muchos casos, son infrautilizados. Se postula un consumo basado en necesidades reales, en definitiva, un consumo responsable. La crisis financiera ha engullido el ahorro de los hogares y se impone la necesidad de controlar el gasto. Máxime ahora que se avecina una potente crisis económica mundial tras la pandemia por Covid-19. La economía colaborativa se impulsó para cubrir esas necesidades reales de los ciudadanos al menor coste posible, a lo que ha contribuido de manera decisiva la rapidez de las transacciones realizadas por internet que facilita la conexión entre las personas que necesitan acceso a un recurso con aquellas otras que dispongan de esos recursos y que están infrautilizados. Y todo ello a unos costes de transacción muy bajos. Este aspecto es clave. Como se ha señalado con un gráfico ejemplo, alguien puede estar dispuesto a pagar diez dólares para comprar un café. También puede haber otro sujeto que esté dispuesto a hacer ese recado cobrando cinco dólares. Está claro que hay un potencial para un comercio mutuamente beneficioso. La razón por la que esto puede no ocurrir es el coste de la transacción. Llevaría mucho tiempo y costaría mucho dinero "descubrir" quién es el otro individuo y negociar un precio (entre 5 dólares y 10 dólares), y hacer cumplir el acuerdo. En este escenario, los costes de transacción "se comen" la rentabilidad de intercambio, impidiendo que se produzca un comercio mutuamente beneficioso ${ }^{19}$. De ahí el importante papel que cumple la plataforma reduciendo tales costes de transacción y favoreciendo la actividad económica.

7. La presencia de esta modalidad de intercambio que viene acompañada de un cambio de cultura de gasto, no parece que sea transitoria, sino que ha llegado para quedarse, configurándose como un fenómeno económico, social y tecnológico imparable e inevitable a nivel mundial ${ }^{20}$.

8. Son muchos los sectores en los que se está desarrollando la economía colaborativa: alojamiento, movilidad y transporte, tareas y trabajo, consumo, conocimiento y educación, gastronomía, finanzas ${ }^{21}$. Aunque se puede decir que el mercado que, por el momento, más ha triunfado en España es el del transporte y alojamiento ${ }^{22} \mathrm{y}$, como veremos, también el que ha generado más litigiosidad. También a nivel europeo, el ámbito de la economía colaborativa que más se ha utilizado por los ciudadanos es el de alojamiento (57\%) y transporte (51\%) mientras que solo el $9 \%$ ha accedido a servicios profesionales por esta vía y el $8 \%$ a servicios financieros. Lo que está claro es que es un fenómeno en expansión. En 2018 en la UE, el 23\% de los ciudadanos han hecho uso de plataformas de economía colaborativa, habiéndose producido un incremento de cinco puntos desde 2016, año en el que el porcentaje fue del $17 \%{ }^{23}$.

${ }^{19}$ Este es uno de los aspectos más relevante que han impulsado el desarrollo de la economía colaborativa. Lo ilustran con un ejemplo C. AlLEN D., Y BerG, "The sharing economy. How over-regulation could destroy an economic revolution", Institute of public affairs, Melbourne pp. 1-39.

${ }^{20}$ Según datos recogidos en el informe de la Comisión EuropeA, "Exploratory study of consumer issues in online peer to peer platform markets. Final report" 12/06/2017, http://ec.europa.eu/newsroom/just/item-detail.cfm?item_id=77704 , p. 12, 191 millones de ciudadano de los 28 Estados miembros gastan 27.900 millones de euros al año en plataformas en línea P2P, según datos de mayo 2015 a mayo de 2016. El total de ingresos se calcula en 17.290 millones de euros. La diferencia de 10.610 millones incluye los ingresos, tanto de la plataforma como de terceros que prestan servicios a través de plataformas, por ejemplo, los servicios de pago, los controles de identidad y de los antecedentes y los servicios de seguros.

${ }^{21}$ Sobre las plataformas dedicadas a la financiación cfr. M. CuENA CASAS, Las FinTech de préstamos o crowdlending. La contratación a través de plataformas intermediarias en línea, Ed. Reus. Madrid, 2019 y M. CuENA CASAS (Dir.), La contratación Aspectos legales de la financiación en masa o crowdfunding, Ed. Tirant Lo Blanch, Valencia, 2020.

${ }^{22}$ El estudio realizado por T. VAughan y R. DaVeirio, "Assessing the size and presence of the collaborative economy in Europe", abril, 2016, PWC, destaca que el intercambio de alojamiento entre particulares supone un $25 \%$ de la oferta total de habitaciones en España y casi el 50\% de la capacidad de los centros turísticos urbanos. Este mercado está repartido básicamente en tres operadores: Airbnb con el $27 \%$, seguido de HomeAway con el $24 \%$ y Niumba con el $14 \%$. https://www.pwc.es/es/ publicaciones/digital/evaluacion-economia-colaborativa-europa.pdf (Consultado el 8 de mayo de 2020).

${ }^{23}$ Comisión Europea, "Flash Eurobarometer 467 Report. The use of the collaborative economy", octubre 2018, https://data. europa.eu/euodp/en/data/dataset/S2184_467_ENG (Consultado el 16 de mayo de 2020). 


\section{Precisión terminológica. De la economía colaborativa a la economía de la plataforma}

9. Como casi siempre sucede cuando emerge una realidad a la que el Derecho debe dar respuesta, no hay unanimidad sobre el concepto de economía colaborativa o, más bien, qué tipo de plataformas tienen la consideración de colaborativas, porque no toda prestación de un servicio entre pares a través de internet merece tal calificativo. Efectivamente, las plataformas digitales pueden ofrecer diversos servicios como motores de búsqueda en Internet (Google, Yahoo, Bing), mercados en línea (eBay, Booking. com, Asos, Allegro, Amazon), plataformas para compartir vídeos (por ejemplo, Dailymotion, Vimeo, YouTube), plataformas de música y vídeo (e. g., Dailymotion, Vimeo, YouTube, Deezer, Spotify, Netflix, Canal Play), redes sociales (p. ej. Facebook, Twitter), herramientas de comparación (Trivago. com, rentalcars.com, Kayac.com, booking.com, Tripadvisor). Uno de los servicios que pueden prestar es precisamente el de la economía colaborativa (AirBnB, Uber, BlaBlaCar, Ulule, Crowdcube) dentro de la cual también se ubica el crowdfunding, que afecta al mercado financiero.

10. Con la expresión "economía colaborativa (sharing economy) se refiere al hecho de "compartir economía", facilitándose el acceso a bienes y servicios a través de plataformas digitales sin tener que detentar su propiedad. En sentido estricto, el concepto de economía colaborativa englobaría únicamente a las plataformas que dan la posibilidad de usar recursos junto con otras personas, y así consumir de forma más eficiente, ya sea económica o medioambientalmente en áreas en las que previamente no se solían compartir esos recursos, por ejemplo, ofertar las plazas libres del coche, tal y como lo facilitan plataformas como Blablacar o Amovens, a cambio únicamente de compartir gastos ${ }^{24}$, reduciéndose el ámbito a las relaciones entre particulares $(\mathrm{C} 2 \mathrm{C})$. Este enfoque restrictivo estaba presente en el documento elaborado por las Comisión Nacional de los Mercados y la Competencia $(\mathrm{CNMC})^{25}$ que se refiere a la economía colaborativa como un modelo basado en "el intercambio entre particulares de bienes y servicios que permanecian ociosos o infrautilizados, a cambio de una compensación pactada entre las partes".

11. La Comisión Europea no se ha mostrado ajena al fenómeno de la economía colaborativa, consciente de que puede contribuir de manera importante al empleo y el crecimiento económico. Entre otras iniciativas que ha puesto en marcha y a las que posteriormente haré mención, destaca el documento sobre "Una agenda para la economía colaborativa", dirigido a dar orientación jurídica y política a las autoridades públicas, los operadores del mercado y ciudadanos interesados tal y como se anunció en la estrategia para el mercado único ${ }^{26}$.

12. Según ha definido la Comisión Europea el término economía colaborativa se refiere a «modelos de negocio en los que se facilitan actividades mediante plataformas colaborativas que crean un mercado abierto para el uso temporal de mercancías o servicios ofrecidos a menudo por particulares. La economía colaborativa implica a tres categorias de agentes i) prestadores de servicios que comparten activos, recursos, tiempo y/o competencias -pueden ser particulares que ofrecen servicios de manera ocasional ("pares") o prestadores de servicios que actúen a titulo profesional ("prestadores de servicios profesionales")-; ii) usuarios de dichos servicios; y iii) intermediarios que - a través de una plataforma en línea- conectan a los prestadores con los usuarios y facilitan las transacciones entre ellos ("plataformas colaborativas"). Por lo general, las transacciones de la economía colaborativa no impli-

${ }^{24}$ A. TOURIÑo, "La economía colaborativa desde la óptica de la competencia desleal. Análisis de los autos de medida cautelares dictados en los casos de Uber, Blablacar y Cabify", Actualidad Civil n 4, abril, 2016 (Smarteca), critica esta concepción porque excluiría servicios que sirven para conectar la oferta con la demanda de forma mucho más ágil que antes, aunque sin que ello suponga realmente compartir un recurso".

${ }^{25}$ Comisión Nacional de los Mercados y la competencia "Los nuevos modelos de prestación de servicios y la economía colaborativa”, 2016 https://www.cnmc.es/ambitos-de-actuacion/promocion-de-la-competencia/mejora-regulatoria/consultaspublicas/economia-colaborativa (Consultado el 16 de mayo de 2020).

${ }^{26}$ Comisión Europea, Comunicación de la Comisión al Parlamento Europeo, al Consejo, al Comité Económico y Social europeo y al Comité de las regiones "Mejorar el mercado único: más oportunidades para los ciudadanos y las empresas", 28 de octubre de 2015. Com. (2015) 550 final. 
can un cambio de propiedad y pueden realizarse con o sin ánimo de lucro ${ }^{27}$. No se acota el concepto a las relaciones $\mathrm{C} 2 \mathrm{C}$ por cuanto se refiere a que los bienes o servicios ofrecidos "a menudo por particulares". Se mantiene un concepto amplio que abarcaría transacciones en las que interviniera un profesional y el uso temporal de bienes y servicios es una de las opciones de mercado, pero no excluyente de otras.

13. La clave es que la plataforma actúa como intermediaria, siendo prestador de servicios de la sociedad de la información, pero, como veremos, también en sentido material, como intermediario de contenidos ${ }^{28}$ facilitando la interacción entre los usuarios. La actividad no es llevada a cabo por la plataforma, sino por los usuarios a través de ella, siendo el medio a través del cual se produce la interacción. Los sujetos que interactúan pueden ser iguales (peer to peer, P2P, Consumer to Consumer, $\mathrm{C} 2 \mathrm{C}$ ) o entre empresarios (Business to Business, B2B), o entre empresario y consumidor (Business to Consumer, B2C). Se genera una relación contractual compleja: contrato celebrado por los usuarios con la plataforma que les permite el acceso para poder lograr la interacción y, posteriormente, el contrato celebrado entre los usuarios. El negocio subyacente lo celebran entre sí los usuarios y en ningún caso lo presta la plataforma. En sentido estricto, la economía colaborativa sería una permuta o una compraventa: intercambio de bienes entre usuarios a través de una plataforma digital. Un ejemplo de ello sería, por ejemplo, la plataforma Wallapop en donde particulares intercambian bienes propios.

14. El mismo esquema tiene lugar en la denominada "economía bajo demanda" que también se suele englobar en el concepto de economía colaborativa en un sentido más amplio que es el que parece adoptar la Comisión Europea en el texto transcrito. Un usuario demanda un bien o servicio (no hay permuta) a través de una plataforma digital y otro usuario se lo presta. Normalmente se genera una relación entre profesional y consumidor (B2C) o entre particulares (P2P). Al igual que en el caso anterior, la plataforma no presta el servicio subyacente. Es el caso, por ejemplo, de Chefly, una plataforma española que ayuda a los usuarios a contactar con cocineros para que se desplacen a sus domicilios y les cocinen comida casera.

15. A mi juicio, la clave diferenciadora sería pues el papel de intermediario material que como prestador de servicios de la sociedad de la información desempeña la plataforma ${ }^{29}$, no llevando a cabo la actividad subyacente. Lo relevante no sería tanto el hecho objetivo de que se comparta un recurso, sino más bien la horizontalidad de la relación entre proveedor y usuario del bien o servicio. Coincido pues con aquellos que incluyen bajo el paraguas del concepto de economía colaborativa también los casos englobados bajo el concepto de economía bajo demanda ${ }^{30}$.

16. Y es que el término economía colaborativa genera cierta confusión por cuanto denota un componente altruista que no existe. Así, en un estudio se señaló que preguntados los ciudadanos americanos acerca del significado de "economía colaborativa", el 40\% pensaron que se refería a un modelo en el que las personas "comparten en sentido literal de forma caritativa para ayudar a los necesitados mediante el intercambio de recursos, ignorándose el aspecto económico de la operación ${ }^{31}$. Pero la reali-

\footnotetext{
${ }^{27}$ Comisión Europea, Comunicación de la Comisión al Parlamento Europeo, al Consejo, al Comité Económico y Social Europeo y al Comité de las Regiones. Una Agenda Europea para la Economía Colaborativa. Bruselas, 2.6.2016 COM (2016) 356 final, p. 3.

${ }^{28}$ Término utilizado por T. Rodríguez de las heras Ballell El régimen jurídico de los mercados electrónicos cerrados (e-Marketplaces), Marcial Pons, Madrid, 2006, p. 149, que me parece muy adecuado porque refleja fielmente la actividad de estos prestadores de servicios de la información a la que posteriormente haré referencia.

${ }^{29}$ En el Sharing España, "Los modelos colaborativos y bajo demanda en plataformas digitales", Sharing España, https:// www.fidefundacion.es/attachment/810605/ (Consultado el 15 de mayo de 2020) se define el modelo de economía "bajo demanda", "como modelos de consumo y provisión de servicios que se basan en la intermediación entre la oferta y la demanda generada habitualmente de profesional a consumidor (B2C) a través de plataformas digitales que no prestan el servicio subyacente y cuya prestación se origina en base a las necesidades del usuario que demanda y se adapta a sus preferencias, prestándose normalmente a cambio de una contraprestación y habitualmente con ánimo de lucro".

${ }^{30}$ A. Touriño, "La economía colaborativa desde la óptica de la competencia desleal, cit., p. 3.

31 A. Sмітн, "How americans define sharing economy", 20 de mayo de 2016 https://www.pewresearch.org/fact-tank/ 2016/05/20/how-americans-define-the-sharing-economy/ (Consultado el 20 de mayo de 2020).
} 
dad es que no hay nada de altruista porque se trata de una actividad que genera ingresos para sus intervinientes. Esa terminología es una especie de "marca blanca" en donde se subsumen variadas actividades que huyen de otra denominación que las pudiera hacer acreedoras de una regulación que se pretende evitar. De ahí que no hayan faltado quienes criticando tal término promueven otro que refleje el aspecto económico como el de "capitalismo de masas (crowd-based capitalism) ${ }^{32}$.

17. El denominador común en todos los supuestos y lo que denota y reclama especialidades de régimen es el papel de la plataforma y la estructura contractual es similar y los retos normativos que plantea son comunes porque se van a generar relaciones jurídicas que difícilmente se incardinan en los esquemas tradicionales y plantean problemas de calificación jurídica. Lo relevante no es tanto el bien o servicio que se contrata, sino la forma en que se contrata y para ello el papel de la plataforma en línea es el aspecto más relevante ${ }^{33}$. Por ello, por ejemplo, no entraría dentro del concepto de economía colaborativa, la denominada "economía de acceso" en la que la plataforma sí presta el servicio subyacente, poniendo a disposición de los usuarios unos bienes para su uso temporal adaptándose al tiempo de uso efectivo que requieren dichos usuarios y flexibilizando la localización espacial de los mismos ${ }^{34}$. Así, por ejemplo, responden a este modelo las plataformas que permiten compartir un coche, propiedad de la empresa titular de la plataforma, entre varias personas de forma no simultánea (carsharing). Otro ejemplo sería la plataforma La Manual, que es un espacio de coworking que ofrece espacios específicos para artistas, artesanos y diseñadores. En este caso, es la plataforma la que presta el servicio subyacente.

18. Puesto que la especificidad radica en la forma de la contratación la intervención legislativa debería hacerse respecto de ello y no tanto por la naturaleza del servicio prestado y de ahí que se haya acuñado el término "economía de la plataforma" ${ }^{35}$. Me parece adecuada la perspectiva amplia que adopta la definición diseñada por la Comisión Europea. La fragmentación del concepto y de su enfoque normativo por sectores de actividad podría conducir a solapamientos legales no deseables como ya hemos padecido en la forma de legislar de la UE en materia de protección del consumidor, en función del tipo contractual celebrado.

19. El enfoque regulatorio debe llevarse a cabo, a mi juicio, atendiendo a las modalidades de contratación realizadas a través de plataformas en línea ${ }^{36}$, es decir, modelos de interacción económica y no tanto por sectores de actividad ${ }^{37}$. Así lo ha puesto de relieve el Consejo Económico y Social Europeo al señalar en relación con el enfoque normativo del consumo colaborativo en función del sector, que

32 A. Sundarajan, The sharing economy. The end of employment and the rise of crowd-based capitalism, 2016. http://pinguet.free.fr/sundararajan.pdf (Consultado el 20 de mayo de 2020).

${ }^{33}$ Adoptan esta perspectiva, C. Busch; H. Schulte-Nölke; A. WiewiórowsKa-Domagalska; F. Zoll, "The Rise of the Platform Economy: A New Challenge for EU Consumer Law", in EuCML - Journal of European Consumer and Market Law, 1, 2016 https://papers.ssrn.com/sol3/papers.cfm?abstract_id=2754100 (Consultado el 20 de mayo de 2020).

${ }^{34}$ Sharing España, "Los modelos colaborativos y bajo demanda en plataformas digitales", cit., p. 8.

${ }^{35}$ Término que empieza a utilizar el Think Tank JPMorgan Chase Institute https://www.jpmorganchase.com/corporate/ institute/document/institute-ope-2018.pdf

Cfr. A., CHANDLER, "What should the sharing economy be called?" https://www.theatlantic.com/business/archive/2016/05/ sharing-economy-airbnb-uber-yada/484505/ (Consultado el 20 de mayo de 2010).

${ }^{36}$ Este es el enfoque, a mi juicio, adecuado, de la iniciativa europea para regular las plataformas intermediarias en línea con objeto de lograr una adecuada protección del consumidor que a su vez permita la innovación. De hecho, ya se ha creado un grupo de trabajo con este objetivo. Cfr. Research Group on the law of Digital services, "Discussion Draft of a Directive on Online Intermediary Platforms", Journal of European Consumer and Market Law, n 4/2016, p. 164 documento que se refiere a "economía de plataforma".

${ }^{37}$ No es este el planteamiento comúnmente aceptado. Así, Soria BARTOLOMÉ B., “Aspectos económicos de la economía colaborativa", en Montero Pascual, JJ., "La regulación de la economía colaborativa, Tirant lo Blanch, Valencia, 2017, p. 69 quien mantiene un concepto restrictivo de economía colaborativa: "aquella en la que un agente (el prestador) facilita a otro (el usuario) la utilización temporal de un bien (el activo) que no fue adquirido para dedicarlo a su uso por terceros, realizándose la transacción a través de un intermediario electrónico". No creo que la autonomía conceptual y la eventual necesidad de dotar de un régimen jurídico a la economía colaborativa deba depender del elemento objetivo (carácter sobrevenido del uso de bienes por terceros), de lo que se negocia, sino más bien la forma en la que se comparten dichos activos, es decir, a través de un intermediario. 
"este fragmentado enfoque de los nuevos modelos de negocio genera inseguridad (en el plano económico o normativo, en relación con la mano de obra, etc.) e incertidumbre (en lo referente a la confianza, los nuevos instrumentos digitales, como la tecnología de registro distribuido (blockchain), las redes de seguridad y la privacidad) entre los operadores tradicionales, los nuevos proveedores de servicios y los consumidores, limitando la innovación, la creación de empleo y el crecimiento ${ }^{38}$ ".

20. El 20 de junio de 2019 se aprobó el Reglamento 2010/1150 sobre el fomento de la equidad y la transparencia para las empresas que utilizan servicios de intermediación en línea ${ }^{39}$, que parte de este enfoque general que defiendo. Su objetivo es establecer un marco jurídico de los servicios de intermediación en línea ${ }^{40}$, incluyendo los motores de búsqueda ${ }^{41}$, que sirven de medio para el acceso de muchas empresas a sus clientes. La finalidad es, entre otras, garantizar la transparencia de las condiciones generales utilizadas por estos proveedores de servicios de intermediación. Respecto de lo que aquí interesa, por el momento basta señalar que abarca todos los servicios de intermediación incluyendo los mercados de comercio electrónico, mercados colaborativos en los que están activas las empresas, los servicios de aplicación de software en línea y los servicios de redes sociales en línea. El objetivo del Reglamento es regular las relaciones entre la empresa proveedora del servicio de intermediación y las empresas proveedoras de bienes o servicios dirigidos a los consumidores. Poco importa cuál sea el objeto del servicio, sino que el denominador común es que las empresas acceden al cliente a través de una plataforma. Se centra en las relaciones B2B en tanto que el acervo comunitario en materia de protección del consumidor ya se aplica a las relaciones entre la plataforma y los consumidores. Como se puede apreciar, pues, el enfoque es general, el de una nueva modalidad de contratación y es a través de una plataforma intermediaria en línea. Poco importa cuál sea el contenido del servicio que los usuarios se procuran a través de ellas.

21. El aspecto clave es determinar en todos los casos si la plataforma es auténtica intermediaria o no, pues caso de no serlo su actuación puede suponer una violación de las normas en materia de competencia desleal en los términos previstos en la Ley 3/1991, de 10 de enero de Competencia Desleal (en adelante, LCD) en el caso de que la plataforma no cumpla la normativa sectorial específica. Sin perjuicio de que este aspecto sea tratado posteriormente, basta adelantar ahora que si la plataforma es un mero

${ }^{38}$ Consejo Económico y Social Europeo (CESE), "Dictamen sobre la «Comunicación de la Comisión al Parlamento Europeo", al Consejo, al Comité Económico y Social Europeo y al Comité de las Regiones - Una Agenda Europea para la economía colaborativa» (2017/C 075/06), apartado 2.5. También T. RODRíGUEZ DE LAS HERAS BALLELL, La contratación en plataformas..., cit., p. 96 señala que la falta de un cuerpo armonizado de normas a nivel europeo de las plataformas debilita su actividad naturalmente transfronteriza y resulta claramente inconsistente con su inherente carácter digital.

${ }^{39}$ DOUE 11 de julio de 2019.

${ }^{40}$ Según el art. 2 del Reglamento, se consideran servicios de intermediación en línea los que cumplen los siguientes requisitos:

a) constituyen servicios de la sociedad de la información según lo previsto en el artículo 1, apartado 1, letra b), de la Directiva (UE) 2015/1535 del Parlamento Europeo y del Consejo;

b) permiten a las empresas ofrecer bienes o servicios a los consumidores, con el objetivo de facilitar el inicio de transacciones directas entre dichas empresas y clientes, con independencia de dónde aquellas se finalicen en última instancia;

c) se prestan a las empresas sobre la base de relaciones contractuales entre el proveedor de los servicios y los usuarios profesionales que ofrecen los bienes o servicios a los consumidores.

${ }^{41} \mathrm{El}$ art. 2.5 del Reglamento define los motores de búsqueda como «un servicio digital que permite a los usuarios introducir consultas para hacer búsquedas de, en principio, todos los sitios web o de sitios web en un idioma concreto mediante una consulta sobre un tema cualquiera en forma de palabra clave, consulta oral, frase u otro tipo de entrada, y que en respuesta muestra resultados en cualquier formato en los que puede encontrarse información relacionada con el contenido solicitado». Los proveedores de servicios de búsqueda, sin tener relación contractual con las empresas, ejercen un impacto en la elección de los clientes en función de lo fácil o difícil que sea para una empresa aparecer anunciada ante la introducción de un término en el buscador por parte de los clientes. El Reglamento pretende un incremento de la transparencia de estos operadores quienes deben exponer para los usuarios de sitios web corporativos los parámetros principales que determinan la clasificación de las webs de las empresas. Así, deben aclarar si el mecanismo de clasificación tiene en cuenta y en qué medida, las características de los bienes y servicios ofrecidos a los consumidores, la importancia de tales características para los consumidores o las características de diseño de los sitios web utilizados por los usuarios corporativos. De esta forma, las empresas pueden actuar con base en dichos criterios para favorecer que su web aparezca con mayor facilidad en los motores de búsqueda. 
prestador de servicios de la sociedad de la información ${ }^{42}$, su actividad no puede estar sujeta a autorizaciones previas o cualquier requisito equivalente dirigidos específica y exclusivamente a la prestación de dichos servicios. Como ha señalado la Comisión Europea ${ }^{43}$ los Estados miembros solo pueden imponer requisitos reglamentarios a las plataformas colaborativas que ofrecen tales servicios de forma transfronteriza desde otro Estado miembro en circunstancias limitadas y sujetos a un procedimiento específico (art. 2 y 2 Directiva Comercio electrónico 2000/31 (en adelante, DCE) ${ }^{44}$. Esta especialidad de régimen jurídico de los proveedores de servicios de la sociedad de la información, junto con el de neutralidad tecnológica garantizan la innovación y la libertad de expresión online y una red de internet abierta que ha favorecido el crecimiento de la economía digita ${ }^{45}$.

22. Teniendo en cuenta lo dispuesto en el art. $15 \mathrm{LCD}^{46}$, podría tener la consideración de competencia desleal la actuación constituida por la ventaja competitiva que pudiera surgir por realizar una actividad sin la licencia pertinente, perjudicándose al resto de operadores del mercado ${ }^{47}$. Pero esto sería así, si la plataforma prestara la actividad subyacente. Por eso es imprescindible definir las características que deben reunir las plataformas intermediarias en línea como protagonistas de esta modalidad de contratación sobre la que se está desarrollando la economía colaborativa o bajo demanda. Delineados estos caracteres será preciso en cada caso valorar si concurren o no en la plataforma cuya actividad se cuestione. Por ello -insisto- lo que dota a esta modalidad de contratación de novedad y, en su caso, acreedora de un régimen jurídico ${ }^{48}$ es precisamente el papel de la plataforma en la contratación realizada entre pares o entre profesionales y particulares y no tanto la naturaleza del bien o servicio que es objeto del contrato celebrado por los usuarios de la plataforma entre $\mathrm{si}^{49}$. La "vedette" del ecosistema digital es la platafor-

${ }^{42}$ Según se define en el Anexo C, de la LSSICE, se trata de la persona física o jurídica que proporciona un servicio de la sociedad de la información. Por tal se entiende todo servicio prestado normalmente a título oneroso, a distancia, por vía electrónica y a petición individual del destinatario. El concepto de servicio de la sociedad de la información comprende también los servicios no remunerados por sus destinatarios, en la medida en que constituyan una actividad económica para el prestador de servicios. En el anexo de la LSS se especifican lo que se considera servicios de la sociedad, entre otros, y siempre que representen una actividad económica, los siguientes:

1. ${ }^{\circ}$ La contratación de bienes o servicios por vía electrónica. 2. ${ }^{\circ}$ La organización y gestión de subastas por medios electrónicos o de mercados y centros comerciales virtuales. $3 .^{\circ}$ La gestión de compras en la red por grupos de personas. $4 .^{\circ} \mathrm{El}$ envío de comunicaciones comerciales. 5. $^{\circ}$ El suministro de información por vía telemática.

${ }^{43}$ Comisión Europea, "Una Agenda Europea para la Economía Colaborativa", cit., p. 6.

${ }^{44}$ Directiva 2000/31/CE del Parlamento europeo y del Consejo de 8 de junio de 2000 relativa a determinados aspectos jurídicos de los servicios de la sociedad de la información, en particular el comercio electrónico en el mercado interior (Directiva sobre el comercio electrónico).

${ }^{45}$ Así lo declaró el Vicepresidente de la Comisión Europea, quien lidera la iniciativa sobre Mercado único digital, ANSIP, A, en el discurso "Trasalantic regulation and the digital economy" https://ec.europa.eu/commission/commissioners/2014-2019/ ansip/announcements/speech-vice-president-ansip-transatlantic-regulation-and-digital-economy-panel-mobile-world-congress_en (Consultado el 12 de marzo de 2018).

${ }^{46}$ El artículo 15 de la LCD dispone que «1. Se considera desleal prevalerse en el mercado de una ventaja competitiva adquirida mediante la infracción de las leyes. La ventaja ha de ser significativa. 2. Tendrá también la consideración de desleal la simple infracción de normas jurídicas que tengan por objeto la regulación de la actividad concurrencial. 3. Igualmente, en el marco de lo dispuesto en el artículo 2, se considera desleal la contratación de extranjeros sin autorización para trabajar obtenida de conformidad con lo previsto en la legislación sobre extranjería».

${ }^{47}$ Esto es lo que se ha discutido precisamente en el caso de la "plataforma UBER": se trata de una aplicación informática que permite conectar a usuarios que necesitan un servicio de transporte con particulares dispuestos a prestar dicho servicio. Dado que tal servicio se presta sin necesidad de autorización administrativa ni licencia, el sector del Taxi entendió que se trataba de un acto de competencia desleal. Sobre ello se ha pronunciado el TJUE en la sentencia de 20 de diciembre de 2017 que será analizada posteriormente.

${ }^{48}$ Así lo ha puesto de relieve el Consejo EConómico y Social Europeo (CESE), en su dictamen sobre la «Comunicación de la Comisión al Parlamento Europeo, al Consejo, al Comité Económico y Social Europeo y al Comité de las Regiones - Una Agenda Europea para la economía colaborativa» (2017/C 075/06), señalando que "las plataformas digitales, en particular, las que sostienen una actividad lucrativa, merecen toda la atención de la Comisión Europea, a fin de regular y armonizar su actividad y garantizar un level playing field, sobre la base de la transparencia, la información, el pleno acceso, la no discriminación y la explotación adecuada de datos. En concreto, resulta imperativo redefinir el concepto de subordinación jurídica de cara a la dependencia económica de los trabajadores y garantizar los derechos laborales con independencia de los formatos que adopte la actividad".

${ }^{49}$ En este sentido, M.A., SÁnchez Huete, “Cuestiones tributarias y economía colaborativa”, Quincena Fiscal no 13, 2017. C.J. Correcher mato, "Economía colaborativa y recaudación tributaria: especial consideración al papel de la plataforma". 
ma. Como acertadamente se ha señalado, las plataformas han trasformado contextos sociales, políticos, educativos y de la vida pública, ofreciendo entornos participativos y de colaboración, creando nuevas oportunidades, facilitando la creación de comunidades, movilizando recursos y capital, y promoviendo la innovación ${ }^{50}$. El cambio está liderado por la plataforma, auténtica nueva protagonista y por todo ello me parece más afortunada la denominación "economía de la plataforma ${ }^{51}$ ".

\section{Características de la contratación a través de plataformas intermediarias en línea}

23. Las plataformas intermediarias en línea presentan características particulares que es preciso individualizar con carácter previo para posteriormente identificar los problemas concretos que plantean y la procedencia o no de su regulación y, en su caso, el enfoque de la misma.

24. La Comisión Europea (CE) mantiene una diversidad conceptual que perturba el análisis de esta problemática modalidad de contratación. La afición por parte de las instituciones europeas de regular distintos aspectos de la misma realidad en distintas normas, contribuyendo sobremanera a la creación de rompecabezas normativos, se está empezando a poner de relieve en la regulación de la «economía de la plataforma». En primer lugar, se alude a «plataformas en línea» que se definen por la CE como «empresas que operan en mercados bilaterales o multilaterales, que utilizan internet para permitir la interacción entre dos o más grupos de usuarios distintos pero interdependientes, de forma que se genere valor para al menos uno de los grupos. Ciertas plataformas pueden ser calificadas como proveedoras de servicios de intermediación $»^{52}$. El denominador común de todas estas plataformas es que permiten la interacción online entre usuarios mediante internet, ofertándose todo tipo de bienes y servicios.

25. Sin embargo, la Directiva ${ }^{53}$ sobre la mejora de la aplicación y la modernización de las normas de protección de los consumidores de la UE en la que se modifica, entre otras, la Directiva 2011/83/ UE sobre los derechos de los consumidores, alude a "mercados en línea". Estos son definidos como un servicio que permite a los consumidores celebrar contratos a distancia con otros comerciantes o consumidores mediante el uso de software, incluido un sitio web, parte de un sitio web o una aplicación operada por el comerciante o por cuenta de este. Concepto lacónico que deja fuera muchas de las características de la actuación de las plataformas.

26. Más desarrollado es el concepto introducido en el Reglamento sobre el fomento de la equidad y la transparencia para las empresas que utilizan "servicios de intermediación en línea" ${ }^{54}$. Se definen éstos en su art. 2 como los servicios que cumplen los siguientes requisitos:

Quincena Fiscal no 22/2018 BIB 2018/14316, para quien "la economía colaborativa, en la medida que se ubica en el intercambio entre particulares de bienes y servicios que aparecen infrautilizados, no resulta un fenómeno novedoso. Lo realmente innovador resulta el uso de medios electrónicos que permiten interconectar un gran número de personas". También ALARCóN Sevilla V., "Los datos personales de los usuarios en la economía colaborativa”, en Alfonso Sánchez, R., y Valero Torrijos (Dir.) Retos jurídicos de la economía colaborativa en el contexto digital, Aranzadi, 2017, P. 135, considera que plantearse actualmente si la economía colaborativa sigue siendo realmente colaborativa es cuestión estéril e infructuosa. J. CAMPOS CARVALHO, "Online platforms: concept, role in the conclusión of contracts and current legal framework in Europe", CDT Vol 12, No 1 (2020) https://doi.org/10.20318/cdt.2020.5227 (Consultado el 25 de mayo de 2020).

50 T. Rodríguez De las heras Ballell, "La contratación en plataformas electrónicas en el marco de la estrategia para el mercado único digital en la Unión Europea”, Castaños Castro, P., Castillo Parrilla, J. A., (Dirs.), El mercado digital de la Unión Europea, Ed. Reus, Madrid, 2019, pp. 89-123.

${ }^{51}$ Este término es el utilizado por el Research Group on the LAW of Digital SERvices, «Discussion Draft of a Directive on Online Intermediary Platforms», Journal of European Consumer and Market Law, no 4/2016, p. 164.

${ }^{52}$ COMISIÓN EUROPEA, "Consultation on Regulatory environment for platforms, online intermediaries, data and cloud computing and the collaborative economy", 24 September 2015 p. 5. Traducción propia.

${ }_{53}$ Directiva del Parlamento Europeo y del Consejo de 27 de noviembre de 2019 por la que se modifican la Directiva 93/13/ CEE del Consejo, de 5 de abril de 1993, la Directiva 98/6/CE del Parlamento Europeo y del Consejo, la Directiva 2005/29/CE del Parlamento Europeo y del Consejo y la Directiva 2011/83/UE del Parlamento Europeo y del Consejo, en lo que atañe a la mejora de la aplicación y la modernización de las normas de protección de los consumidores de la UE.

${ }^{54}$ Reglamento (UE) 2019/1150 del Parlamento europeo y del Consejo de 20 de junio de 2019 sobre el fomento de la equidad y la transparencia para los usuarios profesionales de servicios de intermediación en línea. 
a) constituyen servicios de la sociedad de la información según lo previsto en el artículo 1, apartado 1, letra b), de la Directiva (UE) 2015/1535 del Parlamento;

b) permiten a las empresas ofrecer bienes o servicios a los consumidores, con el objetivo de facilitar el inicio de transacciones directas entre dichas empresas y clientes, con independencia de donde aquellas se finalicen en última instancia;

c) se prestan a las empresas sobre la base de relaciones contractuales entre el proveedor de los servicios y los usuarios profesionales que ofrecen los bienes o servicios a los consumidores.

27. Este concepto es más completo que el anteriormente señalado. La perspectiva global que, a mi juicio, debe adoptarse en la regulación de la contratación a través de plataformas exige una única norma y, sobre todo, un único concepto. No debe suceder en esta materia lo acontecido en el pasado con los conceptos de consumidor y comerciante. El concepto de plataforma intermediaria en línea debe ser único en todas las normas, cualquiera que sea el aspecto que regulen, por más que sea deseable una única norma. Con base en las distintas definiciones, trataremos de establecer cuáles son las características que necesariamente deben concurrir para que nos encontremos en una plataforma intermediaria en línea.

\section{Son mercados multilaterales}

28. Las plataformas intermediarias en línea constituyen un mercado multilateral lo que significa que permiten que el lado de la oferta (los proveedores) satisfaga el lado de la demanda (los clientes), creando una estructura triangular que se basa en las relaciones entre (1) la plataforma y el proveedor (2) la plataforma y el consumidor, y (3) el proveedor y el cliente. Desde el punto de vista jurídico, esta estructura triangular es el aspecto fundamental de las plataformas y lo que más problemas plantea.

29. La relación de la plataforma con los usuarios es «horizontal», la propia de un mercado multi-side en tanto su grado de intervención y de influencia en los productos o servicios que ofrecen no permite configurarlo como prestador de servicios ${ }^{55}$.El valor creado es precisamente la interacción por la que normalmente la plataforma recibe una remuneración que puede cargar al proveedor del servicio o al usuario. Cuanto más fácil sea la interacción, mayor valor tiene la plataforma y crecerá cuantos más usuarios consiga atraer. Se produce así el denominado "efecto de red" que significa que los usuarios obtienen un beneficio adicional por la existencia de más usuarios en el lado opuesto del mercado ${ }^{56}$. El valor de la plataforma para un determinado grupo de usuarios (por ejemplo, proveedores) obtiene una mayor utilidad cuantos más usuarios tenga la plataforma, lo cual es un efecto lógico (es la también denominada interdependencia $)^{57}$. El éxito de la plataforma residirá en el correcto funcionamiento de la interacción y

\footnotetext{
${ }^{55}$ No hay unanimidad doctrinal acerca del concepto del mercado de doble cara. Mientras algunos autores consideran que tiene tal carácter aquellas plataformas que proporcionan efectos en red entre los dos grupos de usuarios conectados a través de ellas (M. Armstrong, «Competition in Two-Sided Markets,» Rand Journal of Economics, 37, 2006 p. 680), otros, J. ROCHET, CH., TIROLE “Two side markets: an overview», 2004 p. 3 http://web.mit.edu/14.271/www/rochet_tirole.pdf(Consultado el 6 de junio de 2020), por el contrario se centran en la falta de neutralidad en la estructura de precios establecida por la plataforma, de forma que se subvencione a un segmento de usuarios: «desde una perspectiva estratégica, las plataformas multisectoriales resuelven este problema subvencionando un segmento de clientes. A pesar de que un operador de plataforma incurre en costos al servir a todos los grupos de clientes, a menudo decide atraer un segmento a la plataforma con una propuesta de valor económico para atraer a los usuarios de las plataformas «otro lado». D.S. EVANS Y R. SCHMALENSEE, "Markets with Two-Sided Platforms. Issues in competition law and policy (ABA section of antitrust Law and Policy) (ABA Section of Antitrust Law), Vol. 1, Chapter 28, 2008. https://ssrn.com/abstract=1094820 (Consultado el 8 de junio de 2020), destacan el papel de la interdependencia de los usuarios como rasgo característico de las plataformas multi-side: la plataforma conecta a dos grupos de usuarios que no pueden captar el valor de su interacción por sí mismos. Es la plataforma la que crea ese valor por los efectos cruzados o interdependencia que se crea. Ello significa que la participación de un grupo de usuarios afecta la forma en que otros grupos valoran el servicio/bien que se proporciona. Claramente no serían plataformas multi-side aquellas que no permiten interacción entre usuarios como es el caso, por ejemplo, de Netflix o Spotify.

${ }^{56}$ Comisión Europea, "Las plataformas en línea y el mercado único digital. Retos y oportunidades para Europa", CoM (2016) 288 final, 25 de mayo de 2016, p.3.

57 Tampoco hay unanimidad doctrinal sobre la significación de la interdependencia entre los usuarios recogida en la definición diseñada por la Comisión Europea. Según ésta, basta que se genere valor para un grupo de usuarios. Para la OCDE
} 
no tanto en el bien o servicio que se intercambia de cuya calidad, en principio, se mantiene al margen por cuanto son los usuarios los que lo proporcionan y no la plataforma que tan solo es un "medio ${ }^{58}$ ".

30. Los usuarios (proveedores y adquirentes del bien o servicio de cualquier naturaleza) se afilian a la plataforma y realizan una "interacción directa" y un aspecto clave es que, como regla general, son los usuarios los que mantienen el control sobre los términos de la interacción (fijación de precios, la entrega del bien o servicio comercializado, la capacidad de determinar la naturaleza y la calidad de los servicios ofrecidos, los términos y condiciones etc... $)^{59}$. De esta forma, si la plataforma "controla" los bienes y servicios ofertados, dejará de ser un simple intermediario y pasará a ser algo más pudiéndosele calificar, como veremos, como prestador del servicio subyacente.

31. La "horizontalidad" de las relaciones jurídicas que se producen en un mercado multilateral es la que genera retos normativos porque el acervo comunitario en materia de protección de los consumidores está basado en un modelo de distribución en cadena: fabricante, mayorista, minorista y consumidor en una escala vertical. El desequilibrio entre las posiciones de las partes (B2C), sirvió de justificación para el diseño de un sistema contractual de protección del consumidor, precisamente porque el canal habitual de adquisición de bienes y servicios era B2C. La economía de la plataforma deja obsoleto este esquema porque los bienes y servicios se intercambian entre usuarios que muchas veces no tienen la consideración de empresarios (B2C). En las plataformas es usual el modelo peer to peer, relaciones entre consumidores a las que no es de aplicación la normativa de protección de consumidores. La protección de los usuarios en la "economía de la plataforma", genera retos normativos por la ineficiencia de la regulación vigente para atenderlos ${ }^{60}$, dada, como veremos, la falta de transparencia de las condiciones de uso de muchas plataformas.

32. De ahí que se haya postulado la necesidad de una intervención europea que regule la contratación a través de plataformas intermediarias en línea, al margen de cuál sea el bien o servicio que se comercie a través de ellas. Tal iniciativa debe resolver tres problemas clave: el papel de la plataforma como intermediario, sus derechos y obligaciones y su eventual responsabilidad en los casos de incumplimiento por parte del oferente del bien o servicio ${ }^{61}$. De hecho, este último aspecto de la responsabilidad del operador de la plataforma y la opacidad de su papel en esta modalidad de contratación el que más preocupa a los usuarios de plataformas. Según el estudio realizado por la CE poco menos de la mitad de los ciudadanos encuestados $(49 \%)$ ven la falta de claridad sobre quién es responsable en caso de un

\footnotetext{
"The economic and social role of internet intermediaries", 2010, p. 17. http://www.oecd.org/internet/ieconomy/44949023.pdf (Consultado el 14 de mayo de 2020), el valor obtenido por un tipo de usuario aumenta con el número o con la calidad del otro tipo de usuarios. El papel del intermediario es precisamente generar estrategias de Mercado para conseguir que ambos grupos de usuarios participen, por ejemplo, fijando precios del servicio para uno de los grupos más atractivos.

${ }^{58}$ En el mismo sentido, OlMEDO PERALTA, E., "Competencia dentro de las plataformas de la economía colaborativa: posibles prácticas restrictivas de los mal llamados "prosumidores" Las viviendas vacacionales: Entre la economía colaborativa y la actividad mercantil / coord. por Beatriz Fonticiella Hernández; Inmaculada González Cabrera (dir.), María del Pino Rodríguez González (dir.), 2019, pp. 207-232: "los nuevos problemas jurídicos no se derivan de la naturaleza de las prestaciones - pues éstas mantienen su configuración, sin que los nuevos medios hayan implicados cambios significativos- sino del modo en que éstas se articulan". Lo de menos es que se trate de "colaborar". Lo importante es el cuadro complejo de relaciones jurídicas que la plataforma como intermediaria, como facilitadora, genera.

${ }^{59}$ Para A. HAGeIU, J. WrIGHT, "Multi-sided platforms", Working paper https://dash.harvard.edu/bitstream/handle/1/15786564/ hagiu,wright_multi-sided-platforms.pdf?sequence=1, p.6 el elemento clave de las plataformas multi- side es precisamente la falta de implicación de la plataforma en el bien y servicio que a través de ella se lleva a cabo. No basta la afiliación de los usuarios a la plataforma, sino que es imprescindible que la plataforma no controle las variables de decisión relevantes como las actividades de marketing, los precios, la entrega etc...

${ }^{60}$ A. WiewiórowsKa-DOMAgalsKa, "Online platforms: How to adapt regulatory framework to the Digital Age, Internal Market and Consumer Protection. European Parliament http://www.europarl.europa.eu/RegData/etudes/BRIE/2017/607323/ IPOL_BRI(2017)607323_EN.pdf p. 4. (Consultado el 29 de febrero de 2018).

${ }^{61}$ Busch ET AL., "The rise of the platform economy: A new challenge for EU Consumer Law", Journal of European Consumer and Market law 1/2016. https://ssrn.com/abstract=2754100 (Consultado el 7 de junio de 2020).
} 
problema como la mayor desventaja de esta modalidad de contratación ${ }^{62}$. Por ello, la transparencia será la clave de la confianza y del éxito de las plataformas. Es necesaria una regulación armonizada a nivel europeo de esta modalidad de contratación al margen del sector de actividad al que afecte.

\section{La diversidad de usuarios que intervienen en la contratación a través de plataformas}

33. El acervo comunitario en materia de consumo se centra en los contratos en los que las empresas establecen relaciones con los consumidores, definidos en el apartado 1 del artículo 2 de la Directiva sobre derechos de los consumidores (2011/83) como cualquier persona física que actúe con fines ajenos a su actividad comercial, empresa, oficio o profesión. Cuando se contrata a través de una plataforma, se pueden involucrar varios tipos de usuarios que, en sus relaciones con la plataforma, pueden tener la consideración de consumidores y, por el contrario, ser empresarios en su relación con el otro usuario que es con quien contrata el bien o servicio.

34. La naturaleza de mercado de doble lado que caracteriza a las plataformas plantea el problema de los estatutos de los usuarios para establecer el régimen jurídico aplicable a los contratos entre el proveedor del bien o servicio y el cliente y a los contratos que vinculan a la plataforma con cada grupo de usuarios.La aplicación de la normativa de protección del consumidor depende del estatuto de los contratantes y éste se torna complejo en su determinación cuando se contrata a través de plataforma en línea. Nos vamos a encontrar con empresas que interactúan con consumidores (B2C), particulares que interactúan entre sí (P2P), empresas que contratan entre sí (B2B) e incluso puede suceder que el proveedor sea consumidor, en tanto que no actúa en el ámbito de su actividad profesional o empresarial y el cliente o adquirente del bien o servicio sea un empresario (C2B). De ahí, que se haya generalizado el llamativo término de "prosumidor" aludiendo a la posibilidad que tiene un sujeto de actuar a la vez como consumidor y proveedor de un bien o servicio ${ }^{63}$, difuminándose la frontera entre productor y consumidor.

35. En definitiva, si ya es compleja, en ocasiones, la distinción entre empresario y consumidor, cuando se contrata a través de plataforma en línea se hace más relevante esta "zona gris", en la que el estatus de la parte interesada evoluciona del consumidor a la empresa y, como tal, escapa a una fácil calificación. El rasgo característico de la economía de la plataforma es que la distinción entre consumidores y empresas se difumina como resultado de la participación de la plataforma en las actividades. Por lo tanto, va a ser necesario proteger a esos clientes, pero en muchas ocasiones van a escapar de las normas europeas de protección del consumidor ${ }^{64}$, y no queda claro cuál es la parte débil que hay que proteger, sobre todo, cuando a veces los propios consumidores actúan como proveedores (prosumer). Los contratos entre particulares quedan fuera del ámbito de protección de la normativa de protección de

${ }^{62}$ COMISIÓN EUROPEA "Flash Eurobarometer 467 Report. The use of the collaborative economy", octubre 2018, https://data. europa.eu/euodp/en/data/dataset/S2184_467_ENG (Consultado el 16 de mayo de 2020).

${ }^{63}$ Este concepto no es nuevo y fue diseñado por Alvin Toffler en su libro "La tercera ola", Mexico 1987, y surge de la combinación entre las palabras "consumidor" y "proveedor". Definía al prosumidor como aquel que participa en los propios bienes y/ servicios que consume. En realidad, consume lo que produce, algo que sucedía de forma habitual antes de la revolución industrial. Las nuevas tecnologías y el desarrollo de la economía colaborativa han provocado un retorno a este concepto que en los términos de Toffler podría considerarse primitivo. El consumidor puede ubicarse en ambas partes del proceso productivo, prestando bienes y servicios sin carácter habitual. Este es el significado de prosumidor en el ámbito de la economía colaborativa y que plantea el problema del establecimiento de los criterios que deben operar para diferenciar entre ciudadanos particulares que prestan servicios de manera ocasional y proveedores que actúan con capacidad profesional. El término ya ha sido utilizado por el Consejo EConómico y Social Europeo (CESE), en el Dictamen sobre la «Comunicación de la Comisión al Parlamento Europeo, al Consejo, al Comité Económico y Social Europeo y al Comité de las Regiones - Una Agenda Europea para la economía colaborativa», $\operatorname{COM}(2016) 356$ final], (2017/C 075/06), considerando que los criterios de frecuencia de los servicios, fin lucrativo y volumen de negocio pueden ser aptos para delimitar cuando nos encontramos ante un prosumidor o un profesional.

${ }^{64}$ Wiewiórowska-Domagalska, “A Online Platforms: How to Adapt Regulatory Framework to the Digital Age?” Parlamento Europeo, http://www.europarl.europa.eu/RegData/etudes/BRIE/2017/607323/IPOL_BRI(2017)607323_EN.pdf (Consultado el 13 de mayo de 2020), p. 5. 
consumidores, siendo de aplicación las normas de Derecho privado que correspondan (Código Civil y Código de Comercio). Se corre el riesgo de que aparezcan comerciantes "encubiertos" que contraten a través de estas plataformas solo para evitar la aplicación de la normativa protectora de los consumidores. En este sentido, deben idearse mecanismos que eviten este fraude, siendo este uno de los retos normativos que plantea la economía de la plataforma.

36. Este aspecto ha sido abordado en el Borrador de Propuesta de Directiva sobre plataformas en línea (en adelante, BPDPL) elaborado por el grupo de trabajo en regulación de los servicios digitales ${ }^{65}$. La Propuesta extiende su ámbito de aplicación a los contratos de suministro de bienes, servicios o contenidos digitales entre un proveedor y un cliente a través de una plataforma de intermediación en línea (art. 1 BPDPL). Se propone un marco regulatorio que abarque las relaciones de la plataforma tanto con oferentes como con demandantes de bienes y servicios, regulando su papel de "facilitador" de la contratación.

37. En el art. 11 del BPDPL se establece que el operador de la plataforma debe asegurarse de que el proveedor que ofrece bienes, servicios o contenido digital informe al cliente, en su caso, de su condición de comerciante. Dadas las dificultades de determinación que en el ámbito online pueden surgir respecto de la condición de consumidores o profesionales de los proveedores, parece razonable que sea la plataforma la que informe sobre este particular en tanto que tiene acceso a más información que el otro usuario.

38. En la misma línea, la Comisión Europea ${ }^{66}$ se ha planteado este problema en el ámbito de la economía colaborativa, y ha establecido una serie de criterios no vinculantes para determinar en qué condiciones el prestador del servicio subyacente debe ser considerado comerciante, dada la diversidad normativa que sería aplicable en cada caso ${ }^{67}$.

39. Aunque ninguno de ellos sería por sí mismo suficiente para que un prestador pudiera ser considerado un comerciante, según las circunstancias del caso su combinación puede apuntar en esa dirección:

- Frecuencia de los servicios: los prestadores que ofrecen sus servicios solo de manera ocasional (es decir, de manera marginal y accesoria, y no regularmente) son menos susceptibles de ser considerados comerciantes. Cuanto mayor es la frecuencia con que se prestan los servicios, más claro está que el prestador puede considerarse un comerciante, ya que ello podría indicar que está actuando con un propósito relacionado con su actividad económica, negocio, oficio o profesión.

- Fin lucrativo: Un fin lucrativo puede ser un indicio de que el prestador puede considerarse un comerciante con respecto a una determinada transacción. Los prestadores cuyo objetivo es intercambiar activos o competencias (por ejemplo, en el caso de las permutas de casas o los bancos de tiempo) no reúnen en principio las condiciones para ser considerados comerciantes. Los prestadores que solo reciben una compensación por los costes en una determinada transacción pueden no estar buscando un beneficio. En cambio, es probable que los prestadores que obtienen una remuneración superior a la compensación de los costes tengan un fin lucrativo.

- Nivel de volumen de negocio: Cuanto más alto es el volumen de negocio generado por el prestador de servicios (procedente de una o más plataformas colaborativas) más indicios

\footnotetext{
${ }^{65}$ Research group on the law of Digital Services umer and Market Law, no 4/2016, pp. 164-169.

${ }^{66}$ COMisión europea, "Comunicación de la Comisión al Parlamento Europeo, al Consejo, al Comité Económico y Social Europeo y al Comité de las Regiones. Una Agenda Europea para la Economía Colaborativa”. Bruselas, 2.6.2016 COM (2016) 356 final, p. 10.

${ }^{67}$ Con respecto a las transacciones entre empresas y consumidores en la economía colaborativa, se aplicaría la Directiva sobre prácticas comerciales, la Directiva 2011/83/EU («Directiva sobre los derechos de los consumidores») y la Directiva 93/13/ EEC sobre cláusulas abusivas en los contratos concluidos con consumidores. Con respecto a las transacciones entre empresas, se aplicaría la Directiva 2006/114/CE sobre publicidad engañosa y publicidad comparativa.
} 
hay de que el prestador reúne las condiciones para ser considerado un comerciante ${ }^{68}$. A este respecto, es importante evaluar si el nivel de volumen de negocio generado por el prestador procede de la misma actividad (p. ej., el uso compartido de vehículos) o de varios tipos de actividades (uso compartido de vehículos, jardinería, etc.). En el segundo supuesto, un mayor volumen de negocio puede no implicar necesariamente que el prestador reúne las condiciones para ser considerado un comerciante, ya que puede no haber sido obtenido necesariamente en relación con el otro negocio (principal) del prestador.

40. A los criterios antes señalados la OCDE ha añadido algunos más: el nivel de organización y planificación de la actividad del proveedor, el número de transacciones, su valor, la duración de la actividad, la forma en que los consumidores perciben la actividad del proveedor ${ }^{69}$.

41. Esta dificultad de la determinación de la naturaleza del usuario que contrata a través de plataformas en línea me parece uno de los problemas clave en esta materia, pues se corre el riesgo de acudir a este mecanismo para huir del bloque regulatorio de protección del consumidor, algo que no es fácil de detectar en la práctica, por mucho que una hipotética regulación le obligue a hacerlo. Sería razonable que la propia plataforma obligara al usuario a pronunciarse sobre su condición, tal y como ya hacen eBay, Windu y Yoopies. De hecho, el gran activo de la plataforma son los datos que proporcionan los usuarios cuando celebran el contrato de acceso. Las plataformas disponen de datos para evaluar los indicadores pertinentes, supervisar la validez de la información facilitada por los proveedores.

42. La Directiva ${ }^{70}$ sobre la mejora de la aplicación y la modernización de las normas de protección de los consumidores declara en su Exposición de Motivos que uno de sus objetivos es lograr más transparencia para los consumidores en los mercados en línea. Se hace eco la UE de que los consumidores no siempre conocen el modo en que se clasifican las ofertas que se les presentan en el mercado en línea, ni a quién compran (a comerciantes profesionales o a otros consumidores). Muchos consumidores creen que compran al mercado en línea y que, por tanto, celebran un contrato con él. En realidad, puede que le estén comprando a un proveedor tercero que figura en el mercado en línea, pero que no es comerciante. Como resultado, los consumidores pueden pensar falsamente que tratan con comerciantes profesionales (y que, por tanto, les asisten sus derechos como consumidores). Esta confusión puede causar problemas en caso de que algo salga mal con una adquisición en línea, porque no siempre es fácil determinar quién es responsable. La Directiva introduce requisitos adicionales en materia de información en la Directiva 2011/83/UE. Se añade el art. 6 bis a la Directiva 2011/83:

\section{Requisitos de información especificos adicionales para contratos celebrados en mercados en línea}

1. Antes de que un consumidor quede obligado por un contrato a distancia, o cualquier oferta correspondiente, en un mercado en línea, el proveedor del mercado en línea facilitará además, sin perjuicio de lo dispuesto en la Directiva 2005/29/CE, la siguiente información de forma clara, comprensible y adecuada a las técnicas de comunicación a distancia: información general, facilitada en una sección especifica de la interfaz en línea que sea fácil y direc-

${ }^{68}$ Así lo ha entendido la sentencia del TJUE de 12 de julio de 2011 (L'Oreal contra eBay): "si las ventas realizadas por un particular en un mercado electrónico superan, por razón de su volumen, su frecuencia y otras características, el ámbito de lo que puede considerarse una actividad privada, habrá que entender que el vendedor está actuando dentro del tráfico económico (..)”. Párrafo 55.

${ }^{69}$ OCDE, "Protecting Consumers In Peer Platform Markets: Exploring The Issues", OECD Digital Economy Papers, No. 253, OECD Publishing, 2016, Paris, http://dx.doi.org/10.1787/5jlwvz39m1zw-en, p. 20.

${ }^{70}$ Directiva del Parlamento Europeo y del Consejo por la que se modifican la Directiva 93/13/CEE del Consejo, de 5 de abril de 1993, la Directiva 98/6/CE del Parlamento Europeo y del Consejo, la Directiva 2005/29/CE del Parlamento Europeo y del Consejo y la Directiva 2011/83/UE del Parlamento Europeo y del Consejo, en lo que atañe a la mejora de la aplicación y la modernización de las normas de protección de los consumidores de la UE. Bruselas, 11.4.2018 COM (2018) 185 final. 
tamente accesible desde la página en la que se presenten las ofertas, relativa a los principales parámetros que determinan la clasificación, tal como se define en el artículo 2, párrafo 1, letra m), de la Directiva 2005/29/CE, de las ofertas presentadas al consumidor como resultado de la consulta y la importancia relativa de dichos parámetros frente a otros parámetros;

a) si el tercero que ofrece los bienes, servicios o contenido digital es un comerciante o no, con arreglo a la declaración de dicho tercero al mercado en línea;

b) cuando el tercero que ofrece los bienes, servicios o contenido digital no sea un comerciante, que los derechos de los consumidores derivados de la legislación de la Unión en materia de protección de los consumidores no son de aplicación al contrato;

c) cuando proceda, cómo se reparten las obligaciones relacionadas con el contrato entre el tercero que ofrece los bienes, servicios o contenido digital y el proveedor del mercado en línea. Esta información se entenderá sin perjuicio de la responsabilidad que el mercado en línea o el comerciante pueda tener en relación con el contrato en virtud de demás legislación nacional o de la Unión.

2. Sin perjuicio de la Directiva 2000/31/CE, el presente artículo no impide a los Estados miembros que impongan requisitos de información adicionales a los mercados en línea. Tales disposiciones serán proporcionadas y no discriminatorias, y estarán justificadas por razones de protección de los consumidores».

43. Esta regulación resuelve algunos de los problemas clave en materia de transparencia: que el consumidor sepa con quién contrata y el régimen jurídico aplicable a su contrato. No obstante, otros problemas subsisten. Esta nueva regulación propuesta no altera lo dispuesto en el art. 15 de la Directiva 2000/31 sobre comercio electrónico que establece que los prestadores de servicios de la sociedad de la información no deben supervisar los datos que transmitan o almacenen. De esta forma, no tienen obligación de verificar el estatuto jurídico de los usuarios, si son consumidores o comerciantes (Considerando $n^{0} 28$ de la Directiva 2019/2161). La norma propuesta se basa en la declaración del propio usuario que puede decir la verdad o no. El riesgo de que comerciantes se «disfracen» de prosumidores para evitar la aplicación de la regulación de protección de consumidores subsiste y la plataforma no responde de ello. La regulación propuesta blinda a las plataformas más que proteger al consumidor. Lo razonable habría sido que tuvieran algunos deberes legales de comprobación de la veracidad de la declaración del usuario acerca de su consideración o no como comerciante ${ }^{71}$. No obstante, nada impide que en el caso concreto se cuestione por el propio adquirente la condición de comerciante del proveedor, pero entiendo que habría sido más razonable que la plataforma tuviera que exigir algún tipo de documentación al usuario que acredite el tipo actividad profesional a la que se dedica. En cuanto a las consecuencias de la omisión de tal información por parte de la plataforma, el nuevo Art. 7, apartado 4 de la Directiva 2005/29 sobre prácticas comerciales desleales establece como consecuencia de la omisión de tal información sobre la condición del suministrador la consideración de que se trata de una omisión engañosa del titular de la plataforma. Por esta razón, este no solo está legitimado para bloquear el acceso en tales casos, sino que es su obligación hacerlo si no quiere incurrir en un comportamiento desleal ${ }^{72}$.

44. Recientemente el TJUE en sentencia de 4 de octubre de $2018^{73}$, se ha pronunciado sobre el problema de la calificación como comerciante del proveedor del bien o servicio a través de una plataforma intermediaria en línea. La sentencia resuelve una cuestión prejudicial planteada por el Tribunal

\footnotetext{
${ }^{71}$ EUROPEAN CONSUMER ORGANIZATION, «Proposal for a better enforcement and modernization of EU Consumer protection rules. Omnibus directive», 20/09/2018. https://www.beuc.eu/publications/beuc-x-2018-081_omnibus_directive.pdf (Consultado el 20 de mayo de 2020), p. 5.

${ }^{72}$ En este sentido, WinNer, M, "La regulación jurídica de los contratos celebrados a través de plataformas: el Derecho europeo", Blog Almacén de Derecho, 2020. https://almacendederecho.org/la-regulacion-juridica-de-los-contratos-celebradosa-traves-de-plataformas-el-derecho-europeo (Consultado el 2 de septiembre de 2020).

${ }^{73}$ Asunto C-105/17. Komisia za zashitita na potrebitelite y Evenlina Kamenova.
} 
Contencioso administrativo de Varna (Bulgaria), en relación con la interpretación del art. 2, letras b) y d) de la Directiva 2005/29/CE de 11 de mayo de 2005 relativa a las prácticas comerciales desleales de las empresas en sus relaciones con los consumidores que determinan quién tiene la condición de comerciante a los efectos de la aplicación de dicha Directiva. Dispone el art. 2 b) que tendrá la consideración de comerciante, «cualquier persona física o jurídica que, en las prácticas comerciales contempladas por la presente Directiva, actúe con un propósito relacionado con su actividad económica, negocio, oficio o profesión, así como cualquiera que actúe en nombre del comerciante o por cuenta de éste».

45. Una consumidora compró un reloj de pulsera en una plataforma de comercio electrónico en virtud de un contrato de compraventa a distancia. Al parecer, dicho reloj no respondía a las características indicadas en el anuncio publicado en la página web. La vendedora del producto (Sra. Kemenova) se negó a facilitar la devolución y la compradora presentó una reclamación ante la Comisión de protección de los consumidores (CPC) quien impuso sanciones administrativas a la vendedora, por haber omitido facilitar información a los consumidores al publicar anuncios de venta en un sitio de Internet. Concretamente, había omitido indicar en el anuncio el nombre, la dirección postal y la dirección de correo electrónico del comerciante, el derecho de desistimiento del contrato de compraventa que corresponde al consumidor, entre otros extremos. La vendedora interpuso un recurso contra la resolución de la Comisión de protección de los consumidores que fue estimado por el Tribunal de Distrito de Varna, en sentencia de 22 de marzo de 2016, que consideró que la vendedora no tenía la condición de comerciante a los efectos de la Directiva 2005/29 y la normativa búlgara de transposición de dichanorma comunitaria. La vendedora utilizaba el pseudónimo «Eveto ZZ» y que había publicado en dicha página un total de ocho anuncios de venta de productos diversos.

46. Contra dicha sentencia se interpone recurso de casación ante el órgano jurisdiccional que plantea la cuestión prejudicial en la que se cuestiona si una persona física que publica simultáneamente en un sitio de Internet una serie de anuncios en los que ofrece la venta de bienes nuevos y usados puede ser calificado como comerciante a los efectos de la aplicación de la Directiva 2005/29, constituyendo tal actividad una práctica comercial de las empresas en sus relaciones con consumidores en los términos previstos en el art. 2 d) Directiva 2005/2974.

47. El TJUE declara que el concepto de comerciante Directiva 2005/29 debe interpretarse de manera homogénea con el concepto que a su vez contiene la Directiva 2011/83 sobre los derechos de los consumidores, ya que su definición el prácticamente idéntica. El sujeto debe actuar con un propósito relacionado con su actividad comercial, empresa, oficio o profesión en nombre de un comerciante o por cuenta de éste. Se trata, a juicio del TJUE, de un concepto «funcional» que exige apreciar si la relación contractual o la práctica comercial forma parte de las actividades que una persona ejerce con carácter profesional. Debe atenderse al caso concreto y es algo que le corresponde examinar al órgano jurisdiccional que ha planteado la cuestión prejudicial.

48. ¿Y cómo lo determina? Aquí está la aportación del TJUE en este caso en cuanto establece una serie de criterios que aclara que no son taxativos ni exclusivos, por lo que el hecho de cumplir uno o varios de esos criterios no determina que el vendedor a través de plataforma en línea deba ser considerado comerciante.

49. Se habrá que comprobar si la venta en la plataforma en línea se ha efectuado de forma planificada y si dicha venta tiene fines lucrativos, si el vendedor dispone de información y competencias técnicas relativas a los productos que pone a la venta de las que el consumidor no dispone necesariamente, de manera que lo coloca en una situación más ventajosa con respecto a dicho consumidor, si el

\footnotetext{
${ }^{74}$ «Prácticas comerciales de las empresas en sus relaciones con los consumidores»: todo acto, omisión, conducta o manifestación, o comunicación comercial, incluidas la publicidad y la comercialización, procedente de un comerciante y directamente relacionado con la promoción, la venta o el suministro de un producto a los consumidores».
} 
vendedor tiene un estatuto jurídico que le permite realizar actos de comercio y en qué medida la venta en línea está vinculada a la actividad comercial o profesional del vendedor, si el vendedor está sujeto a IVA, si el vendedor, que actúa en nombre de un comerciante determinado o por su cuenta o por medio de otra persona que actúa en su nombre y por su cuenta, ha recibido una retribución o una participación, si el vendedor compra bienes nuevos o usados con intención de revenderlos, confiriendo de este modo a dicha actividad un carácter regular, una frecuencia o una simultaneidad con respecto a su actividad comercial o profesional, si los productos en venta son todos del mismo tipo o del mismo valor, en particular, si la oferta se concentra en un número limitado de productos.

50. Concluye el TJUE que el ánimo de lucro y el número de anuncios no basta por sí mismo para calificar a dicha persona como comerciante, sino que debe actuar con un propósito relacionado con su actividad económica, oficio o profesión, extremo que le corresponde examinar al órgano remitente. Por lo tanto, el TJUE no decide si la vendedora tenía la condición de comerciante o no, sino que se limita a establecer una serie de criterios que debe tener en cuenta el juez nacional sin que sea suficiente el ánimo de lucro o el número de anuncios publicados.

\section{El carácter instrumental de la actividad de las plataformas en línea.}

\subsection{Clasificación de plataformas intermediarias en línea en función de su modelo de negocio.}

51. La estructura triangular que genera la contratación a través de una plataforma plantea su papel en las relaciones contractuales que emergen de la interacción que facilita y, por ende, el grado de responsabilidad que puede asumir. Si partimos del concepto de intermediario en internet que, por ejemplo, propone la OCDE, como aquellos que reúnen o facilitan las transacciones entre terceros en internet, proporcionan acceso, alojan, transmiten e indexan contenidos, productos y servicios originados por terceros en internet o prestan servicios basados en internet a terceros ${ }^{75}$, muchas plataformas no tendrían la consideración de intermediarias porque muchas tienen algún grado de control sobre las interacciones que posibilitan.

52. Efectivamente, el grado de participación de la plataforma en la contratación puede ser diferente en cada caso en función del compromiso que asuma, tal y como he señalado al describir los distintos modelos. Con todo, su objeto debe ser una actividad instrumental favorable a la contratación entre usuarios. Pero dicha actividad, siendo instrumental, puede tener diferente intensidad ${ }^{76}$. La clave estará, como veremos, en los criterios que determinan la frontera entre la actividad instrumental y la prestación del servicio subyacente. La intermediación es característica esencial y por ello se incorpora a la definición realizada en el borrador de propuesta de directiva ${ }^{77}$ de "plataformas intermediarias en línea" que las califica como "un servicio de información accesible a través de Internet o por medios digitales similares que permite a los clientes celebrar contratos con proveedores de bienes, servicios o contenidos digitales; no se incluyen los servicios que se limitan a identificar a los proveedores pertinentes y que dirigen a los clientes a los sitios web o a los datos de contacto de dichos proveedores".

\footnotetext{
${ }^{75}$ OCDE, "The economic and social role of internet intermediaries", 2010, p. 9. https://www.oecd-ilibrary.org/science-andtechnology/the-economic-and-social-role-of-internet-intermediaries_5kmh79zzs8vb-en (Consultado el 24 de mayo de 2020).

${ }^{76} \mathrm{Sin}$ embargo, como se pone de relieve en el informe realizado por la consultora OXERA, "Benefits of online platforms", 2015 , p. 14, https://www.oxera.com/wp-content/uploads/2018/07/The-benefits-of-online-platforms-main-findings-October-2015.pdf. pdf (Consultado el 24 de mayo 2020), en la práctica, muchas plataformas conservan cierto grado de control sobre las interacciones que facilitan. Este control puede ser bastante limitado y se refiere a los datos que los usuarios envían cuando crean una cuenta o utilizan una plataforma como Facebook o Twitter. Puede ir más allá e incluir el control sobre ciertos aspectos de las transacciones, tales como las normas de calidad y el pago de comisiones sobre Airbnb y BlaBlaCar. Por último, Amazon y Netflix mantienen un mayor control sobre los precios e incluso distribuyen sus propios productos. Si se exigiera que las plataformas en línea fueran meros intermediarios, Airbnb, BlaBlaCar, Amazon, Netflix o Facebook no se considerarían plataformas en línea.

77 Research Group on the law of digital services, "Discussion Draft of a Directive on Online Intermediary Platforms", Journal of European Consumer and Market Law, n 4/2016, p.166.
} 
53. Según un informe elaborado por la Comisión Europea $^{78}$ tras el estudio de 485 plataformas, cabe distinguir tres modelos de negocio en las plataformas intermediarias en línea en función de su grado de implicación en la transacción realizada entre pares:

$1^{\circ}$. Alojamiento de anuncios: este modelo se caracteriza por la adecuación pasiva de la oferta a la demanda entre iguales: se publican anuncios e información de los participantes que facilita la toma de contacto y el intercambio entre iguales. Estas plataformas obtienen ingresos principalmente al ofrecer opciones para la presentación de los anuncios, la inclusión de fotografías, etc. La principal característica de este modelo es que las plataformas no participan en la transacción de igual a igual. Ejemplos de este modelo serían las plataformas Wallapop, Craiglist, Idealista, Fotocasa.

$2^{\circ}$. Gestión activa de las transacciones entre iguales: este modelo se caracteriza por facilitar y gestionar de forma activa la adecuación de la oferta a la demanda. Las plataformas crean valor al fomentar la confianza entre iguales y gestionar activamente la adecuación de la oferta a la demanda, a fin de facilitar un mayor número de transacciones. Gestionan herramientas de fomento de la confianza y herramientas avanzadas de adecuación de la oferta a la demanda. Cobran comisiones por transacciones o cuotas de suscripción y pueden también percibir ingresos por servicios adicionales, como un seguro o la publicación de anuncios destacados. La principal característica de este modelo es que la plataforma influye en las transacciones de igual a igual pero no las controla.

$3^{\circ}$. La plataforma de transacciones entre iguales: este modelo, se caracteriza por establecimiento de una o varias de las cláusulas contractuales de la transacción de igual a igual y por el control de su ejecución. Entre las cláusulas contractuales que la plataforma puede establecer se incluirían las reglas de las interacciones P2P, las normas y tasas para la cancelación y las normas para el reembolso, así como la fijación (optativa) automatizada de los precios o de los precios máximos. Las plataformas en este modelo gestionan los pagos (reciben y guardan los pagos de los consumidores), supervisan el éxito de la transacción P2P antes de pagar a los proveedores $\mathrm{y}$, con frecuencia, retienen tasas en caso de cancelación. Además, intervienen activamente en caso de reclamación, resuelven litigios y conceden el reembolso y pueden incluir un seguro contra daños como parte de los gastos de transacción. La mayor parte de estas plataformas cobran comisión por transacción y reutilizan los datos de los usuarios. La principal característica de este modelo es que las plataformas limitan la capacidad de los usuarios de decidir entre ellos las cláusulas contractuales y dan la impresión (explícita o implícitamente) de que asumen la responsabilidad (parcial) por la ejecución de la transacción.

54. Hay que analizar el grado de participación de la plataforma en la contratación para valorar si presta o no el servicio subyacente. Efectivamente, puede ser que la plataforma sea intermediaria en el sentido de revendedora, es decir, adquiera los bienes y los revenda o directamente sea la productora del bien o proveedora del servicio. Estas actividades quedan al margen de nuestro análisis y del concepto de plataforma intermediaria en línea diseñado por la Comisión europea, que centra el objeto de la actuación de la plataforma en permitir la interacción entre dos grupos de usuarios. En el caso de reventa, aunque pudiera considerarse a la plataforma como intermediaria en tanto adquiere un bien al proveedor a bajo precio y lo revende al cliente a un precio mayor, se trataría de una plataforma unilateral (one side platform), alejada del modelo de plataforma multilateral que es objeto del presente trabajo.

55. Entre estos dos extremos, como se ha explicado, se encuentran las plataformas que no se limitan a publicar ofertas de los usuarios que otros demandan, sino que su actividad va más allá y crean un entorno que incentiva la interacción a través de muchas fórmulas: aportando más datos del perfil del ofertante, estableciendo sistemas para valorar su reputación, facilidades para la comunicación entre usuarios e incluso gestionan el pago. La mayor sofisticación del servicio, sin embargo, no le priva necesariamente de

\footnotetext{
${ }^{78}$ COMISIÓN EUROPEA, "Exploratory study of consumer issues in online peer to peer platform markets. Final report", cit., p.12.
} 
su carácter instrumental. Por lo tanto, no toda plataforma es "plataforma intermediaria en línea" en sentido técnico: la clave distintiva es si presta o no el servicio subyacente ${ }^{79}$ y lo que genera cadena de valor ${ }^{80}$.

\subsection{Criterios para determinar el rol de la plataforma. En particular, la postura del TJUE: caso Uber y caso Airbnb}

56. Por las razones apuntadas, un aspecto clave de una eventual regulación es que vele por la transparencia respecto del papel de la plataforma en la contratación y que los usuarios puedan conocerlo. Este aspecto ha sido abordado en BPDPL ${ }^{81}$. Así en el art. 11 se establece la obligación del operador de la plataforma de informar al cliente de que el contrato se celebrará entre el proveedor y el cliente y no con la plataforma. Se trata de evitar que se haga creer al cliente que es la plataforma la proveedora del bien o servicio ${ }^{82}$. En caso contrario, podría ser exigido a la plataforma la responsabilidad correspondiente al vendedor, tal y como sucedió en la sentencia del TJUE 9 de noviembre de 2016 (Sabrina Wathelet y Garage Bietheres \& Fils SPRL $)^{83}$. Hay que evitar que "se disfrace" de intermediario a quien no lo es generando un mercado paralelo sin garantías eficientes. Y ello porque la responsabilidad que asume la plataforma no es la misma cuando se limita a coordinar una oferta y una demanda que cuando entra de lleno en aspectos clave como el precio o la calidad del servicio ofertado y ello vincula a los usuarios.

57. En el primer supuesto, puede no tener ningún tipo de responsabilidad en caso de falta de conformidad de un usuario con el producto recibido, dado que no es parte contratante, y en el otro sí. En un caso, la relación de la plataforma con los usuarios es horizontal, convirtiéndose en un intermediario y en otra es vertical, convirtiéndose, en cierta medida, en proveedora del mismo (one side platforms), debiéndose aplicar la normativa relativa a los proveedores del servicio con las autorizaciones que, en su caso, se consideren pertinentes.

58. La Comisión Europea ${ }^{84}$ ha sugerido unos criterios clave para determinar el nivel de control o influencia que la plataforma colaborativa ejerce sobre el prestador de servicios con objeto de dilucidar si su actuación es de mera intermediación o no. En primer lugar, y en lo que se refiere al precio del servicio, hay que atender a si la plataforma fija el precio final que debe pagar el usuario como beneficiario del servicio subyacente. El hecho de que la plataforma colaborativa solo recomiende un precio o de que el prestador de los servicios subyacentes sea libre de adaptar el precio fijado por una plataforma colaborativa, indica que puede que no se cumpla este criterio.

${ }^{79}$ Este es el criterio mantenido por la OCDE "The economic and social role of internet intermediaries", 2010, p. 9 y A. HAGEIU Y J. WRIGHT, "Multi-sided platforms", Working paper https://dash.harvard.edu/bitstream/handle/1/15786564/hagiu,wright_ multi-sided-platforms.pdf?sequence=1, p.6. También parece ser el criterio del que parte la Comisión Europea en la definición que ha sometido a consulta.

${ }^{80}$ OXERA, "Benefits of online platforms", 2015, p. $16 \mathrm{https} / /$ www.oxera.com/getmedia/84df70f3-8fe0-4ad1-b4ba-d235ee5 0cb30/The-benefits-of-online-platforms-main-findings-(October-2015).pdf.aspx?ext=.pdf (Consultado el 24 de mayo 2020).

${ }^{81}$ Research group on the laW of Digital Services, "Discussion Draft cit., p. 165.

${ }^{82}$ Según un estudio que analizaba 4 países reveló que la mayoría de los consumidores desconocían el nombre del oferente del bien o servicio y creyeron que era la plataforma la vendedora. COMISIÓN EUROPEA, "Behavioural study on the transparency of online platforms", 2018, p. 51 https://ec.europa.eu/info/sites/info/files/transparency_of_platforms-study-final-report_en.pdf (Consultado el 3 de junio de 2018).

${ }^{83}$ Así lo hizo el TJUE en sentencia de 9 de noviembre de 2016 (Sabrina Wathelet y Garage Bietheres \& Fils SPRL), C149/15. Señala el TJUE que, aunque el objeto de la Directiva 1999/44 sobre venta y garantías de bienes de consumo no es, en el marco de un contrato de compraventa, la responsabilidad del intermediario frente al consumidor, el desconocimiento del consumidor sobre la calidad en la que el profesional interviene en la compraventa no le priva de los derechos que le concede la Directiva. "Por ello, en circunstancias como las del procedimiento principal, donde, habida cuenta del contexto en el que se efectúa la compraventa, el consumidor puede ser fácilmente inducido a error, debe atribuírsele un grado de protección reforzado. Por tanto, en virtud de la Directiva 1999/44, la responsabilidad del vendedor debe poder ser exigible al intermediario que crea un riesgo de confusión al dirigirse al consumidor, haciéndole creer que actúa en calidad de propietario del bien objeto de la compraventa".

${ }^{84}$ Comisión europea, "Comunicación de la Comisión al Parlamento Europeo, al Consejo, al Comité Económico y Social Europeo y al Comité de las regiones. Una agenda europea para la economía colaborativa". 2 de junio de 2016. Com. (2016) 356 FINAL, p. 7. 
59. Este criterio puede ser problemático en la práctica pues son pocas las plataformas que se mantienen al margen del mismo. Lo precios de los servicios son esenciales, pues sobre los mismos fijan sus comisiones y porque tenerlos demasiado altos puede provocar externalidades negativas en los efectos en red.

60. Efectivamente, los precios elevados pueden suponer un incentivo negativo al uso de la plataforma por parte de los usuarios que disminuya los "efectos en red", que es el principal activo de la plataforma. Como he dicho, característica de la plataforma es la interdependencia de los usuarios por lo que la demanda de un lado dependerá en gran medida del número de usuarios que haya en el otro lado. Así mismo, el consumidor valorará más una plataforma cuantos más consumidores haya en la plataforma y, desde luego, el precio del servicio ofertado a través de la misma, incide en el volumen de usuarios e impacta negativamente sobre la capacidad de atraer usuarios. Lo habitual es que las plataformas sugieran precios de referencia de los que el prestador del bien o servicio puede desviarse ${ }^{85}$. El aspecto clave debe ser la libertad de la que debe gozar el prestador del bien o servicio.

61. En segundo lugar, se atiende a otras condiciones contractuales clave: ¿Establece la plataforma colaborativa términos y condiciones distintos del precio que determinan la relación contractual entre el prestador de los servicios subyacentes y el usuario (por ejemplo, instrucciones obligatorias sobre la prestación del servicio subyacente, incluida cualquier obligación de prestar el servicio)? En tercer lugar, se comprueba si la plataforma tiene propiedad de activos clave para prestar el servicio subyacente.

62. A juicio de la Comisión, cuando se cumplen estos tres criterios, hay indicios claros de que la plataforma colaborativa ejerce una influencia o control significativos sobre el prestador del servicio subyacente, lo que puede indicar a su vez que debe considerarse que presta dicho servicio, además, claro está, de las obligaciones que se derivan como prestador de un servicio de la sociedad de la información.

63. Según el caso de que se trate, otros criterios pueden también desempeñar un papel relevante. Por ejemplo, si la plataforma colaborativa sufraga los gastos y asume todos los riesgos relacionados con la prestación del servicio subyacente. $\mathrm{O}$ si existe una relación laboral entre la plataforma colaborativa y la persona que presta el servicio subyacente en cuestión Estos elementos podrían indicar que la plataforma colaborativa ejerce un gran nivel de control e influencia sobre la prestación del servicio subyacente, debiéndose en tal caso someterse a las autorizaciones pertinentes.

64. El BPDPL establece en su art. 18 la responsabilidad del operador de la plataforma conjuntamente con la del proveedor por incumplimiento de éste cuando el cliente puede razonablemente el operador tiene una predominante influencia sobre el proveedor. Para determinar si cabe deducir tal influencia, se establecen una serie de criterios:

a) El contrato proveedor-cliente se concluye exclusivamente en instalaciones de la plataforma.

b) El operador de la plataforma puede retener los pagos realizados por los clientes en el ámbito de los contratos proveedor-cliente;

c) Los términos del contrato proveedor-cliente son esencialmente determinados por el operador de la plataforma;

d) El precio que debe pagar el cliente lo determina el operador de la plataforma;

e) El operador de la plataforma proporciona una imagen uniforme de los proveedores o una marca comercial;

f) El marketing se centra en el operador de la plataforma y no en los proveedores;

g) El operador de la plataforma se compromete a supervisar la conducta de los proveedores.

\footnotetext{
${ }^{85}$ M. SOBRINO, P. hinoJo, "Retos para la competencia de las plataformas digitales de economía colaborativa”, en S. Rodríguez Martín, y A. Muñoz García, Aspectos legales de la economía colaborativa y bajo demanda en plataformas digitales, Bosch, 2018, p. 121.
} 
Parece claro que unos criterios uniformes y objetivos son imprescindibles para delimitar la naturaleza del rol de la plataforma y contribuirán a lograr la seguridad jurídica, pues como hemos visto, la litigiosidad en esta materia se centrará en este extremo.

65. El TJUE se ha pronunciado ya respecto a la cuestión de cuándo una plataforma presta o no el servicio subyacente, particularmente en el caso del "transporte colaborativo" ". Cabe destacar el caso de la "plataforma UBER" sobre la que se ha pronunciado el TJUE en la sentencia de 20 de diciembre de $2017^{87}$. La cuestión planteada gira en torno a la aplicación de la regulación en materia de competencia desleal, y para determinarlo, se discute si la plataforma "Uber System Spain” se limita a una actividad de intermediación o directamente presta el servicio de transporte, para lo cual debería contar con la autorización administrativa correspondiente. En caso contrario, se trataría de un acto de competencia desleal.

66. En relación con los hechos que enjuicia la sentencia, Élite Taxi interpone una demanda ante el Juzgado mercantil $\mathrm{n}^{\circ} 3$ de Barcelona solicitando que se declare que las actividades "Uber System Spain" constituyen un acto de competencia desleal. La forma de operar de Uber consiste en proporcionar a sus clientes una red de transporte privado, a través de un software con una aplicación móvil que conecta los pasajeros con los conductores de vehículos registrados en su servicio, los cuales ofrecen un servicio de transporte. Por cada servicio realizado Uber recibe una remuneración por lo que su actividad es con ánimo de lucro.

67. El Juzgado de lo Mercantil $n .^{\circ} 3$ de Barcelona considera necesario que se dilucide si los servicios prestados por Uber deben considerarse servicios de transporte, servicios propios de la sociedad de la información o una combinación de ambos tipos de servicios. El Juzgado decidió suspender el procedimiento y plantear al Tribunal de Justicia cuestión prejudicial preguntándose, entre otras cuestiones, si la actividad realizada por Uber Systems Spain debe considerarse una mera actividad de transporte o ha de considerarse un servicio electrónico de intermediación, o un servicio propio de la sociedad de la información en los términos que define el artículo 1.2 de la Directiva 98/34 que podría beneficiarse del principio de libertad de prestación de servicios en los términos que dispone el art. 56 TFUE, Directivas $2000 / 123^{88}$ y $2000 / 31^{89}$.

68. El TJUE señala que "un servicio de intermediación consistente en conectar a un conductor no profesional que utiliza su propio vehículo con una persona que desea realizar un desplazamiento urbano constituye, en principio, un servicio distinto del servicio de transporte, que consiste en el acto físico de desplazamiento de personas o bienes de un lugar a otro mediante un vehículo". Y añade que tal servicio tiene la consideración de servicio de la sociedad de la información. Sin embargo, señala que Uber "no se limita a un servicio de intermediación consistente en conectar, mediante una aplicación para teléfonos inteligentes, a un conductor no profesional que utiliza su propio vehículo con una persona que desea realizar un desplazamiento urbano". Y ello porque "el prestador de este servicio de intermediación crea al mismo tiempo una oferta de servicios de transporte urbano, que hace accesible concretamente mediante herramientas informáticas, como la aplicación controvertida en el litigio principal, y cuyo funcionamiento general organiza en favor de las personas que deseen recurrir a esta oferta para realizar un desplazamiento urbano (...).

${ }^{86}$ Cfr. M.C. Chamorro Domínguez,"Las nuevas modalidades de prestación de servicios de transporte urbano desde la óptica del Derecho de la competencia" La Ley Mercantil, $n^{\circ} 38$, julio-agosto 2017, $n^{\circ}$ 38, 1 de julio de 2017 donde analiza las distintas resoluciones judiciales dictadas por los tribunales españoles en relación con las plataformas UberPop y Cabify.

${ }^{87}$ ECLI:EU:C: 2017:981. Asunto C: 434/15. Las partes litigantes son la Asociación Profesional Élite Taxi Uber Systems Spain, S.L. Vid. Comentario a la misma realizado por A. PAnIZA Fullana "El caso Uber: la sentencia del TJUE de 20 de diciembre de 2017”, Revista Aranzadi Doctrinal Civil-Mercantil, n 3/2018. (BIB 3/2018).

${ }^{88}$ Directiva 2006/23/ CE del Parlamento Europeo y del Consejo de 12 de diciembre de 2006 relativa a los servicios en el mercado interior.

${ }^{89}$ Directiva 2000/31/CE del Parlamento Europeo y del Consejo, de 8 de junio de 2000, relativa a determinados aspectos jurídicos de los servicios de la sociedad de la información, en particular el comercio electrónico en el mercado interior (en adelante, DCE). 
El servicio de intermediación de Uber se basa en la selección de conductores no profesionales que utilizan su propio vehículo, a los que esta sociedad proporciona una aplicación sin la cual, por un lado, estos conductores no estarían en condiciones de prestar servicios de transporte y, por otro, las personas que desean realizar un desplazamiento urbano no podrían recurrir a los servicios de los mencionados conductores".

69. Lo relevante está en esta afirmación que hace el TJUE: "Uber ejerce una influencia decisiva sobre las condiciones de las prestaciones efectuadas por estos conductores. Sobre este último punto, consta en particular que Uber, mediante la aplicación epónima, establece al menos el precio máximo de la carrera, que recibe este precio del cliente para después abonar una parte al conductor no profesional del vehículo y que ejerce cierto control sobre la calidad de los vehículos, así como sobre la idoneidad y el comportamiento de los conductores, lo que en su caso puede entrañar la exclusión de éstos. Por consiguiente, debe considerarse que este servicio de intermediación forma parte integrante de un servicio global cuyo elemento principal es un servicio de transporte y, por lo tanto, que no responde a la calificación de «servicio de la sociedad de la información". La intervención en la "calidad" del servicio, fijación de precios existiendo un grado de intervención y de influencia en los productos o servicios resulta determinante, a juicio del TJUE para concluir que se trata de un servicio en el ámbito de los transportes y, por lo tanto, no afectado por el principio de libertad de prestación de servicios, debiendo ser aplicable la regulación y requisitos para la prestación de dicho servicio ${ }^{90}$.

70. Muy diferente es la solución a otro caso que ha llegado a los tribunales españoles, que enfrentó a Confebus (Confederación Española de Transportes de Autobús) con la plataforma Bablacar. Al igual que en el caso de Uber, se plantea que esta plataforma vulnera la normativa en materia de competencia desleal por cuanto actúa como una empresa de transporte sin contar con las autorizaciones correspondientes. El tema se ha resuelto en la sentencia del Juzgado Mercantil $\mathrm{n}^{\mathrm{o}} 2$ de Madrid, de 2 de febrero de 2017 (Ref. Ar. AC 2017/207), donde se cuestiona si la actividad realizada por esta plataforma es un servicio de transporte terrestre y si está o no incluida en el art. 101 de la Ley de Ordenación de Transportes Terrestres que define lo que es transporte privado.

71. Como textualmente se recoge en la sentencia, se trata de "una plataforma virtual a la que pueden acceder los pretendientes de hacer viajes o los pretendientes de abaratar los suyos, poniéndose de acuerdo en cuyo caso intervienen identificando a las personas no para hacer los viajes o para pagar los gastos, sino para poner a unos y a otros de acuerdo en función de determinadas reglas que publican claramente en su página web para hacerlo a través de su intervención. En la plataforma se puede adscribir cualquier persona que se registre en la página www.blablacar.es, en la que introducen sus datos personales, edad, teléfono, etc., y que una vez introducidos dichos datos se consigna la procedencia y el destino del viaje, configurados igualmente los voluntarios que pueden realizar dichos viajes. Los viajes pueden buscarse mediante anuncios en internet, en las universidades, o incluso en el cartel de anuncios de un supermercado. La plataforma perfecciona el sistema de manera que genera un volumen enorme de usuarios y de proveedores mucho más allá de la cuestión artesanal, pues debido a su fama y a la publicidad que realiza, todo el que quiere abaratar su viaje, o el que quiere hacerlo en un coche particular puede acceder de forma infinitamente más efectiva que si lo hace a través de un anuncio mecánico o

${ }^{90}$ Esta resolución ha condicionado la que ha dictado el Tribunal Supremo en relación con los conflictos judiciales planteados por Uber en España, particularmente, el recurso presentado por la Generalitat de Cataluña contra la decisión del juez de Barce- lona de anular la sanción de 4.001 euros impuesta a la plataforma Uber (sentencia de 6 de octubre de 2016, del Juzgado de lo Contencioso Administrativo n ${ }^{\circ} 15$ de Barcelona). El litigio surgió a raíz de la sanción impuesta en 2015 a Uber por la Dirección General de Transportes de la Generalitat de Cataluña por la facturación en nombre propio de servicios de transporte público discrecional de viajeros en vehículos de hasta 9 plazas sin estar autorizado. Uber recurrió la sanción considerando que era un prestador de servicios de la sociedad de la información. La resolución judicial acogió las pretensiones de Uber, anulando la sanción excluyendo la actividad de Uber de la normativa de transporte terrestre y considerándolo prestador de servicios de la sociedad de la información, teniendo la condición de intermediario. Frente a esta resolución se ha interpuesto recurso de casación resuelto por el TS (Sala 3 ${ }^{\text {a }}$ ) en sentencia de 24 de enero de 2018 (Rec. 1277/2017) haciéndolo en la misma línea de la doctrina dictada por el TJUE. 
informático (...). Sin embargo, BLABLACAR, además de ser intermediario en el contacto, es también quien pone reglas sobre las personas que lo organizan, el formato en que debe realizarse, el precio que debe pagarse, recibe el dinero y lo paga e incluso es beneficiada por un margen preestablecido en sus normas de contacto".

72. La clave está en el valor jurídico que haya de dar a esta "intervención" de la plataforma en la prestación de los servicios que se prestan entre particulares. En la sentencia se niega que el control de los datos facilitados por el usuario de la plataforma sea actividad integrada y regulada por la LOTT, "pues es lógico que una plataforma virtual controle a quienes utilizan sus contactos y servicios". Tampoco la identificación del conductor (con el que carece de relación laboral) y su perfil como persona idónea para contactar con el usuario, la prohibición de determinadas conductas (fumar, oír música) son suficientes para incluir la actividad dentro del ámbito del transporte. Pero quizá lo decisivo sea el problema de la fijación del precio que los establece la plataforma calculados por la distancia $(0,06$ y $0,09 € / \mathrm{km})$ y se abonan a través de ella. La plataforma, según se explica en la sentencia, lo único que hace es calcular los kilómetros y recomendar a fuerza de expulsar de la plataforma en caso de abuso, el importe que debe pagar el viajero en función de la distancia y de la cantidad de viajeros en relación al coste total del viaje. Tampoco considera que el pago directo del precio a la plataforma signifique que sea ésta la que presta el servicio, ya que posteriormente lo transfiere al particular, percibiendo la plataforma la correspondiente comisión.

73. En suma, concluye que la actividad realizada por la plataforma se limita a la transmisión de datos entre usuarios, a poner en contacto a particulares que quieren realizar un viaje juntos, y compartir determinados gastos del trayecto, y para dar calidad al servicio de contacto ha puesto unos márgenes y unos límites y un formato de actuación, que en modo alguno es obligatorio para quienes lo usan o para quienes prestan una plaza en su coche para realizar el trayecto. Éstos no están contratados por la plataforma, ni pertenecen a una empresa o a una industria dedicada a este fin. Son particulares que a su cuenta y riesgo se ofrecen a la plataforma buscando a personas que tengan interés en realizar ese mismo viaje y pagar, no en el sentido de pagar un canon o un servicio, sino de pagar, -en el fondo es el concepto del pago el que define la cuestión-, el coste de un viaje.

74. La relación de la plataforma es "horizontal", la propia de un mercado multi-side en tanto su grado de intervención y de influencia en los productos o servicios que ofrecen no permite configurarlo como prestador de servicios. El hecho de que el formato de actuación diseñado por la plataforma no sea "obligatorio" para los particulares que intervienen, me parece un dato decisivo favorable a la naturaleza de la plataforma como intermediario y prestador de servicios de la sociedad de la información, no pudiendo ser limitada su actuación con la imposición de autorizaciones administrativas, tal y como veremos establece la LSSICE ni considerada como un acto de competencia desleal.

75. Por el contrario, en el caso Uber, esta plataforma ejerce una influencia decisiva en el servicio prestado por los conductores quienes se ven obligados a su cumplimiento: fija un precio máximo por servicio y ejerce un control sobre la calidad de los vehículos y el comportamiento de los conductores, considerándose que presta un servicio de transporte por lo que debe sujetarse a autorización administrativa previa y a la amalgama de regulación intervencionista que opera en este sector ${ }^{91}$.

76. El TJUE ha tenido oportunidad de pronunciarse de nuevo sobre el problema con ocasión de la plataforma de alojamiento Airbnb en la sentencia de 19 de diciembre de $2019^{92}$. En la sentencia se

\footnotetext{
${ }^{91}$ Sobre las características de la regulación del sector y su impacto en la economía colaborativa, vid., G. DOMENECH PASCUAL, "La regulación de la economía colaborativa. El caso Uber contra taxi”, Revista CEFLEGAL, n 175-17, 2015, p. 83.

${ }_{92}$ C 390/18 Ireland Airbnb. http://curia.europa.eu/juris/liste.jsf?language=es\&jur=C\%2CT\%2CF\&num=C-390/18

El lobby hotelero francés AHTOP, presentó una denuncia penal por intrusismo contra AirbnB Ireland, considerando que la plataforma realizaba una una actividad de intermediación y de gestión de inmuebles y de fondos de comercio sin estar en posesión de la tarjeta profesional exigida por la Ley Hoguet, necesaria para el ejercicio de la actividad de agente inmobiliario. Airbnb se opuso alegando que prestaba un servicio de la sociedad de la información al amparo de la Directiva de Comercio
} 
discuten varias cuestiones, pero me voy a centrar en la que considero más relevante: si Airbnb presta o no el servicio de alojamiento. La conclusión a la que llega el TJUE en esta sentencia es que Airbnb es un prestador del servicio de la sociedad de la información y su actividad es de mera intermediación entre demandantes y oferentes de alojamiento, sin que se pueda considerarse que sea la plataforma la prestadora de dicho servicio subyacente. La plataforma proporciona un instrumento que facilita la conclusión de contratos en futuras transacciones". Y ello a pesar de que la plataforma preste unos servicios accesorios que generan un valor añadido, como son la presentación organizada del conjunto de las ofertas, junto con las herramientas de búsqueda, de localización y comparación entre ellas. La decisión del TJUE se sustenta en los siguientes argumentos:

- La prestación del servicio realizado por Airbnb, no es indispensable para llevar a cabo la prestación de servicios de alojamiento. Propietarios y arrendadores pueden recurrir a otro tipo de medios (agentes inmobiliarios, anuncios clasificados, etc...). "El mero hecho de que Airbnb Ireland compita directamente con estos últimos cauces ofreciendo a sus usuarios, tanto arrendadores como arrendatarios, un servicio innovador basado en las particularidades de una actividad comercial de la sociedad de la información no permite concluir que sea indispensable para la prestación de un servicio de alojamiento".

- A diferencia de lo que sucedió en el caso Uber, en el caso de Airbnb, el servicio de intermediación que presta no forma parte integrante de un servicio global cuyo elemento principal sea un servicio al que corresponda otra calificación jurídica. En el caso de Airbnb, su actividad es perfectamente disociable de la transacción inmobiliaria de alojamiento que la plataforma no presta.

- Airbnb no ejerce una influencia decisiva en las condiciones de prestación de los servicios de alojamiento a los que está vinculado su servicio de intermediación. La plataforma no determina o limita el importe del alquiler solicitado por los arrendadores que utilizan su plataforma. A lo sumo, pone a su disposición una herramienta opcional de estimación del precio de su arrendamiento en función de los precios medios del mercado en dicha plataforma, dejando a los arrendadores la responsabilidad de fijar el precio del arrendamiento. Tampoco selecciona los arrendadores ni los arrendatarios, ni establece condiciones de calidad de los inmuebles.

77. Esta es la posición del TJUE, pero carece de normativa específica que dé soporte legal a estos criterios. Es en este punto en el que, a mi juicio, debe centrarse la intervención legislativa a nivel europeo. No es el TJUE el que debe diseñar tales criterios, sino que deben estar establecidos en la ley en aras a una elemental seguridad jurídica ${ }^{93}$. Son muchas las consecuencias que se derivan de que la plataforma sea considerada un intermediario o no. Veamos cuáles son.

\section{Las plataformas intermediarias en línea como prestadoras de servicio de la sociedad de la in- formación. Consecuencias}

78. Aunque ya se ha dicho que las plataformas intermediarias en línea son prestadoras de servicios de la sociedad de la información, conviene detenerse someramente en algunos aspectos particulares de régimen jurídico que se derivan de tal condición. Al margen de la naturaleza del contrato que celebra la plataforma con los usuarios, a cuya calificación luego me referiré, adicionalmente será de aplicación la regulación contenida en la $\operatorname{LSSICE}^{94}$ (que transpone la Directiva 2000/31 de comercio electrónico) ${ }^{95}$.

\footnotetext{
electrónico 2000/31en el marco de la libre prestación de servicios.

${ }^{93}$ En este sentido, A. DE FRANCHESCI"Uber Spain and the "Identity Crisis" of Online Platforms", Journal of European Consumer and Market Law (EuCML) 1/2018. Vo. 7, pp. 1-4.

${ }^{94}$ Ley 34/2002, de 11 de julio, de servicios de la sociedad de la información y de comercio electrónico.

${ }_{95}$ Directiva 2000/31/CE del Parlamento Europeo y del Consejo, de 8 de junio de 2000, relativa a determinados aspectos jurídicos de los servicios de la sociedad de la información, en particular el comercio electrónico en el mercado interior (en adelante, DCE).
} 
79. El anexo, letra a) de la LSSICE define los servicios de la sociedad de la información como "todo servicio prestado normalmente a título oneroso, a distancia, por vía electrónica y a petición individual del destinatario. El concepto de servicio de la sociedad de la información comprende también los servicios no remunerados por sus destinatarios, en la medida en que constituyan una actividad económica para el prestador de servicios".

80. Tal y como se deduce de la definición, la onerosidad no es requisito esencial y, cuando se trata de plataformas multilaterales, es posible que la remuneración esté a cargo de uno de los grupos de usuarios. La clave es que los prestadores de estos servicios realicen actividad económica, lo cual no exige que deban ser necesariamente remunerados. Ello no excluye que para el prestador el servicio constituya una actividad económica, ya que puede obtener ingresos indirectos, por ejemplo, a través de la publicidad. Se considera actividad económica una actividad realizada en la página web que constituye una prestación sucesiva de carácter oneroso, como puede ser aquella que se limita a hacer publicidad de un servicio, aunque no pueda este ser contratado por internet. Hay actividad económica, aunque los servicios sean gratuitos para los destinatarios. Muchas veces el activo que obtiene el prestador de los servicios son precisamente sus datos personales ${ }^{96}$. Que no es precisa la remuneración es un extremo aclarado en el Considerando 18 de la DCE aclara el concepto de servicio de la sociedad de la información ${ }^{97}$

81. Debe tratarse de un servicio prestado a distancia, es decir, sin que las partes estén presentes simultáneamente ${ }^{98}$. Resultan excluidos, por no reunir este requisito, los servicios prestados en presencia física del prestador y del destinatario del servicio, aunque impliquen la utilización de dispositivos electrónicos (Anexo IV. RD 1337/1999) ${ }^{99}$. El servicio debe prestarse a petición individual del destinatario de servicios, quedando fuera los servicios proporcionados mediante transmisión de datos, sin petición individual y recibidos por un número ilimitado de destinatarios (por ejemplo, servicio de radiodifusión sonora, teletexto). Este requisito también tiene lugar en las plataformas en las que son los usuarios los que voluntariamente se convierten en proveedores y clientes de los bienes y servicios que se intercambian.

82. En el anexo de la LSSICE se especifica (lista no exhaustiva) que son servicios de la sociedad de la información, siempre que representen actividad económica, $1 .^{\circ}$ La contratación de bienes o servicios por vía electrónica. 2. ${ }^{\circ}$ La organización y gestión de subastas por medios electrónicos o de mercados y centros comerciales virtuales. $3 .^{\circ}$ La gestión de compras en la red por grupos de personas. $4 .^{\circ} \mathrm{El}$ envío de comunicaciones comerciales. $5{ }^{\circ} \mathrm{E}$ suministro de información por vía telemática.

83. Se excluyen de manera expresa del concepto de servicios de la sociedad de la información

1. Los servicios prestados por medio de telefonía vocal, fax o télex.

2. El intercambio de información por medio de correo electrónico u otro medio de comunicación electrónica equivalente para fines ajenos a la actividad económica de quienes lo utilizan.

${ }^{96}$ P.A. De Miguel Asensio, Derecho privado en Internet, 2011 BIB 2011/961, p. 4.

97 "Los servicios de la sociedad de la información cubren una amplia variedad de actividades económicas que se desarrollan en línea; dichas actividades en particular consisten en la venta de mercancías en línea. Las actividades como la entrega de mercancías en sí misma o la prestación de servicios fuera de la línea no están cubiertas. Los servicios de la sociedad de la información no se limitan únicamente a servicios que dan lugar a la contratación en linea, sino también, en la medida en que representan una actividad económica, son extensivos a servicios no remunerados por sus destinatarios, como aquéllos que consisten en ofrecer información en línea o comunicaciones comerciales, o los que ofrecen instrumentos de búsqueda, acceso y recopilación de datos. Los servicios de la sociedad de la información cubren también servicios consistentes en transmitir información a través de una red de comunicación, o albergar información facilitada por el destinatario del servicio".

${ }_{98}$ Artículo 1.b) i) Directiva 2015/1535 del Parlamento Europeo y del Consejo, de 9 de septiembre de 2015 por la que se establece un procedimiento de información en materia de reglamentaciones técnicas y de reglas relativas a los servicios de la sociedad de la información. El concepto se reproduce en el art. 92 del Texto Refundido para la defensa de los consumidores y usuarios (TRLCU).

${ }^{99}$ Real Decreto 1337/1999, de 31 de 31 de julio que regula la remisión de información en materia de normas y reglamentaciones técnicas y reglamentos relativos a la sociedad de la información, de 4 de agosto de 1999 (en adelante, RD 1337/1999). 
3. Los servicios de radiodifusión televisiva (incluidos los servicios de cuasi vídeo a la carta).

4. Los servicios de radiodifusión sonora.

5. El teletexto televisivo y otros servicios equivalentes como las guías electrónicas de programas ofrecidas a través de las plataformas televisivas.

El prestador del servicio de la sociedad de la información es la persona física o jurídica que proporciona un servicio de la sociedad de la información (Anexo c) LSSICE).

84. La definición legal de prestador de servicios de la sociedad de la información ensancha artificialmente el concepto. En sentido técnico, el concepto de prestador de servicio de la sociedad de la información incluye dos grandes categorías: a) los llamados "intermediarios electrónicos" (proveedores de servicio de internet) y b) proveedores de contenidos, es decir, quienes suministran información o envían o permiten la descarga de archivos (musicales, de vídeo u otros) o programas informáticos. Sin embargo, la LSSICE incluye en la categoría de prestadores de servicios de la información a quien vende electrónicamente productos materiales, pues no encaja en la categoría de intermediarios electrónicos ni en la de proveedores de contenidos. En los contratos de compraventa de bienes, las partes contratan gracias a ciertos servicios de la sociedad de la información (el que le permite al comprador acceder a internet y el que aloja la tienda virtual del vendedor), pero no se erigen ellos en proveedores de servicios de la sociedad de la información. Con todo, por disposición expresa de la ley sí lo son ${ }^{100}$. Existen tres tipos de prestadores de servicios de la sociedad de la información: los prestadores intermediarios (intermediación técnica), los prestadores de contenidos y quienes ofrecen en la red la contratación de sus productos o servicios.

85. Es claro que las plataformas de intermediación en línea entran en el amplio concepto de prestadores de servicios de la sociedad de la información ${ }^{101}$, siendo personas jurídicas que realizan actividad económica, a distancia, por medios electrónicos y a petición individual de un destinatario de servicios.

86. Dado que el objeto de nuestro estudio son las plataformas multi-side, es clave que no lleven a cabo la prestación del servicio subyacente, sino que se limiten a favorecer la interacción de los usuarios del sistema que son los que efectivamente contratan. Si la plataforma además prestara el servicio, le sería de aplicación la regulación específica del servicio prestado (art. 6.2 LSSICE). Por tanto, la regulación de la LSSSI se solapa (no es excluyente) con la eventual regulación de la actividad subyacente caso de que la misma fuera prestada por la propia plataforma en su modalidad one side, es decir, aquella que no presta servicios de intermediación, sino que ella misma presta el servicio.

\subsection{El principio de no sujeción a autorización previa}

87. Una de las especialidades de régimen jurídico más sobresalientes que presenta el régimen de los prestadores de servicios de la sociedad de la información es que su actividad no está sujeta a au-

${ }^{100}$ S. CAVANillas MúGica, "La responsabilidad de los proveedores de información y de comercio electrónico", en (AA. VV.), Responsabilidad de los proveedores de información en Internet, Ed. Comares, Granada, 2007, p. 131.

101 Así lo ha puesto de relieve la Comisión Europea, "Comunicación de la Comisión al Parlamento Europeo, al Consejo, al Comité Económico y Social Europeo y al Comité de las Regiones. Una Agenda Europea para la Economía Colaborativa”. Bruselas, 2.6.2016 COM (2016) 356 final, p. 6. También lo reconoció expresamente la sentencia del TJUE de 12 de julio de 2011 (caso L'Oreal vs. eBay): "un servicio en Internet que consiste en facilitar el contacto entre vendedores y compradores de productos tiene, en principio, la consideración de un servicio en el sentido de la Directiva 2000/31. (...) Del concepto de «servicios de la sociedad de la información» se desprende que se encuentran comprendidos en la misma los servicios prestados a distancia a través de equipos electrónicos de tratamiento y almacenamiento de datos, a petición individual de un destinatario de servicios y, normalmente, a cambio de una remuneración. Resulta evidente que la explotación de un mercado electrónico puede reunir todos estos elementos" (párrafo 109). 
torización previa (art. 6 LSSICE). Pero como dispone el art. 6.2 LSSICE, “esta norma no afectará a los regímenes de autorización previstos en el ordenamiento jurídico que no tengan por objeto específico y exclusivo la prestación por vía electrónica de los correspondientes servicios". De ahí la importancia de determinar caso por caso el papel de las plataformas intermediarias en línea, de forma que quede claro si prestan o no el servicio subyacente. Caso de hacerlo, como he dicho, necesitarán las autorizaciones pertinentes para la realización de tal servicio. En este punto se ha centrado la litigiosidad en el caso Uber a la que me he referido. Si la plataforma se limita a prestar servicio de mediación y de favorecer la interacción entre los usuarios que son los que prestan el servicio, no será precisa autorización previa.

88. Este aspecto ha sido recalcado por la Comisión Europea al señalar que "el hecho de que las plataformas colaborativas puedan estar o no sujetas a requisitos de acceso al mercado, y en qué medida lo estén, depende de la naturaleza de sus actividades. En la medida en que las plataformas colaborativas proporcionan un servicio prestado normalmente a cambio de una remuneración, a distancia, por vía electrónica y a petición individual de un prestatario de servicios, ofrecen un servicio de la sociedad de la información. Por lo tanto, no pueden estar sujetas a autorizaciones previas o cualquier requisito equivalente dirigidos específica y exclusivamente a dichos servicios (...). Sin embargo, puede haber situaciones en las que puede considerarse que las plataformas colaborativas ofrecen otros servicios además de los servicios de la sociedad de la información, actuando como intermediarios entre los prestadores de los servicios subyacentes y sus usuarios. En particular, en determinadas circunstancias, una plataforma puede ser también un proveedor del servicio subyacente (p. ej., servicio de transporte o de alquiler a corto plazo). En tal caso, las plataformas colaborativas podrían estar sujetas a la normativa sectorial específica, incluidos los requisitos de autorización y concesión de licencias empresariales aplicados por lo general a los prestadores de servicios" 102 .

89. El hecho de que a los prestadores de servicios de la sociedad de la información no se les pueda exigir autorización cuando su actividad se centra solo en la prestación de dichos servicios, condiciona una eventual regulación de las plataformas intermediarias en línea, ya que podría suponer una excepción a dicho régimen general. Por lo tanto, a los efectos de determinar el régimen jurídico de una plataforma, lo primero que hay que valorar es si presta o no el servicio subyacente y debe o no serle exigida la autorización correspondiente a la actividad que desarrolle. Pero este problema no debe confundirse con otro, bien distinto, al que me refiero a continuación, cual es si las plataformas pueden considerarse o no un servicio de intermediación definido en el Anexo de la LSSICE. Ello tiene consecuencias no en la necesidad o no de autorización previa, sino en si las plataformas se benefician o no de determinadas exenciones de responsabilidad. El lenguaje en esta materia, como veremos, traiciona y confunde.

\subsection{Plataformas intermediarias en línea y prestador de servicio de intermediación en la sociedad de la información. La responsabilidad del operador de la plataforma}

90. Siendo las plataformas prestadoras del servicio de la sociedad de la información, es preciso determinar en qué categoría se integran, ya que existen especialidades de régimen para determinados prestadores en función del servicio que prestan. Es decir, si prestan servicio de intermediación técnica, provisión de contenidos o contratación de bienes o servicios.

91. Como ya hiciera la DCE, la LSSICE establece un régimen jurídico específico para los operadores que prestan un servicio de intermediación a que se refiere el Anexo b) y art. 13.2 de la LSSICE. El mismo se define como aquel por el que se facilita la prestación o utilización de otros servicios de la sociedad de la información o el acceso a la información. Son servicios de intermediación la provisión

${ }^{102}$ Comisión Europea, "Comunicación de la Comisión al Parlamento Europeo, al Consejo, al Comité Económico y Social Europeo y al Comité de las regiones. Una agenda europea para la economía colaborativa”. 2 de junio de 2016. COM (2016) 356 FINAL, p. 6. 
de servicios de acceso a Internet, la transmisión de datos por redes de telecomunicaciones, la realización de copia temporal de las páginas de Internet solicitadas por los usuarios, el alojamiento en los propios servidores de datos, aplicaciones o servicios suministrados por otros y la provisión de instrumentos de búsqueda, acceso y recopilación de datos o de enlaces a otros sitios de Internet.

92. Los prestadores de servicios de intermediación hacen posible que los contenidos de terceros circulen, se alojen y sean accesibles en la red, haciendo de puente entre quienes generan o editan los contenidos y quienes acceden a éstos. Su función es, por tanto, facilitar las condiciones y medios técnicos requeridos para la transmisión y acceso de datos sin intervenir en su elaboración ${ }^{103}$, siendo intermediarios "en sentido técnico", no necesariamente en sentido material. Realizan una actividad instrumental en la medida que permite la operatividad de la infraestructura de internet. Entran en este concepto los proveedores de acceso a la red, proveedores de alojamiento (hosting), proveedores de copia temporal (catching) y proveedores que faciliten enlaces a contenidos o instrumentos de búsqueda. Rasgo característico de los prestadores intermediarios es que mantienen una posición pasiva con respecto a los contenidos, no participando ni en su creación ni en la decisión de hacerlos accesibles ${ }^{104}$. Ciertamente trabajan con datos, con contenidos, pero respecto a ellos desempeñan funciones informativamente neutras. Trabajan con datos (información no gestionada ni procesada) ${ }^{105}$ y no con información (información procesada). Se trata, para entendernos, de la intermediación técnica necesaria para que funcione internet.

93. Como señaló la Sentencia del Tribunal Europeo de Derechos Humanos de 16 de junio de 2015, dictada en el asunto 64569/09 (caso DELFI AS vs. Estonia), presta servicios de intermediación el prestador de servicios de la sociedad de la información "cuya actividad se limita al proceso técnico operativo y da acceso a una red de comunicación a través de la que la información puesta a disposición por terceros se transmite o se almacena temporalmente, con el único propósito de hacer más eficiente la transmisión; esta actividad es de naturaleza meramente técnica, automática y pasiva, lo que implica que el PSSI no tiene ni conocimiento ni control de la información transmitida o almacenada. Por lo tanto, los proveedores de los así llamados "servicios de albergador de datos" que tienen control sobre el contenido de la información almacenada no pueden basarse en las exenciones previstas en los artículos 12 a 15 de la Directiva".

94. Efectivamente, por su posición pasiva en relación con los contenidos, la LSSICE establece un régimen específico de responsabilidad en los arts. 13-17 que transponen los arts. 12-15 DCE. Después de establecerse con carácter general en el art. 13 LSSICE que "los prestadores de servicios de la sociedad de la información están sujetos a la responsabilidad civil, penal y administrativa establecida con carácter general en el ordenamiento jurídico, sin perjuicio de lo dispuesto en esta Ley", los arts. 14 y siguientes establecen una serie de exenciones de responsabilidad (denominadas (safe harbour regime), para los prestadores de servicios por el ejercicio de actividades de intermediación.

95. Nos centramos en la exención prevista en el art. 16 LSSICE (art. 14 DCE) que es la que se ha alegado por las plataformas de intermediación. Dispone este precepto que:

1. Los prestadores de un servicio de intermediación consistente en albergar datos proporcionados por el destinatario de este servicio no serán responsables por la información almacenada a petición del destinatario, siempre que:

${ }^{103}$ S. Camacho Clavijo, "Régimen jurídico de los prestadores de servicios de la sociedad de la información" en Navas Navarro, S., y Camacho Clavijo, S, Mercado digital. Principios y reglas jurídicas, Tirant lo Blanch, Valencia, 2016 , p. 114.

104 P. MÁrquez lobillo, "Prestadores de servicios de intermediación. Algunas especialidades de su estatuto jurídico", Revista de la contratación electrónica, $n^{\circ} 88,2007$, p. 8.

105 T. RodríGueZ DE LAS HeRAS BALLELL , "El régimen jurídico de los mercados electrónicos cerrados (e-Marketplaces), cit., p. 147. 
a) No tengan conocimiento efectivo de que la actividad o la información almacenada es ilícita o de que lesiona bienes o derechos de un tercero susceptibles de indemnización, o

b) Si lo tienen, actúen con diligencia para retirar los datos o hacer imposible el acceso a ellos.

96. Se entenderá que el prestador de servicios tiene el conocimiento efectivo a que se refiere el párrafo a) cuando un órgano competente haya declarado la ilicitud de los datos, ordenado su retirada o que se imposibilite el acceso a los mismos, o se hubiera declarado la existencia de la lesión, y el prestador conociera la correspondiente resolución, sin perjuicio de los procedimientos de detección y retirada de contenidos que los prestadores apliquen en virtud de acuerdos voluntarios y de otros medios de conocimiento efectivo que pudieran establecerse. La exención de responsabilidad establecida en el apartado 1 no operará en el supuesto de que el destinatario del servicio actúe bajo la dirección, autoridad o control de su prestador.

97. Los prestadores de servicios de intermediación permiten que se difundan los contenidos en la red por parte de terceros. Si tales intermediarios fueran responsables de los daños que ocasionen contenidos y actividades ilícitas realizadas por terceros, ello supondría un obstáculo jurídico que entorpecería el buen funcionamiento del mercado interior y haría menos atractivo el ejercicio de la libertad de establecimiento y de la libre circulación de servicios. Evitarlo fue uno de los objetivos de la DCE (Considerando 5). Estas actividades ilícitas han sido frecuentes en el ámbito de la propiedad intelectual, derecho al honor, marcas, competencia desleal etc... Se excluye cualquier tipo de responsabilidad, tanto penal como civil, que resulte del contenido intermediado ${ }^{106}$ y se aplica horizontalmente a todo tipo de información ${ }^{107}$.

98. La divergencia de las normativas y jurisprudencias nacionales actuales o futuras en el ámbito de la responsabilidad de los prestadores de servicios que actúan como intermediarios entorpece el correcto funcionamiento del mercado interior al obstaculizar, en especial, el desarrollo de servicios transfronterizos y producir distorsiones de la competencia (Considerando 40 DCE). De ahí que se establezca la exclusión de responsabilidad de estos prestadores de intermediación que se limitan a facilitar técnicamente la transmisión de contenidos por internet, por los daños que resulten de las actividades ilícitas que se realicen gracias a su ayuda meramente tecnológica ${ }^{108}$. No hacerlo, comprometería la innovación tecnológica y el propio funcionamiento de internet ${ }^{109}$.

99. Como acertadamente se ha señalado, este régimen especial de responsabilidad se justifica en el carácter gravoso que, desde la perspectiva económica y técnica, supondría para los intermediarios imponerles aquella obligación de control de todos los contenidos que transmitan o alberguen y que en la práctica supondría una obligación de realizar búsquedas activas de hechos o circunstancias que indiquen la existencia de datos o hechos susceptibles de causar daños ilícitos de imposible cumplimiento. Desde la perspectiva estrictamente jurídica resulta razonable no atribuir a los prestadores de servicios de alojamiento y acceso la función de supervisar contenidos que podría colisionar con la libertad de expresión e información y con los artículos $20.2 \mathrm{CE}^{110}$. No obstante, a pesar de que los prestadores de servicios

${ }^{106}$ C. Meoro, "Responsabilidad civil de los prestadores de servicios de la sociedad de la información” en S. Cavanillas, S., y C. Meoro, Responsabilidad civil y contratos en internet, Granada, 2003omares, p. 74.

107 Comisión Europea, "Primer informe sobre la Directiva 2000/31, relativa a determinados aspectos de la sociedad de la información, en particular el comercio electrónico en el mercado interior”. 21/11/2003. COM (2003) 702 al final, p. 16.

108 Vid. Al respecto el trabajo de Arroyo Amayuelas, E., "La responsabilidad de los intermediarios en internet ¿Puertos seguros a prueba de futuro?" Cuadernos de Derecho Transnacional (marzo 2020), vol. 12, No 1, DOI: https://doi.org/10.20318/ $\underline{\text { cdt. } 2020.5225}$

${ }^{109}$ Como han señalado, R.J. MAnN, y S. BelzLey, “The Promise of Internet Intermediary Liability”. William and Mary Law Review, Vol. 47, 2005, p. 20. https://ssrn.com/abstract=696601. La clave está en determinar si es factible que el intermediario detecte la conducta ilícita y, caso de que sea posible, los costes que ello conllevaría. Si, por ejemplo, Google respondiera por daños causados por cualquier enlace a contenidos ilícitos eliminaría el carácter automático de las búsquedas y reduciría el catálogo de websites que tendría que rastrear a cambio, probablemente de un precio. El control de la conducta debería ser no solo posible, sino viable económicamente".

110 JM. Busto LAGo, "La responsabilidad civil de los prestadores de servicios de intermediación en la sociedad de la información”, Actualidad Jurídica Aranzadi núm. 542 (BIB 2002/1091). 
de intermediación no tienen obligación de supervisar los contenidos, sí tienen un deber de colaboración cuando se les requiera (art. 17.1.b) LSSICE).

100. Tal y como se hace constar en el Considerando 42 DCE, la intermediación a la que se refiere es meramente técnica. "Las exenciones de responsabilidad establecidas en la presente Directiva solo se aplican a aquellos casos en que la actividad del prestador de servicios de la sociedad de la información se limita al proceso técnico de explotar y facilitar el acceso a una red de comunicación mediante la cual la información facilitada por terceros es transmitida o almacenada temporalmente, con el fin de hacer que la transmisión sea más eficiente. Esa actividad es de naturaleza meramente técnica, automática y pasiva, lo que implica que el prestador de servicios de la sociedad de la información no tiene conocimiento ni control de la información transmitida o almacenada".

101. Y precisamente por esta falta de control de la información esta modalidad de proveedor no responde por los contenidos y actividades ilegales que se realicen en la red. En este sentido, no es la actividad de intermediación la que reclama este específico régimen de responsabilidad, sino la falta de conocimiento efectivo de que la actividad o la información almacenada es ilícita o de que lesiona bienes o derechos de un tercero susceptibles de indemnización, la cual se presupone por el carácter de intermediario del prestador que adopta posición neutral. No basta que no conozca, sino que además no tenga posibilidad de conocer la actividad ilícita ${ }^{111}$. Por ello, se establece la excepción del conocimiento efectivo en el art. 16 LSSICE. Habrá intermediarios que sí respondan por tener conocimiento efectivo de la ilegalidad del contenido y proveedores que no tengan la condición de prestadores de servicios de intermediación que no puedan alegar las exenciones de responsabilidad, lo cual no significa que necesariamente deban ser necesariamente responsables, sino que se tendrán que dar todos los requisitos legales del régimen que corresponda y, con carácter general, una acción u omisión, daño, culpa o negligencia y relación de causalidad ${ }^{112}$.

102. ¿Son las plataformas intermediarias en línea prestadores de servicios de intermediación, siéndoles aplicables estas exenciones de responsabilidad? En caso afirmativo, habría que examinar caso por caso si se cumplen los requisitos para que tal exención de responsabilidad opere. Pero se trata de dos problemas distintos. El primero y prioritario es determinar si su actividad puede calificarse de intermediación en la sociedad de la información según el concepto proporcionado en el Anexo de la LSSICE. Si la respuesta a esta cuestión es negativa, no procede entrar a valorar en si se cumplen o no los requisitos del art. 16 LSSICE. Aclaro este extremo pues, como veremos, se han mezclado ambos problemas y creo que se evitarían muchos litigios si se aclarara la posición jurídica de estos proveedores de servicios intermediarios de la sociedad de la información.

103. Aunque pueda resultar redundante, a mi juicio, no toda plataforma intermediaria en línea presta servicios de intermediación de la sociedad de la información (Anexo LSSICE), en particular, las plataformas colaborativas no necesariamente entran en ese concepto a pesar -insisto- de que sean intermediarias en sentido material por favorecer la interacción entre los usuarios ${ }^{113}$. Su carácter de inter-

${ }^{111}$ La interpretación de la exención de responsabilidad prevista en el art. 16 LSSICE ha sido ha dado lugar a mucha litigiosidad, siendo numerosas las resoluciones dictadas por el TS. Particularmente, el problema de cuándo opera la excepción del "conocimiento efectivo de que la actividad o la información almacenada es ilicita o de que lesiona bienes o derechos de un tercero susceptibles de indemnización" prevista en el art. 16.1 LSSICE y que deja inoperante la exención de responsabilidad. El TS entiende que el concepto de conocimiento efectivo es abierto y engloba también la "posibilidad de conocer directamente o a partir de datos aptos para posibilitar la aprehensión de la realidad" (sentencias de del TS de 9 de noviembre de 2009 (RJ 2009/131) y de 18 de mayo de 2010 (RJ 2010/2319). Vid. Comentario a la misma de S. Cavanillas Múgica, "Responsabilidad de un prestador de un servicio intermediario de la sociedad de la información, de alojamiento, por la intromisión ilegítima causada por un comentario enviado a un foro", CCJC n ${ }^{\circ}$ 85/2011. BIB 2011/41.

112 M. Peguera Poch. "Sólo sé que no sé nada (efectivamente): la apreciación del conocimiento efectivo y otros problemas en la aplicación judicial de la LSSICE, Revista Internet, Dret i Política, junio 2007, p. 9.

113 Para T. Rodríguez de las Heras Ballell, "El régimen jurídico de los mercados electrónicos cerrados (e-Marketplaces), cit., p. 149, junto con los intermediarios técnicos y proveedores de contenidos existe otra categoría de prestadores de servicios 
mediario debe examinarse desde dos ópticas distintas: la falta de prestación de servicio subyacente y su papel como intermediario técnico de servicio de la sociedad de la información.

104. En diversos litigios planteados ante el TJUE en los que se ha demandado a las plataformas exigiendo responsabilidad por vulneración de normativa relacionada con la actividad realizada por los usuarios, las plataformas se han pretendido acoger a la exención de responsabilidad del art. 14 DCE (art. 16 LSSICE), alegando que prestaban servicios de alojamiento de datos (hosting) proporcionados por el destinatario del servicio. De hecho, si se observan las condiciones generales de uso de las plataformas, aparentemente, quieren parecer prestadores de servicios de intermediación pues aparentan que el servicio que ofrecen es una licencia para utilizar un software que permite la interacción entre los usuarios ${ }^{114}$

105. Según el Anexo de la LSSICE son prestadores de servicios de intermediación "el alojamiento de datos en los propios servidores" de datos o contenidos facilitados por terceros. Por ejemplo, aquellos proveedores que facilitan el espacio para alojar una página web, y siempre que el contenido de la misma sea proporcionado por terceros. Como veremos, el concepto es meramente técnico y no todo prestador de servicio de la sociedad de la información que permita alojamiento de datos puede ser considerado intermediario y beneficiarse de esta exoneración de responsabilidad, sino solo aquellos que prestan exclusivamente tal servicio. Hay otros tipos de supuestos en los que se pueden alojar datos de terceros, como blogs en los que se admiten comentarios de terceros, wiki ${ }^{115}$, que, a mi juicio, no son los proveedores de alojamiento a los que se está refiriendo la LSSICE cuando habla de prestadores de servicios de intermediación ${ }^{116}$. Cuando el Anexo de la LSSI se refiere al servicio de alojamiento de datos, la ley señala que debe serlo "en sus propios servidores", lo que parece reducir la aplicación del art. 16 LSSICE a los prestadores de hosting sin incluirse el alojamiento de datos en blogs o sitios web como YouTube ${ }^{117}$. Estas plataformas en línea no podrían beneficiarse de la exoneración de responsabilidad del art. 14 DCC (art. 16 LSSICE).

106. De hecho, como veremos, en la jurisprudencia del TJUE, se acaba negando la exención de responsabilidad de estos proveedores de alojamiento en sentido amplio, por entender que, aunque

de la sociedad de la información que denomina intermediarios de contenidos. No consisten en aproximar físicamente a proveedor y cliente, sino en enlazar de la forma más eficiente la información con su destinatario haciéndola "visible" y "manejable", en facilitar la interacción entre compradores y vendedores creando las denominadas comunidades virtuales. Estas comunidades virtuales tienen tres elementos clave: un propósito común a través de una interacción "many to many"; unas fronteras, es decir, una política de acceso y salida del grupo; y un conjunto de normas que regulan el comportamiento de la comunidad virtual. A juicio de la autora citada, tales intermediarios, en cuyo concepto entran las plataformas intermediarias en línea, no son prestadores de servicios de intermediación pura en el sentido técnico de la LSSICE (p. 161). A diferencia de los intermediarios técnicos, los intermediarios de contenido desempeñan un conjunto de funciones que les permiten un mayor conocimiento del contenido que manejan y consecuentemente una más razonable posibilidad de control del mismo. Ejemplos de estos intermediarios de contenidos serían portales, buscadores, mercados virtuales, grupos de discusión. Sin embargo, la autora defiende una interpretación extensiva del art. 17 LSSICE de forma que estos intermediarios de contenidos se vean beneficiados de la exención de responsabilidad. Justifica su postura en que el establecimiento de medidas de control y supervisión son irrazonables (p. 596). Las exenciones de responsabilidad deben ser objeto de interpretación restrictiva. No creo que tal interpretación pueda deducirse con los textos vigentes. Creo que las exenciones están pensadas para el intermediario electrónico.

114 Amazon o sus proveedores de contenidos le conceden una licencia limitada no exclusiva, no transferible y no sublicenciable, de acceso y utilización, a los Servicios de Amazon para fines personales no comerciales. Dicha licencia no incluye derecho alguno de reventa ni de uso comercial de los Servicios de Amazon ni de sus contenidos, ni derecho alguno a compilar ni utilizar lista alguna de productos, descripciones o precios. Tampoco incluye el derecho a realizar ningún uso derivado de los Servicios de Amazon ni de sus contenidos, ni a descargar o copiar información de cuenta alguna para el beneficio de otra empresa, ni el uso de herramientas o robots de búsqueda y extracción de datos o similar". https://www.amazon.es/gp/help/ customer/display.html?nodeId $=200545940$

${ }^{115}$ Mantiene este concepto amplio, M. Peguera Poch, "Sólo sé que no sé nada (efectivamente)..., cit., p. 5. A su juicio, alojar un comentario enviado por un lector de un blog supone que el titular del blog está llevando a cabo un servicio de alojamiento de datos que entra en el ámbito del art. 16 LSSICE. Este artículo no debe entenderse referido a la actividad de hosting en sitios web, sino a cualquier supuesto de alojamiento de datos suministrados por terceros".

${ }^{116}$ Por esta razón se les ha denominado "falsos proveedores de hosting", Vid., ROSATI, E., Why a reform of hosting providers' safe harbour is unnecessary under EU copyrightlaw, CREATe Working Paper 2016/11, 2016, p. 4. https://papers.ssrn.com/sol3/papers. cfm?abstract id=2830440 (Consultado el 20 de marzo de 2018).

117 S. CAmacho Clavijo, Régimen jurídico de los prestadores de servicios de la sociedad de la información, cit., p. 146. 
alojen datos, su actividad no es de mera intermediación técnica. Por ello, respecto de estas modalidades de alojamiento, no haría falta valorar si entran en la excepción del conocimiento efectivo de la ilegalidad del contenido. Pueden ser responsables porque no son los prestadores de servicios de intermediación en que estaba pensando el legislador europeo. Sin embargo, aunque se mantenga un concepto amplio de prestación de servicio de alojamiento, lo cierto es que la aplicación práctica evidencia que solo si el prestador de servicios realiza una actividad neutral o técnica, puede acogerse a esta exención de responsabilidad.

107. La sentencia del TJUE de 23 de marzo de 2010 Google France y Google vs. Louis Vuitton resuelve una cuestión prejudicial planteada por el Tribunal Supremo francés en relación con la demanda presentada por Louis Vuitton contra Google por violación de sus derechos de marca ${ }^{118}$, la cual fue estimada por el tribunal de instancia. El litigio se centra en el servicio prestado por la plataforma Google Adwords que permite, mediante la inclusión de varias palabras clave, enlaces promocionales que, en el caso enjuiciado, llevaban a páginas web que vendían productos Louis Vuitton falsificados.

108. En lo que aquí interesa, el tribunal pregunta si Google presta un servicio de intermediación de la sociedad de la información y le resulta de aplicación la exención de responsabilidad prevista en el art. 14 DCE (equivalente al art. 16 LSSICE). Considera el TJUE que para comprobar si es aplicable tal exención de responsabilidad "es necesario examinar si el papel desempeñado por el prestador es neutro, es decir, si su comportamiento es meramente técnico, automático y pasivo, lo que implica que no tiene conocimiento ni control de la información que almacena". Estas son las características que determinan que la actividad de la plataforma sea un servicio de intermediación de la sociedad de la información: carácter técnico, automático y pasivo. No entra en si tuvo o no conocimiento o control de la información, sino que el TJUE analiza la actividad de la plataforma en primer lugar. No se discute si hay o no responsabilidad por cumplirse los requisitos del art. 14 DCE, sino que la resolución se centra, a mi juicio acertadamente, en analizar si Google proporciona o no un servicio de intermediación lo cual debe valorarse en el caso concreto analizando si la plataforma asume "un papel activo que pueda darle conocimiento o control de los datos almacenados" (párrafo 120). Lo decisivo no es que la plataforma realice actividad de alojamiento de datos (hosting), sino que, caso por caso, habrá que determinar si tiene naturaleza meramente técnica, automática y pasiva, lo que implica que aquél no tiene conocimiento ni control de la información transmitida o almacenada (en el mismo sentido, la sentencia del TJUE de 11 de septiembre de 2014, asunto C-291/13, Caso Papasavvas, párrafo 45) ${ }^{119}$.

109. Más claridad arroja la sentencia del TJUE de 12 de julio de 2011 (L'Oreal contra eBay) que resuelve una cuestión prejudicial planteada por el Tribunal Supremo del Reino Unido. Su objeto es analizar si existe infracción en el uso no autorizado de una marca por particulares que ofertan y realizan ventas esporádicas de productos de marcas famosas a través de plataformas de comercio electrónico. En lo que se refiere al tema que nos ocupa, se plantea el problema de la posible responsabilidad del operador de la plataforma eBay por las infracciones del derecho de marcas realizada por los usuarios de la plataforma que vendían productos falsificados.

110. En primer lugar, se aclara que la plataforma no es la que presta el servicio subyacente, sino que son los clientes vendedores por lo que la posible vulneración de la normativa en materia de marcas es imputable a éstos y no a la plataforma que es un intermediario. La plataforma no viola la regulación

${ }^{118}$ Asuntos C-236/08 a C-238/08 acumulados. Google es prestador de un servicio remunerado de referenciación que pone a disposición de los anunciantes palabras clave que reproducen o imitan marcas registradas y, mediante el contrato de referenciación, organiza la creación y la aparición en pantalla en una posición privilegiada, a partir de dichas palabras clave, de enlaces promocionales hacia sitios en los que se ofrecen productos falsificados.

${ }^{119}$ En consecuencia, como una sociedad editora de prensa que publica en su página de Internet la versión digital de un periódico tiene conocimiento, en principio, de la información que publica y ejerce un control sobre ésta, no puede ser considerada un «prestador de servicios intermediarios», en el sentido de los artículos 12 a 14 de la Directiva 2000/31, con independencia de que el acceso a la página sea de pago o gratuito. 
en materia de marcas (Directiva 89/104 y del Reglamento $n^{\circ} 40 / 94$ ) y cabe solo plantear su eventual responsabilidad en el marco de la DCE.

111. En relación con su posible papel como prestador de servicios de intermediación y de la eventual aplicación del art. 14 DCE, la sentencia es especialmente clara al respecto. Reconoce que eBay almacena datos de los clientes y por lo tanto presta un servicio de alojamiento: "eBay lleva a cabo este almacenamiento cada vez que un cliente abre una cuenta de vendedor y le proporciona los datos de sus ofertas de venta. Por otra parte, eBay percibe normalmente una remuneración consistente en un porcentaje de las operaciones realizadas a partir de dichas ofertas de venta (párrafo 110).

112. Pero lo relevante de la doctrina sustentada es que ese solo dato no lo convierte en prestador intermediario de la sociedad de la información. "La circunstancia de que el servicio prestado por el operador de un mercado electrónico comprenda el almacenamiento de información que le facilitan sus clientes vendedores no basta por sí misma para concluir que, en cualquier caso, a tal servicio le es aplicable lo dispuesto en el artículo 14, apartado 1, de la Directiva 2000/31. En efecto, esta disposición debe interpretarse no sólo teniendo en cuenta su tenor sino también su contexto y los objetivos perseguidos por la normativa de la que forme parte" (párrafo 111).

113. Según la interpretación del TJUE, la prestación de servicios de intermediación no cabe deducirla de la naturaleza de la actividad en el sentido de que preste un servicio de alojamiento o almacenamiento de datos. Ello convertiría a todas las plataformas en servicios de intermediación y no es esta la voluntad de la norma europea que tasa específicamente determinados servicios. Tal y como se deduce del Considerando 42 antes citado, y de la doctrina emanada de las sentencias a las que he hecho referencia, es preciso que dicho servicio de almacenamiento de datos constituya una "una prestación neutra, mediante un tratamiento meramente técnico y automático de los datos facilitados por sus clientes (párrafo 113)". No será servicio de intermediación de servicio de la sociedad de la información el que preste una plataforma que, aunque actúe como intermediaria, "desempeñe un papel activo que le permite adquirir conocimiento o control de tales datos" (párrafo113). Se postula, de facto, un concepto restrictivo de servicio intermediario de sociedad de la información.

114. Las plataformas colaborativas que actúan como mercado multi-side no se limitan a poner en contacto, sino que generan valor añadido para facilitar los efectos en red que son los que garantizan su éxito. No se limitan a alojar datos, sino que intermedian entre los usuarios con herramientas avanzadas de adecuación de la oferta y la demanda, imponen reglas de comportamiento a sus usuarios y tienen cierta capacidad de control ${ }^{120}$. Como señala el TJUE (sentencia L'Oreal) normalmente la plataforma "presta una asistencia consistente, entre otras cosas, en optimizar la presentación de las ofertas de venta en cuestión o en promover tales ofertas" (párrafo 116). Incluso, como veremos seguidamente, diseñan sistemas de reputación en línea para optimizar sus servicios y favorecer el aumento de usuarios. Por lo tanto, ni son ni pasivas, ni son neutrales ${ }^{121}$.

115. El argumento de que poner medidas de control y supervisión sistemáticos sería irrazonable y dificultaría la actividad ${ }^{122}$ no me parece argumento suficiente. Las plataformas se lucran con la trans-

${ }^{120}$ Así, por ejemplo, podemos leer en las condiciones de uso de varias plataformas (Airbnb, BlaBlaCar y eBay) que se reservan el derecho a restringir el acceso a los usuarios que no cumplan las condiciones de uso.

${ }^{121}$ Ello es evidente en plataformas como Airbnb: actúa como agente de cobros, la plataforma presta el servicio de alojamiento cuando el "anfitrión" (usuario proveedor) no puede proporcionar el alojamiento reservado y el cliente rechaza alternativas ofrecidas, el proveedor de servicio de alojamiento (anfitrión) no puede cobrar directamente del cliente. Airbnb "asesora al anfitrión para elegir las reservas de su alojamiento. Airbnb comprueba las identidades o antecedentes de los usuarios e incluso puede modificar los precios redondeando al alza o a la baja. https://www.airbnb.es/terms Esta plataforma controla y mucho y desde luego, a mi juicio, no es un mero "albergador de datos" beneficiario de la exoneración de responsabilidad. Y ello, aunque se disfrace de tal, definiendo el contrato con los usuarios como contrato de "acceso a sitio web". El servicio es mucho más potente que permitir el acceso a un sitio web.

${ }^{122}$ T. Rodríguez de las Heras Ballell, Responsabilidad..., cit., p. 596. 
misión de bienes que a través de ellas se producen y pueden y deben establecer mecanismos de control, por ejemplo, números de registro o certificados de autenticidad pertinentes si es un requisito que establezca la normativa aplicable. Pero lo más importante es que creo que tanto la DCE como la LSSICE que la desarrolla están pensando en intermediarios técnicos cuando establecieron las exenciones de responsabilidad. Si éstas se quieren ampliar a los intermediarios de contenidos, es el legislador el que lo tiene que establecer.

116. Sin perjuicio de que sea necesario analizar caso por caso, se puede concluir tras el análisis de la jurisprudencia del TJUE, que lo normal es que las plataformas de servicios intermediarios en línea no sean prestadores de servicios de intermediación de la sociedad de la información a pesar de prestar servicio de alojamiento de datos, pues suelen adoptar un papel activo en su actividad de intermediación, no siéndoles de aplicación la exención de responsabilidad prevista en el art. 16 LSSICE ${ }^{123}$. La razón es que la actividad de estos prestadores excede del mero ejercicio de actividades de intermediación en el sentido señalado en el Anexo b) LSSICE (alojamiento de datos proporcionados por el destintario). Su papel no es de carácter técnico, automático y pasivo, tal y como exige el TJUE tras la interpretación de las exenciones de responsabilidad reguladas en la DCE ${ }^{124}$.

117. Dado que desde el punto de vista sustantivo sí son intermediarios y no prestan el servicio subyacente, y se limitan a facilitar la interacción de los usuarios, no serán responsables de los incumplimientos que entre éstos se puedan producir. Cosa distinta es que la plataforma no haya sido transparente sobre su papel en la contratación ${ }^{125}$, en cuyo caso, tal y como ha reconocido el TJUE, puede derivarse para el intermediario la misma responsabilidad que para el vendedor. La sentencia del TJUE de 9 de noviembre de 2016 Sabrina Wathelet contra Garage Bietheres \& Fils SPRL (asunto C149/15) se plantea el problema de si se puede considerar que un intermediario profesional es parte en un contrato de venta entre dos consumidores en virtud de la Directiva 1999/44/CE sobre ventas y garantías de los bienes de consumo si no informa adecuadamente al consumidor-comprador de la identidad y la condición del consumidor-vendedor. El TJUE responde afirmativamente señalando que:

${ }^{123}$ Como se recoge en el Considerando 38 de la Propuesta de Directiva del Parlamento Europeo y del Consejo sobre derechos de autor en el mercado único digital de 14 de septiembre de 2016 (COM (2016) 593 final), "en lo que se refiere al artículo 14, es preciso comprobar si el proveedor de servicios desempeña un papel activo, en particular optimizando la presentación de las obras o prestaciones cargadas o promocionándolas, independientemente de la naturaleza de los medios utilizados a tal fin”. El desempeñar un papel activo es un requisito para tener la consideración de prestador intermediario en línea, sin que sea preciso entrar en si se da conocimiento efectivo o no de la actividad ilícita, es decir, sin necesidad de entrar en la aplicación del art. 14 DCE.

${ }^{124}$ Se muestra crítica con el criterio jurisprudencial que atiende al rol activo o pasivo de los proveedores de hosting, E. Arroyo Amayuelas, "La responsabilidad..., cit., p. 816 porque perjudica enormemente a los prestadores de servicios de internet que explotan su negocio con actividades esencialmente dinámicas que no existían cuando se aprobó la DCE. Y no le falta razón. De ahí que este sea un extremo que deba ser objeto de regulación la responsabilidad de estos nuevos operadores que llevan a cabo una intermediación material no meramente técnica.

${ }_{125}$ Cfr. la condición de uso $\mathrm{n}^{\mathrm{o}} 12$ publicada por Amazon. https://www.amazon.es/gp/help/customer/display.html/ref=footer cou?ie=UTF8\&nodeId=201909000 No obstante, Amazon realiza una actividad mixta ya que hay productos en los que Amazon es el vendedor.

También eBay anuncia claramente su posición de intermediario en sus condiciones de uso: "eBay es una plataforma de compraventa que permite a los usuarios ofrecer, vender y comprar prácticamente de todo, en una amplia variedad de formatos de precio y ubicaciones.

eBay no posee ninguno de los artículos en venta o vendidos a través de eBay, y no está involucrado en la transacción real entre compradores y vendedores. El contrato de compraventa se hace directamente entre el comprador y el vendedor. eBay no es una casa de subastas tradicional.

Podemos orientar acerca de precios, gastos de envío, y otras cuestiones en nuestros Servicios, si bien dichas orientaciones se realizan a título informativo, por lo que puedes optar por no seguirlas. eBay no revisa los anuncios de los usuarios o su contenido. Aunque podemos ayudar a facilitar la resolución de controversias a través de diversos programas, eBay ni controla ni garantiza, la existencia, calidad, seguridad o legalidad de los artículos anunciados; la veracidad o exactitud de los contenidos, anuncios o valoraciones de los usuarios; la capacidad de los vendedores para vender artículos; la capacidad de los compradores para pagar los artículos; o que un comprador o vendedor llegarán a formalizar una transacción o a devolver un artículo". http:// pages.ebay.com/es/help/policies/user-agreement.html 
"en virtud de la Directiva 1999/44, la responsabilidad del vendedor debe poder ser exigible al intermediario que crea un riesgo de confusión al dirigirse al consumidor, haciéndole creer que actúa en calidad de propietario del bien objeto de la compraventa. La interpretación contraria, que excluiría en todo caso del ámbito de aplicación del artículo 1, apartado 2, letra c), de la Directiva 1999/44 al profesional que actúa como intermediario, se opone al objetivo global perseguido por la normativa de la Unión en materia de protección de los consumidores y consagrado en el artículo 169 TFUE, que consiste en garantizar un alto nivel de protección de los consumidores y, por tanto, en preservar su confianza" (párrafos 41 y 41).

118. Aunque la sentencia no se refiera a una adquisición a través de una plataforma intermediaria en línea, su doctrina tiene mucha importancia porque si no se informa adecuadamente del papel de intermediario de la plataforma ${ }^{126}$, podrá serle exigida a ésta la misma responsabilidad que al vendedor, sin perjuicio, de la acción de repetición que en su caso pueda corresponder a la plataforma contra el verdadero vendedor.

119. La plataforma responderá, en su caso, como prestador de servicio de la sociedad de la información según las reglas generales de responsabilidad civil (art. 13.1 LSSICE). Será contractual cuando incumpla el contrato celebrado con el usuario, a cuya naturaleza me referiré más adelante. En el ámbito de la responsabilidad extracontractual, no cabe hablar de responsabilidad por el hecho ajeno (art. 1903 CC), sin que pueda imputarse a la plataforma los daños causados por los usuarios ${ }^{127}$. Cosa distinta es que se estime que, por la infracción por parte del usuario, también sea posible imputar responsabilidad a la plataforma por acto propio al fomentar dicha actuación dañosa ${ }^{128}$. Su responsabilidad será por hecho propio, aplicándose los requisitos generales de imputación (art. 1902 CC), atendiendo a las circunstancias del caso concreto.

120. En cualquier caso, la tendencia legislativa a nivel europeo avanza, en general, hacia una mayor responsabilidad de las plataformas en línea: "lo que es ilegal en el mundo real, lo es también en el mundo virtual". Son palabras recogidas en el documento publicado por la Comisión Europea sobre "Lucha contra el contenido ilícito en línea. Hacia una mayor responsabilidad de las plataformas en línea"129. Se pretende que se adopten medidas proactivas eficaces para detectar y retirar contenidos ilícitos en línea de forma que no sería de aplicación la exención de responsabilidad del art. 14 DCE. Estas reformas parece que se van a tomar por sector de actividad. Creo que sería más eficiente aportar más claridad sobre los sujetos que se benefician de la exención ${ }^{130}$ adoptando un criterio legal más restrictivo en la línea de la jurisprudencia del TJUE. Creo que las exenciones de responsabilidad deben ser excepcionales y adaptarse a la actuación real de cada plataforma. Hay que evitar situaciones de riesgo moral. Así parece que se ha sugerido en un documento no oficial de la Comisión Europea que se ha filtrado ${ }^{131}$ dirigido a actualizar la DCE con la aparición de estos nuevos operadores que son las plataformas online. Ya he

${ }^{126}$ Este aspecto ha sido puesto de relieve por la Comisión Europea, en el ya citado informe, "Exploratory study of consumer issues in online peer to peer platform markets. Final report", cit., p.129, "en la mayoría de los casos de estudio, las plataformas establecen al menos una parte de las cláusulas contractuales de la transacción P2P, lo cual puede hacer que los usuarios tengan la impresión de que la plataforma comparte cierto grado de responsabilidad en caso de no ejecución o grado de incumplimiento (...). Sin embargo, las plataformas excluyen de forma sistemática cualquier responsabilidad en relación con los contratos celebrados entre iguales e indican explícitamente que estas no son partes en los mismos".

${ }^{127}$ En este sentido, F. CARBAjo CAscón, "Problemas de distribución..., cit., p. 13.

${ }^{128}$ Así sucedió en el asunto resuelto por el Tribunal Supremo francés (Cass. Com. 4 de diciembre de 2012, 11-27729, Publicité Sté Pewterpassion.com/Sté Leguide.com.). Se trataba de un sitio web de comparación de precios que ofrecía clasificar en los primeros puestos los productos de los comerciantes que pagaban una tasa adicional, el Tribunal Supremo francés constató que, al clasificar los productos en los primeros puestos cobrando una remuneración de terceros comerciantes, la plataforma estaba promocionando indirectamente esos productos y, por tanto, actuaba como proveedor activo de un servicio comercial a esos comerciantes.

${ }^{129}$ Comisión Europea, Comunicación de la Comisión al Parlamento Europeo, al Consejo, al Comité Económico y Social Europeo y al Comité de las Regiones. "Lucha contra el contenido ilícito en línea. Hacia una mayor responsabilidad de las plataformas en línea" COM (2017), 555 FINAL. 28/09/2017.

${ }^{130}$ Así se ha puesto de manifiesto en la Consulta pública sobre plataformas intermediarias online Comisión EuROPEA Public consultation on the regulatory environment for platforms, online intermediaries, data and cloud computing and the collaborative economy, 24 septiembre de 2015, p. 2.

${ }_{131} \mathrm{https}: /$ netzpolitik.org/2019/leaked-document-eu-commission-mulls-new-law-to-regulate-online-platforms/ (Consultado el 10 de junio de 2020). 
dicho que no todas las plataformas son iguales, y las intermediarias que favorecen la contratación entre usuarios tienen particularidades de régimen. No se atiende al rol activo o meramente pasivo o técnico de la plataforma para determinar su grado de responsabilidad, sino al grado de conocimiento real y control que tiene la plataforma sobre el contenido y el material sobre el que se comercia. Habrá cambios legales a nivel europeo en este terreno que se han anunciado en la reciente consulta pública puesta en marcha por la Comisión europea en junio de 2020 acerca de la normativa de los servicios digitales. Se anuncia una modificación de la Directiva de comercio electrónico. ${ }^{132}$

\section{Mecanismos para la valoración de bienes y servicios. Los sistemas de reputación online}

121. La interdependencia de los usuarios es un rasgo característico de esta modalidad de plataformas y clave de su éxito. Su actividad se centra en conseguir el mayor número de usuarios tanto proveedores como adquirentes de bienes y servicios. Para ello es habitual que la propia plataforma $\mathrm{u}$ otra que se dedique a esta finalidad diseñe un sistema de reputación que se construye sobre la base de las opiniones de los propios usuarios ${ }^{133}$. Mientras las empresas convencionales generan confianza entre los consumidores mediante el cumplimiento de la normativa gubernamental que regula la actividad, las plataformas lo hacen tanto a través de la gestión de los sistemas de evaluación entre iguales y de calificación y reputación como a través de la verificación de la exactitud de la identidad facilitada.

122. Los sistemas de reputación tratan de evitar los riesgos de información asimétrica que son connaturales a esta modalidad de contratación. Así, el usuario puede tener conocimiento de la "seriedad" del prestador del servicio, lo que aumenta la confianza en la contratación, esencial en el tráfico económico. Con razón se ha dicho, que la confianza es el "pegamento social" que facilita el consumo colaborativo y el funcionamiento de la economía de la plataforma ${ }^{134}$. Según un estudio realizado en los EEUU, el 82\% de los clientes tienen en cuenta las reseñas a la hora de tomar la decisión de compra ${ }^{135}$

123. Un consumidor valora que existan más usuarios, no solo por un efecto cuantitativo (pues así el número de evaluaciones es mayor y éstas son menos manipulables ${ }^{136}$ ), sino también por un efecto cualitativo de «agenda de contactos» (pues aumenta la probabilidad de que personas conocidas, en cuyo criterio confía más, hayan efectuado evaluaciones), razón por la cual muchas plataformas exigen o incentivan la integración del perfil del usuario con las redes sociales ${ }^{137}$. Así, por ejemplo, algunas plataformas como AirBnb dan la opción a los usuarios, sobre todo, los que tienen poco historial, de consolidar su reputación enlazando su perfil con otras redes como Facebook. Esto facilita la creación de reputación

${ }_{132} \mathrm{https} / / /$ ec.europa.eu/commission/presscorner/detail/es/ip_20_962 (Consultado el 2 de septiembre de 2020).

${ }^{133}$ Según el informe realizado en el Reino Unido sobre la base de opiniones de consumidores y proveedores, ComPETITION MARKET AUTHORITY “Online reviews an endorsements" 2015, p. 3 https://www.gov.uk/government/uploads/system/uploads/attachment_data/file/436238/Online_reviews_and_endorsements.pdf (Consultado el 15 de junio de 2020), "los consumidores que usan los sistemas de valoración del servicio de proveedores los encuentran valiosos y son usados por más de la mitad de los adultos del Reino Unido. Se estima que 23 mil millones de libras al año de gasto del consumidor del Reino Unido se ve potencialmente influenciado por estos sistemas de valoración. Se trata de un sistema en el que los consumidores confían y basan en ellos sus decisiones de compra. Mayoritariamente los consumidores dijeron que el producto o servicio adquirido después de leer las valoraciones coincidía con sus expectativas. Estos datos evidencian la importancia de los sistemas de reputación y su grado de fiabilidad.

${ }^{134}$ C. BuSCH, "Crowdsourcing Consumer Confidence: How to Regulate Online Rating and Review Systems in the Collaborative Economy. Alberto De Franceschi (ed.), European Contract Law and the Digital Single Market, Intersentia, Cambridge 2016.. https://ssrn.com/abstract=2799489, p. 3.

${ }_{135} \mathrm{https}: / /$ www.pewresearch.org/internet/2016/12/19/online-reviews/ (Consultado el 12 de junio de 2020.

${ }^{136}$ Se trata de evitar el "sesgo por selección según el cual las opiniones son realizadas por un subgrupo de consumidores que no es representativo de la totalidad. Cuantos más usuarios tenga la plataforma más valoraciones habrá y más fiables serán porque representan una visión de una pluralidad de usuarios amplia siendo más improbable la manipulación o, caso de existir, ser menos relevante en términos cualitativos.

${ }^{137}$ M. Sobrino, y P. Hinojo, "Retos para la competencia de las plataformas digitales de economía colaborativa" en A. Muñoz García y S. Rodríguez Marín, (Coord.), Aspectos legales de la economía colaborativa y bajo demanda en plataformas digitales, Wolters Kluver, 2018, (Smarteca). 
inicial a nuevos usuarios que aún no han sido valorados. De hecho, a través de esta forma de generación de confianza, esencial para el funcionamiento del mercado a través de la red (el comportamiento pasado es el mejor predictor del comportamiento futuro), se están creando plataformas, cuyo objeto es precisamente aunar y gestionar la reputación de un usuario en varias plataformas ${ }^{138}$.

124. En esta modalidad de contratación la reputación ${ }^{139}$ es un importante activo ${ }^{140}$ (difícil de obtener y muy fácil de perder), por lo que el diseño del sistema de recopilación de opiniones de los usuarios debe ser fiable, pues se corre el riesgo de que se produzcan situaciones en las que usuarios que no han utilizado el servicio ${ }^{141}$ puedan valorarlo negativamente, ocasionándose un perjuicio injustificado en el proveedor. Hay algunos tipos de plataformas que se prestan más al fraude como es el caso, por ejemplo, de eBay donde muchos usuarios son proveedores y consumidores pudiendo darse el caso de que las partes lleguen a un acuerdo tácito o explícito para intercambiarse puntuaciones elevadas ${ }^{142}$. Empresas que pagan para recibir valoraciones positivas ${ }^{143}$ o pagan para que se hagan valoraciones negativas a empresas de la competencia, plataformas que hacen una selección de las valoraciones incluyendo solo las positivas. Se trata de actuaciones que pueden perjudicar y mucho al consumidor porque le inducen a error en la contratación ${ }^{144}$. Obsérvese que el error no procede del proveedor directamente porque vende lo que realmente dice vender, sino a través de otros usuarios que realizan valoraciones que no se corresponden con la realidad del producto. A su vez, la plataforma no controla adecuadamente la veracidad de las valoraciones. Cualquier exigencia de responsabilidad desde la estricta teoría general del contrato se torna compleja en esta estructura triangular de contratación.

125. Las valoraciones erróneas dañan gravemente al consumidor y al proveedor ${ }^{145}$ y hay que tener en cuenta que en muchas ocasiones nos encontramos en relaciones $\mathrm{C} 2 \mathrm{C}$, no siendo de aplicación la normativa de protección del consumidor. Por ello, resulta imprescindible que se diseñen modelos fiables

\footnotetext{
${ }^{138}$ Es el caso, por ejemplo, de la plataforma Atribus http://atribus.com/ Booking.com, Tripadvisor, Yelp

139 Otros métodos tradicionalmente utilizados para generar confianza en las transacciones económicas son i) la regulación
} por el sector público, ii) la auto-regulación de los operadores del sector, ii) las certificaciones concedidas por un tercero creíble, iv) el aseguramiento o v) las garantías.

140 Destaca este aspecto J. BLOCHER, "Reputation as property in virtual economies", 200 https://www.yalelawjournal.org/ forum/reputation-as-property-in-virtual-economies (Consultado el 13 de mayo de 2020), para quien la reputación puede asimilarse a una forma de propiedad sin necesidad de demostrar su valor económico. "La importancia del éxito en este mercado reputacional puede ser tan importante para algunas personas como los activos financieros: las vidas de muchas personas giran virtualmente en torno a sitios y blogs de redes sociales. De hecho, ya es noticia que millones de personas pasan más tiempo pensando en sus perfiles de Facebook que en sus perfiles de inversión".

${ }^{141}$ Hay sistemas de reputación “abiertos" y "cerrados". En los abiertos solo puede el usuario hacer la valoración una vez que ha confirmado la operación de compra de bien o servicio. Es el caso de Airbnb. Otros, por el contrario, no tienen estas restricciones y cualquier usuario registrador puede hacer una valoración de cualquier producto, con la salvedad de que no aparece el sello de "verificada". Es el caso de Amazon Marketplace". Una eventual regulación europea deberá determinar si los sistemas deben ser abiertos o cerrados. Una plataforma con un sistema de valoración abierto es mucho menos fiable y lo importante es que los usuarios conozcan este extremo

142 Comisión Nacional del Mercado de la Competencia "Estudio sobre los nuevos modelos de prestación de servicios de la economía colaborativa", marzo 2016, p.48.

${ }^{143}$ El periódico digital El Confidencial se hace eco de este problema denunciando "la última treta de las reseñas en Amazon: cartas con 20 euros de regalo si das cinco estrellas". https:/www.elconfidencial.com/tecnologia/2019-07-03/vendedoresamazon-descuento-cartas-resenas-reviews_2103875/(Consultado el 7 de junio de 2020).

${ }^{144}$ Competition Market Authority “Online reviews an endorsements” 2015, p. 3 https://www.gov.uk/government/uploads/ system/uploads/attachment_data/file/436238/Online_reviews_and_endorsements.pdf (Consultado el 13 de marzo de 2018).

145 Destaca E. Olmedo Peralta, "Competencia dentro de las plataformas de la economía colaborativa: posibles prácticas restrictivas de los mal llamados "prosumidores", en Beatriz Fonticiella Hernández (Coord.) Inmaculada González Cabrera (Dir.), María del Pino Rodríguez González (dir.), Las viviendas vacacionales: Entre la economía colaborativa y la actividad mercantil, 2019, págs. 207-232, cómo los sistemas de reputación pueden favorecer actos de competencia desleal. "El sistema de valoración de usuarios sirve como elemento para la fijación de un estándar mínimo de calidad, de modo que obtener una puntuación media inferior a un determinado mínimo es, en ciertas aplicaciones, causa de expulsión del sistema (...). "Ciertas prácticas de falseamiento de la competencia basadas en verter opiniones falsas sobre los competidores podría suponer la salida de éstos del mercado. Es el caso de aplicaciones de transporte urbano como Uber, en las que obtener una puntuación baja implica la expulsión del conductor del sistema”. 
de reputación, ya que, bien construidos ${ }^{146}$, pueden más eficientes para la protección de los intereses de las partes que la propia regulación del mercado ${ }^{147}$.

126. Por otro lado, si algo favorecen las plataformas online es el mercado transfronterizo y los distintos sistemas de valoración de la reputación pueden suponer una barrera en el mercado interior europeo $^{148}$. No me cabe duda de que la regulación ${ }^{149}$ de feedback reputacional es procedente ${ }^{150}$ y oportuna porque la reputación digital incentiva comportamientos adecuados. Deben existir mecanismos de control que eviten los "falsos positivos" y los "injustos negativos" que pueden producir la expulsión injustificada de un proveedor del mercado. Me muestro favorable a este sistema que dota al consumidor (responsable) de un instrumento potente para favorecer el correcto cumplimiento de las obligaciones, incluso más potente que otros mecanismos tradicionales como la denuncia a los reguladores.

127. Cosa distinta son las opciones de política legislativa que existen a este respecto. Como se ha señalado ${ }^{151}$, desde un plano de libertad, cabría imponer un deber de transparencia sobre las normas y criterios de diseño, construcción y publicación para que sean conocidas por los usuarios. Otra opción consiste en recurrir al establecimiento de estándares sobre las modalidades de recogida, procesamiento, agregación y publicación que aseguren la fiabilidad, la diligencia y la transparencia del sistema. Estos estándares pueden ser simplemente recomendados o de obligado cumplimiento ${ }^{152}$. La mala reputación

${ }_{146}$ Así lo ha puesto de relieve la Comisión europea, Comunicación de la Comisión al Parlamento Europeo, al Consejo, al Comité Económico y Social Europeo y al Comité de las Regiones. Una Agenda Europea para la Economía Colaborativa. Bruselas, 2.6.2016 COM (2016) 356 final, p. 4 al señalar respecto de los sistemas de evaluación de la reputación que los mismos pueden contribuir a aumentar la calidad de los servicios y reducir posiblemente la necesidad de determinados elementos reguladores, siempre que pueda confiarse adecuadamente en la calidad de las evaluaciones y calificaciones. Sin embargo, como se ha puesto de relieve en el informe COMISIÓN EUROPEA, "Exploratory study of consumer issues in online peer to peer platform markets. Final report", cit., p.87, después de analizarse el funcionamiento de 485 plataformas, tanto las principales herramientas de fomento de la confianza, los sistemas de evaluación entre iguales y de calificación de la mayoría de las plataformas no son ni totalmente fiables ni transparentes. Su eficacia es objeto de serias dudas.

${ }^{147}$ Así lo manifiestan, C. Koopman, M. Mitchel, y A. Thierer, "Sharing Economy and Consumer Protection Regulation: THe Case for Policy Change", e Journal of Business, Entrepreneurship \& the Law, Vol. 8, Issue 2, 2015, p. 543, https://digitalcommons.pepperdine.edu/cgi/viewcontent.cgi?referer=https:/www.google.es/\&httpsredir=1\&article=1130\&context=jbel (Consultado el 15 de marzo de 2020).

${ }^{148}$ C. Busch, "Crowdsourcing Consumer Confidence: How to Regulate Online Rating and Review Systems in the Collaborative Economy", cit., p.2.

${ }^{149}$ No lo entiende así la Comisión Nacional del Mercado de la Competencia en su informe sobre "Estudio sobre los nuevos modelos de prestación de servicios de la economía colaborativa", marzo 2016, p. 45 https://www.agorarsc.org/10942-2/

(Consultado el 14 de mayo de 2020). Señala en este sentido que la intervención pública en estos sistemas reputacionales conllevaría un incremento en el coste regulatorio de la actividad redundando, quizás sin beneficio para los usuarios, en un mayor precio final.

${ }^{150}$ Así lo ha puesto de relieve el Comité Económico y Social Europeo (CESE) que, respecto a las herramientas de calificación y reputación de los proveedores, considera que, si bien cumplen el objetivo de interés público de reducir para los consumidores los riesgos vinculados a las asimetrías de información, también pueden conducir a una selección adversa y a un riesgo moral. A este respecto, las autoridades públicas y los gestores de las plataformas digitales deben velar por la calidad y la fiabilidad de las informaciones, las evaluaciones y las calificaciones de las plataformas colaborativas, haciendo uso de organismos independientes de control. Consejo eConómico y social europeo (CESE), en el Dictamen sobre la «Comunicación de la Comisión al Parlamento Europeo, al Consejo, al Comité Económico y Social Europeo y al Comité de las Regiones - Una Agenda Europea para la economía colaborativa», COM (2016) 356 final], (2017/C 075/06).

${ }^{151}$ T. Rodríguez de las heras BaLlell, "Una regulación europea para las plataformas electrónicas. Propuestas en curso y alternativas”, en Blanco Sánchez M.J. y Madrid Parra, A., (Dir.), Derecho mercantil y tecnología, Ed: Thomson Reuters Aranzadi, 2018, pp. 427-452.

152 Este es el modelo acogido en el art. 8 BPDPL que establece la obligación del operador de la plataforma de proporcionar información sobre las modalidades de recogida, procesamiento y publicación de calificaciones y revisiones. Exige, con carácter general que el feedback reputacional debe cumplir con los siguientes estándares de diligencia profesional:

1. Debe tomar todas las medidas razonables y proporcionadas para verificar que las revisiones se basen en una transacción efectivamente realizada.

2. Deberá indicar si, en su caso, el usuario ha obtenido algún tipo de beneficio o contraprestación por haber dado su opinión sobre el producto o servicio.

3. Si se rechaza una crítica, el usuario que la ha realizado debe ser informado sin demora indebida sobre el rechazo y las razones de dicho rechazo. 
puede tener consecuencias indeseables de las que podría derivar responsabilidad civil contractual por parte de la plataforma en el caso de que no adopte unos estándares mínimos de diligencia y la misma se derive de valoraciones falsas.

128. A mi juicio, en este punto la transparencia es fundamental. Si no se opta por la imposición de unos estándares mínimos, el usuario debe tener conocimiento del diseño del sistema de reputación: si hay comprobación de la autenticidad de las reseñas y si son realizadas por clientes que han realizado transacciones, si las reseñas son remuneradas o no en la línea del citado art. 8 BPDPL.

129. Como ha puesto de relieve la Comisión Europea ${ }^{153}$ hay que tener en cuenta que las plataformas pueden tener la consideración de comerciantes a los efectos de la aplicación la Directiva 2005/29, sobre prácticas comerciales desleales de 11 de mayo de $2005^{154}$ (en adelante, DPCD), siéndoles de aplicación los arts. $6.1 \mathrm{~b}$ y 7.4 a) de la DPCD que establecen lo que es publicidad engañosa sobre el producto o servicio ofrecido. Se considera que, al publicar reseñas de usuarios, se requiere que el operador de la plataforma proporcione información veraz sobre las principales características de sus servicios. En particular, la plataforma no debe inducir a error a los usuarios en cuanto al origen de las revisiones: debe evitar crear la impresión de que las valoraciones publicadas a través de ella provienen de usuarios reales, cuando no puede garantizarlo adecuadamente. En tal caso, el operador de la plataforma debe informar claramente a los consumidores sobre este hecho. $\mathrm{Si}$, a contrario, un proveedor de herramientas de valoración por usuarios afirma explícitamente que sus revisiones proceden de usuarios, debe tomar medidas razonables y proporcionadas que aumente la probabilidad de que dichas revisiones reflejen las experiencias reales de los usuarios.

\footnotetext{
${ }^{4}$ Las evaluaciones deben publicarse sin demora indebida.

5. El orden en que se presentan las opiniones no debe ser confuso. Los usuarios de la plataforma deben poder visualizar las revisiones en orden cronológico.

6. Si el sistema de información sobre la reputación excluye las valoraciones antiguas, deberá indicarse esta circunstancia a los usuarios de la plataforma. El período de exclusión debe ser razonable pero no inferior a 12 meses.

${ }^{7}$ Si las revisiones se consolidan en una calificación global, debe indicarse el número total de revisiones en las que se basa la calificación.

8. El operador de la plataforma debe proporcionar de forma gratuita un sistema que permita a los usuarios de la plataforma enviar una comunicación si tienen dudas sobre la autenticidad de una revisión.

Al margen de estos estándares de diligencia, se contempla la obligación del proveedor de la plataforma de facilitar al usuario la portabilidad de las valoraciones que sobre su actividad se han realizado en un formato estructurado y legible de forma digital. Como se puede apreciar, se cuenta con el hecho de que existen plataformas cuya finalidad sea precisamente procesar estos datos relativos a la reputación de los proveedores.

Respecto a lo que acontece cuando el operador incumple alguno de los estándares previstos en el diseño de su sistema reputacional, el BPDPL no establece una responsabilidad específica de la plataforma. Tan solo en el capítulo V dedicado expresamente a este extremo, después de declarar la irresponsabilidad de la plataforma por el incumplimiento del contrato entre proveedor y usuario, se centra en la responsabilidad de la plataforma por publicar información falsa acerca de los proveedores de bienes y servicios cuando no empleó toda la diligencia debida para rectificar dicha información.

${ }^{153}$ Comisión europea, "Guidance on the implementation/application of Directive 2005/29/EC on unfair commercial practices”, Commission staff working document, 25 de mayo de 2016, COM (2016) 320 final. http://eur-lex.europa.eu/legal-content/ EN/TXT/PDF/?uri=CELEX:52016SC0163\&from=EN (Consultado el 15 de marzo de 2018), p. 126. Lo normal que es la plataforma no lo asegure. A título de ejemplo, Airbnb no aclara expresamente en sus condiciones: "Airbnb no verifica la exactitud de las Valoraciones y las Evaluaciones, que podrían así ser incorrectos o engañosos". "Si decidimos realizar una verificación de identidad o comprobaciones de antecedentes sobre algún Miembro, en la medida permitida por la legislación aplicable, renunciamos a cualquier garantía de ningún tipo, ya sea expresa o implícita, respecto a que dichas comprobaciones acaben detectando pasadas conductas inapropiadas por parte de un Miembro o que se garantice que un Miembro no vaya adoptar un comportamiento inapropiado en el futuro." Ello viene acompañado de una absoluta exención de responsabilidad https://www. airbnb.es/terms\#sec10

${ }^{154}$ Artículo 2.a) Directiva 2005/29 define al comerciante como "cualquier persona física o jurídica que, en las prácticas comerciales contempladas por la presente Directiva, actúe con un propósito relacionado con su actividad económica, negocio, oficio o profesión, así como cualquiera que actúe en nombre del comerciante o por cuenta de éste". La norma europea fue transpuesta al Derecho español por la Ley 29/2009, de 30 de diciembre que modifica entre otras la Ley 3/1991, de 10 de enero de competencia desleal.
} 
130. La cuestión es que no se sabe hasta qué punto la plataforma puede garantizar la fiabilidad de las valoraciones. Bastaría que declarara que no puede hacerlo, para que estuviera exenta de responsabilidad ${ }^{155}$, exención que se recoge en la mayoría de sus clausulado ${ }^{156}$. Caso de que la publicación de una valoración errónea en los términos que sugiere la Comisión europea en el documento citado, las consecuencias serían las establecidas en el art. 32 de Ley 3/1991, de 10 de enero de competencia desleal, entre ellas la indemnización de los daños y perjuicios causados por parte de la plataforma por una especie de "culpa in vigilando", por la falta de control de la veracidad de las valoraciones.

131. La Directiva del Parlamento Europeo y del Consejo relativa a la mejora de la aplicación y la modernización de las normas de protección de los consumidores de la UE de 27 de noviembre de $2019^{157}$ introduce modificaciones en la Directiva 2005/29/CE relativa a las prácticas comerciales desleales de las empresas en sus relaciones con los consumidores en el mercado interior. Se añade el apartado 6 al art. 7 dedicado a las omisiones engañosas. Se establece en dicho nuevo apartado se señala que «cuando un comerciante facilite el acceso a las reseñas de los consumidores sobre los productos, se considerará fundamental la información acerca de si el comerciante garantiza que las reseñas publicadas pertenezcan a consumidores que hayan adquirido o utilizado el producto y de qué modo lo hace». Se considera que tal información es sustancial. El considerando 47 dispone que el proveedor habrá que especificar qué procesos de verificación se han usado y si se aplican a todas las reseñas.

132. También se modifica el Anexo I de dicha Directiva 2005/29 dedicado a determinar prácticas que se consideran desleales. Se añaden los apartados 23 ter y 23 quater en los siguientes términos:

«23 ter) Afirmar que las reseñas de un producto son presentadas por consumidores que han utilizado o adquirido realmente el producto, sin tomar medidas razonables y proporcionadas para comprobar que dichas reseñas pertenecen a tales consumidores.

23 quater) Presentar o encargar a otra persona fisica o jurídica que presente reseñas o aprobaciones de consumidores falsas, o distorsionar reseñas de consumidores o aprobaciones sociales con el fin de promover productos».

Como en tantas otras ocasiones, un aspecto clave como es el mecanismo sancionador, se deja en manos de los Estados miembros. Así se señala en el nuevo art. 11 bis ${ }^{158}$ de la Directiva 2005/29/CE.

133. Tras la aprobación de esta directiva, los sistemas de reputación gozan de regulación, pero sólo en el ámbito de la Directiva 2005/29. Esta iniciativa hay que aplaudirla, pero resuelve el problema parcialmente, es decir, cuando se utilizan las reseñas para falsear la competencia.

134.De hecho, este ha sido el problema que se ha planteado en España con el caso Tripadvisor resuelto por la sentencia dictada por el Juzgado mercantil n 7 de Barcelona de 18 de septiembre de 2019.

${ }^{155}$ En la sentencia IZR 94/13 de 19 de marzo de 2015, el Tribunal Federal de Justicia alemán consideró que un sitio web de valoración de hoteles no era el responsable de una opinión publicada por un usuario en la que indicaba que, en determinado hotel, «cobraban 37,50 EUR por persona y noche y había chinches». El propietario del hotel reclamó daños y perjuicios a la plataforma. La pretensión fue desestimada. El Tribunal observó que el sitio web no había fomentado ni difundido activamente la opinión del usuario, sino que había adoptado una actitud neutral al respecto sin obligarse a la comprobación de las valoraciones. El tribunal llegó a la conclusión de que el sitio web de valoración de hoteles solo hubiera sido responsable de los contenidos de las opiniones de los usuarios si hubiese vulnerado su obligación de llevar a cabo comprobaciones de las opiniones.

${ }^{156}$ Comisión EUROPEA, "Exploratory study of consumer issues in online peer to peer platform markets. Final report", cit., p. 94.

157 Directiva (UE) 2019/2161 del Parlamento Europeo y del Consejo de 27 de noviembre de 2019 por la que se modifica la Directiva 93/13/CEE del Consejo y las Directivas 98/6/CE, 2005/29/CE y 2011/83/UE del Parlamento Europeo y del Consejo, en lo que atañe a la mejora de la aplicación y la modernización de las normas de protección de los consumidores de la Unión.

158 "Los consumidores perjudicados por prácticas comerciales desleales tendrán acceso a medidas correctoras proporcionadas y eficaces, incluida una indemnización por los daños y perjuicios sufridos por el consumidor y, cuando proceda, una reducción del precio o la resolución del contrato. Los Estados miembros podrán establecer las condiciones de la aplicación y los efectos de dichas medidas correctoras. Los Estados miembros podrán tener en cuenta, cuando proceda, la gravedad y la naturaleza de la práctica comercial desleal, los daños y perjuicios sufridos por el consumidor y otras circunstancias pertinentes". 
El litigio se plantea entre la empresa "Recaba inversiones turísticas S.L." que demanda a Tripadvisor Spain LS.L. y Tripadvisor LLC, ejercitando las acciones declarativas, de cesación, remoción de efectos y resarcimiento (arts. 4, 12, 15 y 32 de la LCD). Precisamente, la demanda se fundamenta en una serie de comentarios vejatorios ${ }^{159}$ (no meramente negativos) realizados por los usuarios en dicha plataforma y sobre dos restaurantes de la demandante. Se considera que hay contravención de las exigencias de la buena fe, en el aprovechamiento indebido de la reputación ajena y en la violación de normas. Hay que aclarar que Tripadvisor es una plataforma que establece herramientas de comparación de hostelería y alojamiento (online review sites o sitios de valoración online). Se trata de un motor de búsqueda al que recurre cualquier persona que demanda un determinado bien o servicio. En el caso de Tripadvisor, la plataforma hace una comparativa de proveedores de servicio de hostelería y alojamiento. La plataforma se nutre de opiniones de los usuarios, pero el titular del alojamiento o servicio de hostelería carece de vínculo contractual con la plataforma. Cualquier usuario puede "dar de alta" el establecimiento en la plataforma y publicar opiniones sobre el establecimiento. No se pide ninguna autorización al establecimiento el cual es expuesto en la web sin su consentimiento. La mera descripción del fenómeno provoca tensión. No en vano es ya práctica habitual la extorsión a empresarios bajo la amenaza de calificación negativa.

135. La existencia de este tipo de portales tiene su lado positivo pues supone un incentivo al buen comportamiento contractual y a la calidad de los bienes y servicios. Pero tiene su lado oscuro pues puede mentirse y lesionarse el honor de personas físicas como jurídicas. Este tema es el que se planteó en la sentencia citada que absolvió a Tripadvisor al estimar que no se violaba la normativa de competencia desleal. Lo cierto es que dos de los comentarios fueron removidos por Tripadvisor de la web al día siguiente de su publicación, tras haberlo solicitado la demandante.

136. ¿Qué responsabilidad asume el operador de la plataforma respecto de las barbaridades que puedan llegar a decirse en estos portales que albergan reseñas de los usuarios? Hay partir de la base de que se declaró probado que Tripadvisor tenía un control de contenido de los comentarios, si bien se trataba de un sistema previo de control mediante algoritmos y un sistema de control posterior llevado a cabo por personal contratado por la compañía, ofreciendo a los establecimientos la posibilidad de responder a las observaciones de los usuarios y denunciar a Tripadvisor la incorrección de un comentario.

137. La sentencia es criticable entre otras razones por negar la aplicación del art. 12 LCD (aprovechamiento indebido de reputación ajena) con base en que Tripadvisor tiene más reputación que los dos restaurantes afectados lo que parece que a juicio del juez autorizaría a la plataforma a aprovecharse de la reputación ajena. No juzgo el resultado, pero sí el argumento.

138. También descarta la sentencia que haya un ilícito desleal por violación de las normas (art. 15 LCD), en particular por la violación del art. 16 LSSICE. Esta norma se refiere a la responsabilidad de los prestadores de servicios de alojamiento o almacenamiento de datos a la que ya he hecho referencia. Las plataformas no responden de la información almacenada por los usuarios si no tienen conocimiento efectivo de la ilicitud de la misma, o teniéndolo, actúen con diligencia para retirar los datos o hacer imposible el acceso a ellos. Según la sentencia, el mero hecho de que Tripadvisor de manera voluntaria tenga sistemas de control de los comentarios, implica que no hay violación del art. 16 LSSICE y no hay acto desleal con base en el art. 15 LCD.

${ }^{159}$ Se trataba de tres comentarios. Uno de ellos se limitó a poner como título "Estafa a la Seguridad Social, personal enchufado mal cualificado, una chapuza de gestión de negocio". El segundo se refería a uno de los restaurantes de las demandante al que denominaba "Tóxico Beach" y señalaba: "El tartar de atún nos proporcionó fuertes diarreas a los que lo comimos. Es inconcebible para un restaurante que tiene ínfulas de restaurante elegante". El tercero llevaba por título: "Es una empresa sin derechos laborales", y su contenido era el siguiente: "El dueño es un sinvergüenza que no paga horas extra, se queda un $30 \%$ de las propinas cuando factura millonadas y no da de alta a los trabajadores las horas que hacen. ES UNA EMPRESA SIN DERECHOS LABORALES. Cómo va a funcionar con los trabajadores malpagados y agotados... Lo mejor de todo es que solo se acerca allí para maltratar y humillar gritando a los empleados delante de toda la gente". 
139. La mera exposición de este caso evidencia la problemática y la posible indefensión en la que se pueden encontrar los proveedores de bienes y servicios de la mano de un sistema de reputación sin regulación. Basta que haya un control de comentarios por parte de la plataforma para que no respon$\mathrm{da}$, aunque tal control haya sido ineficiente. A día de hoy, el operador de la plataforma no responde de los comentarios que se hacen en las páginas, aunque sea el operador el que organice el sistema de reputación. Según el art. 16 LSSICE no responde el operador de la plataforma si éste desconoce la ilicitud del comentario o, si lo conoce, lleva a cabo gestiones para eliminarlo. La única defensa que puede tener el proveedor afectado es informar al operador de la plataforma (previa la cesión de sus datos) para que retire el comentario. El responsable es el autor del comentario que puede no identificarse de manera real y hacer un comentario anónimo o con pseudónimo (cuentas avatar).

140. No será el último caso. El mal uso de los sistemas de reputación online inundará los juzgados ${ }^{160}$ si no se establece una regulación adecuada y disuasoria. La clave es evitar que estos hechos se produzcan, porque, una vez producidos, la reparación del daño causado es difícil de probar y de lograr ${ }^{161}$.

141.La inclusión de reseñas falsas no solo puede falsear la competencia, lesionar el honor si son denigratorias, sino que siendo falsas también puede afectar a la formación del contrato del adquirente del bien o servicio a través de la plataforma. Si la plataforma que actúa como intermediaria en la transaccion entre pares no controla la veracidad de las reseñas, éstas cuando son falsas pueden inducir a error en la contratación. No hay engaño por parte del prestador del bien o servicio, sino de un tercero. Si bien es cierto que el dolo de un tercero no es invalidante del contrato, sí podría ser anulable el contrato si el error reúne los requisitos legales (art. 1.266 CC). Con todo, el encaje del supuesto en el error como vicio del consentimiento puede tener dificultades pues el comprador debe fijarse en la información proporcionada por el vendedor (prosumidor o no) y no en las reseñas. Pero la realidad nos evidencia que las reseñas tienen un extraordinario poder en la toma de decisión de contratar.

142. Este es solo un ejemplo de los perjuicios que puede ocasionar un sistema de reputación poco transparente y que es diseñado por la plataforma que en este punto asume un papel activo para favorecer los "efectos en red". A mi juicio, la regulación no debe hacerse a través de códigos de conducta, sino que creo que el instrumento normativo debe ser otro, normas de obligado cumplimiento ${ }^{162}$, ya que es necesario un régimen de responsabilidad del operador de la plataforma que incentive a tales comportamientos adecuados. Cierto es que el operador de la plataforma tiene ya un incentivo a que su sistema de valoración sea fiable, pero la trascendencia que tiene para el consumidor aconseja una regulación más agresiva en esta materia, pues pienso que es un mecanismo potente de protección del consumidor, dado el poder que estos sistemas tienen en su decisión de contratar. La falta de control de los sistemas de reputación puede provocar la ineficiencia de las normas de protección del consumidor y comprometer el éxito del tráfico a través de plataformas en línea que depende de la confianza que generen.

160 Tripadvisor ha sido de nuevo denunciado y condenado por la sentencia de Juzgado de Primera Instancia de Mérida de 27 de noviembre de 2019 por un comentario realizado por un usuario anónimo contra un hotel. La condena fue a eliminar el comentario difamatorio objeto del presente procedimiento, difundiendo íntegramente la sentencia y la obligación de abonar 300 euros al demandante en concepto de daños y perjuicios. Se entiende que ha habido lesión al derecho al honor. No obstante, la sentencia ha sido anulada por la de la Audiencia Provincial de Badajoz (Sección 3a) de 5 de mayo de 2020 (JUR/2020/168632), por fallos en la citación del demandado. Pero realmente no todos los casos llegarán a los juzgados debido al denominado "efecto Streisand": intentar ocultar de cierta información en Internet acaba siendo contraproducente, ya que esta acaba siendo ampliamente divulgada, recibiendo mayor publicidad de la que habría tenido si no se la hubiese pretendido acallar. Cfr. MARTíNEZ Nadal, A., y Roselló Rubert, F., "La experiencia del cliente: el análisis jurídico de la publicación online de comentarios de clientes (reviews). En particular, el caso de Tripadvisor". https://idus.us.es/bitstream/handle/11441/52694/martinez-nadal.pdf;j sessionid=37F79A5EC9DA6EC16CF9E7BCC336E333?sequence=1 (Consultado del 12 de junio de 2020).

${ }^{161}$ Además de la vía de la LCD, frente a una reseña denigratoria puede ejercitarse las acciones derivadas de la Ley Orgánica 1/1982, de 5 de mayo, de Protección Civil del derecho al honor y en su caso, cuando se den los requisitos, las acciones de responsabilidad en el marco de la Ley 34/2002, de 11 de julio, de Servicios de la Sociedad de la Información y de Comercio Electrónico.

${ }^{162}$ Así se ha establecido en el Código del Consumo francés (L- 131-4) con sanciones pecuniarias para el caso de incumplimiento de los deberes de información precontractual que es el marco en el que se diseña la regulación de los sistemas de valoración online. 


\section{Régimen jurídico aplicable en la contratación a través de plataformas intermediarias en línea.}

\section{La relación jurídica entre el operador de la plataforma y los usuarios}

\subsection{Naturaleza de relación jurídica entre los usuarios y el operador de la plataforma: contrato de mediación electrónica}

143. Dado que la plataforma intermediaria opera como un mercado multilateral no siendo prestador del servicio subyacente, cualquiera que sean los servicios que oferten los usuarios entre sí, la naturaleza del contrato celebrado entre la plataforma y éstos será la misma. Como se ha señalado repetidamente, las plataformas ponen en contacto a dos grupos de usuarios: clientes y proveedores de bienes y servicios, proporcionando una infraestructura tecnológica que permite la contratación. La plataforma puede adoptar un papel pasivo, ser un mero tablón de anuncios ${ }^{163}$, o un papel más activo prestando otros servicios complementarios (gestión de pagos, herramientas avanzadas de búsqueda y selección de contenidos), dirigidos a impulsar la perfección del contrato, pero sin actuar por encargo concreto ni en representación de los usuarios.

144. Característica de la actividad de las plataformas es la obtención de una comisión por parte de uno de los grupos de usuarios o por ambos. Existe, pues, ánimo de lucro, devengándose la comisión a su favor cuando se perfecciona el contrato entre los usuarios, aunque en ocasiones, se cobra la comisión por el hecho de publicar el anuncio en determinadas condiciones ${ }^{164}$. Otras plataformas, por el contrario, no cobran ninguna comisión, obteniendo ingresos de la publicidad (es lo que sucede, por ejemplo, con Wallapop). Muchas plataformas, por lo tanto, prestan servicios mixtos ${ }^{165}$, pero siempre orientados a una finalidad común: favorecer la interacción, sin que tales servicios, a mi juicio, puedan ser individualizados en modalidades contractuales distintas porque están ordenados a un objetivo común.

145. Procede analizar la naturaleza del contrato de acceso ${ }^{166}$ a la plataforma por parte de los usuarios, ya sean proveedores o clientes, en relación con la actividad de intermediación que lleva a cabo la plataforma.En el Derecho español no hay una regulación general sobre la figura de los intermediarios, es decir, personas dedicadas a poner en contacto a futuros contratantes, sino que existen distintos tipos contractuales en función del papel que juegue el intermediario en la contratación ${ }^{167}$.

146. Como en tantas ocasiones, la realidad social está impulsando el nacimiento de una nueva modalidad contractual de la mano de la actividad de las plataformas de intermediación. Las particularidades de régimen que genera el medio electrónico dificulta el encaje de este contrato de acceso en los modelos contractuales tradicionales. Como sucede en los contratos atípicos, la fuente de su regulación se encuentra en el principio de autonomía de la voluntad (art. 1255 CC) y en los principios generales

${ }^{163}$ Como se señala en el informe del Working Group on the collaborative economy "Impulse paper on specific liability issues raised by the collaborative economy in accomodation sector. Paris, Amsterdam, Barcelona, University of Groningen, 14 de marzo de 2016, p.12, para determinar si una plataforma es un mero tablón de anuncios se establece como criterio si el servicio proveedor del servicio prestado y el cliente pueden contactar directamente porque la plataforma se limita a dar datos de contacto. En caso afirmativo, podrá considerarse como tal. http://europa.eu/geninfo/query/index.do?\&queryText=\%22impu lse + paper\%22\&query_source=GROWTH\&summary=summary\&swlang=en (Consultado el 22 de mayo de 2020).

${ }^{164}$ Así sucede, por ejemplo, en la plataforma eBay http://pages.ebay.es/help/sell/seller-fees.html

${ }^{165}$ Por supuesto, si la plataforma, a su vez, presta el servicio subyacente, entonces el contrato celebrado será el correspondiente a la prestación realizada. Así, por ejemplo, Amazon actúa como vendedora en muchos casos y en otros intermedia con otros vendedores.

${ }^{166}$ El término "contrato de acceso" me parece adecuado por su neutralidad en relación con la naturaleza que, como veremos, no tiene una clara identidad con contratos típicos. Utiliza esta denominación T. Rodríguez DE LAS Heras BALLELL, "El régimen jurídico de los mercados electrónicos cerrados (e-Marketplaces), cit., p.231.

${ }^{167}$ Como señala J.A. Álvarez CAPerochipi, El mandato y la comisión mercantil, Granada, Comares, 1997, p. 47, la noción de "intermediario" vendría a destilar una nueva actividad económica propia de la sociedad industrial que agrupa numerosas formas de intermediación: mandato, comisión, agencia, concesión, distribución, contrato estimatorio... 
de integración contractual del art., $1258 \mathrm{CC}$, junto con las normas generales de la teoría general de la obligación y del contrato regulada en el Código Civil.

147. La necesidad de determinar la naturaleza del contrato de acceso se impone con el objeto aplicar analógicamente el régimen jurídico del contrato afín, en aspectos no pactados expresamente por las partes. El contrato celebrado entre los usuarios y profesionales a través de plataformas intermediarias online parece aproximarse en cuanto a su naturaleza al contrato de mediación o corretaje ${ }^{168}$, que carece de una regulación en nuestro ordenamiento ${ }^{169}$. Se trata de un contrato atípico cuya naturaleza ha sido muy discutida, pero con una importante tipicidad social que lo convierte en nominado ${ }^{170}$, cuyos caracteres han sido diseñados por la jurisprudencia, dada su extraordinaria aplicación práctica. Parecería que la calificación del contrato celebrado por las plataformas con los usuarios como mediación o corretaje no sería de gran ayuda, dada la ausencia de un régimen jurídico específico para esta modalidad contractual. Sin embargo, la presencia de una consolidada doctrina jurisprudencial y el marco legal de contratos afines pueden ser especialmente útiles para diseñar las obligaciones y el régimen de responsabilidad de las partes en el contrato de acceso a plataformas intermediarias en línea.

148. Procede analizar las características del contrato de mediación o corretaje, comprobando si la actividad de la plataforma intermediaria tiene o no encaje en esta modalidad contractual, teniendo en cuenta los clausulados contractuales de las plataformas que, a pesar de la diversidad de servicios prestados, presentan una gran homogeneidad estando estandarizados sus elementos esenciales ${ }^{171}$.

149. El Tribunal Supremo se ha pronunciado en numerosas ocasiones sobre el contrato de mediación o corretaje, de cuyas resoluciones podemos extraer sus caracteres para probar su encaje con la actividad realizada por las plataformas de intermediación. Resume la doctrina jurisprudencial al respecto, la sentencia del TS de 14 de noviembre de 2012 (RJ2013/13), que recoge doctrina de sentencias anteriores. Se entiende que "el contrato de mediación se integra en los contratos de colaboración y gestión de intereses ajenos, cuya esencia reside en la prestación de servicios encaminados a la búsqueda, localización y aproximación de futuros contratantes, sin intervenir en el contrato ni actuar propiamente como mandatario. Constituye un contrato atípico, consensual, bilateral y aleatorio, puesto que su resultado es incierto, y se rige por las estipulaciones de las partes que no sean contrarias a la ley, a la moral o al orden

${ }^{168}$ M.I Grimaldos García, «El contrato de intermediación entre las plataformas colaborativas y sus usuarios», en Alfonso Sánchez, R., Valero Torrijos, J., (Dirs.) Retos jurídicos de la economía colaborativa en el contexto digital, Thomson ReutersAranzadi, Navarra, 2017, p. 366 y JJ. MonTERo PASCuAL, "El régimen jurídico de las plataformas colaborativas" en Montero Pascual JJ., (Dir.), El régimen jurídico de las plataformas colaborativas. La regulación de la economía colaborativa. Airbnb, BlaBlaCar, Uber y otras plataformas, Tirant lo Blanch, 2016. p. 97. JL. García PITA Y LASTRES, "Plataformas de financiación participativa y financial crowdfunding, Tirant lo Blanch, Valencia 2016, p. 68, considera que se trata de una "modalidad especial del contrato de mediación o corretaje". I. RODRíGuEZ MARTíNEZ, "El servicio de mediación electrónica y las obligaciones de las plataformas de la economía colaborativa" en JJ. Montero Pascual, El régimen jurídico de las plataformas colaborativas. La regulación de la economía colaborativa. Airbnb, BlaBlaCar, Uber y otras plataformas, Tirant lo Blanch, Valencia, 2017, p. 142, después de afirmar que el contrato no tiene un encaje perfecto en ninguna estructura contractual de colaboración conocida, "no parece aventurado calificarlo como una subespecie de la mediación y corretaje". Para RodRíGUEZ MARÍN, s., "Aspectos jurídicos de la economía colaborativa y bajo demanda en plataformas digitales” en A. Muñoz García, y S. Rodríguez Marín, (Coord.), Aspectos legales de la economía colaborativa y bajo demanda en plataformas digitales, Wolters Kluver, 2018, (Smarteca), no se trata de un contrato de mediación o corretaje porque no parece que la plataforma intervenga directamente en el contrato, ni que exista un mandato previo y el devengo de la comisión por parte de la plataforma no siempre depende de la ejecución de la ejecución del contrato por las partes ni siempre existe imparcialidad de la plataforma respecto del contrato entre las dos partes.

${ }^{169}$ Sí se regula la mediación con carácter general en los arts. 1754 y siguientes del Código Civil italiano. Se define el mediador como aquella persona "que conecta a dos o más partes para concluir un negocio, sin estar vinculado a ninguna de ellas por relaciones de colaboración, dependencia o representación". También se regula en los arts. 412 y ss, del Código de obligaciones suizo y en los parágrafos 652 y ss del BGB alemán. El Anteproyecto de Código Mercantil prevé una regulación para los "contratos de colaboración" (Título IV, Libro V), entre los cuales se propone una regulación del contrato de mediación en los arts. 544-1 a 544-6.

${ }^{170}$ El contrato tiene nomen iuris y está dotado de tipicidad social, dotado de cierta regulación consuetudinaria. Cfr. JB: Jordano Barea, "Los contratos atípicos”, RGLJ 1953, p. 58.

171 T. Rodríguez de Las heras BaLlell, “El régimen jurídico de los mercados electrónicos, cit., p. 352. 
público y, en lo no previsto, por los preceptos correspondientes a figuras afines, como el mandato, el arrendamiento de servicios o la comisión mercantil".

150. En relación con el cobro de la comisión, "el mediador no tiene derecho a la remuneración: $\left(1^{\circ}\right)$ si el contrato encargado no llega a celebrarse (no se produce la perfección del mismo); $\left(2^{\circ}\right)$ si se ha celebrado pero no por la actividad del mediador (falta el nexo causal); y $\left(3^{\circ}\right)$ si se celebra una vez transcurrido el plazo pactado (es causa de extinción del contrato) a no ser que se pruebe que el contrato se celebró después, pero por razón de la actividad mediadora, con cuyo retraso las partes contratantes han querido evitar el pago al mediador" ( Sentencia del TS de 25 de noviembre (RJ 2011/8161)).

151. En una primera aproximación, se puede decir que el servicio prestado por la plataforma cumple la misma función que el contrato de mediación, en cuanto facilita la interacción de los usuarios, sin intervenir en el contrato, devengándose el derecho al cobro de la comisión cuando se perfecciona el contrato entre ellos.

152. Los usuarios que contratan con una plataforma no encargan a la plataforma que procure la celebración del contrato con el otro usuario, y en este sentido, no cabe hablar de contrato de mandato ${ }^{172}$, ni de comisión mercantil (art. $244 \mathrm{Cco})^{173}$, ni tampoco de contrato de agencia ${ }^{174}$. Cuando los usuarios se inscriben en la plataforma, usualmente, la relación contractual tiende a prolongarse en el tiempo, a modo

\footnotetext{
${ }^{172}$ Aunque inicialmente la jurisprudencia cuestionó la independencia de la mediación respecto del mandato, actualmente se mantiene la autonomía contractual de la mediación (STS de 10 de marzo de 1992, RJ1992/2167). A diferencia del mandato, el mediador no tiene una relación de colaboración, representación o dependencia, ni hay encargo concreto (art. 1709 CC). Se limita a poner en contacto a las personas, quedando fuera del contrato resultante. Por el contrario, como ha señalado la sentencia de la AP de Madrid (Sección 14) de 7 de julio de 2004(JUR 2004/275497), "el mandatario no media, sino que contrata en nombre y por cuenta de su principal en caso de mandato representativo, o lo hace en nombre y por cuenta propia en caso de mandato oculto. Por esa nota de gestión no mandataria es por lo que solo los interesados son los llamados a concluir el contrato mediante la expresión del consentimiento reciproco, salvo que el cliente hubiese concedido mandato al agente con carácter expreso y representativo para que en su nombre y por su cuenta concluya el contrato sustituyéndole íntegramente".

Lo mismo sucede con las plataformas de intermediación en línea, que no son parte en el contrato celebrado por los usuarios a los que se limita a poner en contacto. El mandatario celebra el contrato. El mediador no.

${ }^{173}$ Según el art. 244 Cco., «se reputará comisión mercantil el mandato, cuando tenga por objeto un acto u operación de comercio y sea comerciante o agente mediador del comercio el comitente o comisionista». Se trata del mandato mercantil y presenta las mismas diferencias conceptuales que ya he señalado respecto del mandato civil. Dado que la plataforma tiene la condición de empresario, la delimitación conceptual de la mediación procede hacerla respecto del contrato de comisión mercantil. Como señala la sentencia de la AP Castellón de 31 de julio de 2000 (AC 2000/1791): "la función del mandatario o comisionista es siempre una finalidad estrictamente jurídica, que es la de que se celebre un contrato, mientras que la del mediador o corredor es básicamente material, se trata de promover la celebración del contrato sin intervención para nada en el mismo".

${ }^{174}$ En el contrato de agencia, al igual que en el de mediación, el agente es un intermediario independiente dirigido a promover la celebración de contratos, sin asumir el riesgo y ventura de las operaciones. Se trata de un contrato típico regulado por la Ley 12/1992, de 27 de mayo. Sin embargo, la actividad del agente es más extensa, pudiendo concluir operaciones en nombre y por cuenta ajena, si así se pacta (arts. 1 y 2 Ley 12/1992), cosa que no sucede con el mediador y menos con las plataformas de intermediación que aclaran este extremo en sus condiciones de uso. La actividad del agente es parcial, y debe actuar con buena fe y lealtad a su principal. El mediador, por el contrario, debe ser imparcial si contrata con ambas partes del contrato mediado, que es precisamente lo que sucede en las plataformas. El contrato de agencia es estable y de tracto sucesivo (sentencias del TS de 9 de noviembre de 2011 (RJ 2012/1371) y 30 de julio de 2014 (2014/4793)). La mediación es una actividad de tracto y ejecución instantánea, aunque nada impide que haya sucesión se contratos de mediación. Sí es cierto que, en este punto, el contrato celebrado con las plataformas se acerca a la agencia, por cuanto se trata de un contrato de tracto sucesivo que no se agota con la perfección de un contrato con los usuarios. Éstos pueden acceder al sitio web y realizar pluralidad de contratos a lo largo del tiempo. Pero esta circunstancia no acerca el contrato de acceso a la agencia, dada la imparcialidad e independencia de las plataformas que no tiene lugar en el contrato de agencia. Una relación continuada no desnaturaliza el contrato celebrado con la plataforma como contrato de mediación. Otra diferencia relevante es que, en el contrato de agencia, según lo dispuesto en el art. 14 de la Ley 12/1992, el agente cobrará su comisión cuando el empresario hubiera ejecutado el acto u operación de comercio o éstos hubieran sido ejecutados total o parcialmente por el tercero. El mediador percibe la comisión cuando se perfecciona el contrato mediado. Ciertamente la estabilidad y permanencia es una característica clave del contrato de agencia que también se da en el contrato celebrado con las plataformas, pero ello no implica su asimilación porque ni el mediador ni las plataformas son portadoras de los intereses del oferente o usuario sobre todo cuando hay pluralidad de contratos de mediación. Vid. M. R., Quintans EIRAS "Problemas suscitados en la dogmática del contrato de corretaje, con ocasión de la promulgación de la Ley 12/1992, de 27 de mayo, sobre contrato de agencia”. Cuadernos de Derecho y Comercio, n 20, 1996, p. 104.
} 
de contrato de tracto sucesivo, de forma que, el contrato que inicialmente se celebra, no se extingue con la perfección del contrato mediado, sino que se proyecta en el tiempo con la eventual perfección de sucesivos contratos. Esta característica se compadece mal con el contrato de comisión o con el mandato, que son contratos de tracto único ${ }^{175}$. El automatismo y la despersonalización que caracterizan el funcionamiento de las plataformas son incompatibles con mandatos concretos adaptados a las necesidades del oferente.

153. Tampoco la plataforma actúa como representante de ninguno de ellos, sino que se limita a proporcionar una infraestructura tecnológica gracias a un programa informático, acompañada en su caso de servicios auxiliares que favorecen la contratación, pero manteniéndose al margen del contrato celebrado ${ }^{176}$. En este punto se acerca la posición de la plataforma al mediador que se caracteriza por su independencia ${ }^{177}$.

154. La prestación realizada por la plataforma presenta particularidades por cuanto la intermediación que fomenta es puramente técnica ${ }^{178}$ de aproximación de las partes contratantes y, hasta cierto punto, material, aunque sea a través de medios técnicos. Buena prueba de ello son las herramientas de comparación que se ponen a disposición de los usuarios y la posibilidad de casar las ofertas con las demandas. Este carácter técnico no creo que ello sea suficiente para negar que la plataforma pueda prestar servicios de mediación y corretaje ${ }^{179}$. Lo importante, a mi juicio, es el objetivo de facilitar la contratación de terceros, al margen de los medios utilizados para tal interacción. El medio electrónico obliga a aplicar además la regulación en materia de contratación electrónica (arts. 23 y ss LSSICE), pero este solo hecho no convierte el contrato en un tipo específico ${ }^{180}$.

155. La otra opción sería considerar que el contrato que los usuarios celebran con la plataforma sería un simple contrato de servicios informáticos ${ }^{181}$, de naturaleza técnica ${ }^{182}$. La prestación de la platafor-

175 Rodríguez DE LAS heras BaLlell, T., "El régimen jurídico de los mercados electrónicos cerrados (e-Marketplaces), cit., p. 455 .

176 Busto Lago J.M. "El contrato de mediación y corretaje” en Bercovitz Rodríguez Cano, R., (Dir.) Tratado de contratos, t. III, Tirant lo Blanch, Valencia 2009, p. 3076.

177 Argudo PÉriz, JL y SESMA SÁnChez, B., "El contrato de mediación y corretaje” en Yzquierdo Tolsada, M., (Dir.) Contratos civiles, mercantiles, públicos, laborales e internacionales, con sus implicaciones tributarias. T. IV. Contratos de prestación de servicios y realización de obras (I), Thomson-Aranzadi, 2014, p. 588. "La independencia no debe ser confundida con la imparcialidad y es característica del contrato de mediación y no del mandato. En el caso de que recaiga el mediador el encargo de dos partes interesadas en celebrar el mismo contrato, es más relevante la imparcialidad". Como señala BusTo LAGO J.M., "El contrato de mediación o corretaje..., cit., p. 3081, esta independencia del mediador implica que el mediador no está facultado, por el mero hecho de haberse concertado un contrato de mediación o corretaje, a perfeccionar el contrato pretendido con el tercero, por cuenta del oferente. La independencia del mediador permite distinguir la mediación del arrendamiento de servicios. El arrendador de servicios está vinculado al arrendatario o principal por una relación de dependencia. En este sentido, ÁlvAREZ GARCíA, M.D. ., "El contrato de mediación y corretaje”, en Los contratos de gestión, Consejo General del Poder Judicial, 1995 , p. 234.

178 Pero ello no la convierte en un mero prestador de servicios de intermediación de la sociedad de la información en el sentido del art. 16 LSSICE. Así lo entiende, por el contrario, RoDríGUEZ DE LAS HERAS BALLELL, T., "El régimen jurídico de los mercados electrónicos cerrados (e-Marketplaces), cit.,p. 398. A mi juicio, el comportamiento de la plataforma no es si su comportamiento es meramente técnico, automático y pasivo, lo que implica que no tiene conocimiento ni control de la información que almacena, tal y como exige el TJUE. Vid supra apartado 2.5.2.

179 Así lo entiende, por el contrario, RoDRÍGUEZ DE LAS HERAS BALLELL, T., "El régimen jurídico de los mercados electrónicos cerrados (e-Marketplaces), cit., p. 461, quien considera que la plataforma no recibe encargo alguno de ninguna de las partes para facilitar la negociación entre ellas.

180 Así lo entiende, por el contrario, RodríGUEz MARTínez, I., "El servicio de mediación electrónica..., cit., p. 135.

181 Esta es, a juicio de T. RoDRÍGUEZ DE LAS HERAS BALLELL, "El régimen jurídico de los mercados electrónicos cerrados ( $e$-Marketplaces), cit., , p. 466, la calificación que merece el contrato de acceso a la plataforma de intermediación. En virtud del contrato de acceso, el participante podrá acceder, mediante el debido uso de las claves, a un entorno electrónico cerrado que le ofrece las funcionalidades adecuadas para negociar y concluir contratos con otros participantes de conformidad con un conjunto de reglas predeterminadas La obligación asumida por la plataforma es una obligación de medios y no se realizan actos materiales de aproximación de las partes típicas de la mediación. Considera que es contrato de servicios por la independencia técnica y económica, el que se diseñe como contrato de duración, las distintas modalidades de fijación del precio y la falta de causalización del resultado. A mi juicio, las razones alegadas no son suficientes para descartar la naturaleza del contrato de acceso como contrato de mediación, el cual no deja de ser una modalidad de contrato de prestación de servicios. Coincido con la autora en que la prestación a la que se obliga la plataforma es de medios, al igual que lo que acontece, a mi juicio, con la obligación que corresponde al mediador.

${ }^{182}$ Este es aparentemente el contrato que ofertan algunas plataformas como Airbnb: “La Plataforma Airbnb es un mercado 
ma se reduciría a la puesta a disposición de un software cuyas funcionalidades facilitan el intercambio de información estandarizada entre los participantes y su negociación ${ }^{183}$. Ello significaría que la plataforma podría obtener una remuneración al margen de que se perfeccionara o no el contrato entre los usuarios.

156. La mayoría de las plataformas cobran una comisión precisamente cuando el contrato se perfecciona, lo cual acerca la figura a la mediación antes descrita, con un componente de aleatoriedad. Por supuesto, habrá que atender al clausulado particular de cada plataforma para determinar su exacta naturaleza, pero lo cierto es que la mayoría de las plataformas de intermediación, como he dicho, presentan importantes denominadores comunes en sus condiciones de uso.

157. Una particularidad del servicio que presta la plataforma intermediaria en línea es que lo lleva a cabo para dos grupos de usuarios: el cliente que quiere adquirir un bien o servicio y el proveedor que desea prestarlo. En el contrato de mediación solo son partes el oferente y el mediador y no se considera parte en el contrato, la otra parte contratante con la que eventualmente se perfecciona el contrato media$\mathrm{do}^{184}$. Sin embargo, en la contratación a través de plataformas intermediarias, ambos grupos de usuarios celebran un contrato con la plataforma, tratándose de contratos distintos ${ }^{185}$. En este caso, el mediador (la plataforma), podría cobrar una comisión de ambos grupos de usuarios ${ }^{186}$. Puede que esto no suceda y solo se cobre una comisión al usuario, por ejemplo, que actúa como proveedor del bien o servicio, lo

en línea que permite que los usuarios registrados ("Miembros") y ciertos terceros que ofrecen servicios (los Miembros y terceros que ofrecen servicios son "Anfitriones" $y$ los servicios que ofrecen son "Servicios de Anfitrión") publiquen dichos Servicios de Anfitrión en la Plataforma Airbnb ("Anuncios") y comuniquen y gestionen directamente con los Miembros que desean reservar dichos Servicios de Anfitrión (los Miembros que utilizan los Servicios de Anfitrión son "Huéspedes"). Los Servicios de Anfitrión pueden incluir la oferta de propiedades desocupadas o de otro tipo para su uso ("Alojamientos"), actividades de uno o varios días en diversas categorías ("Experiencias"), acceso a eventos y lugares únicos ("Eventos"), así como toda una gama de demás servicios relacionados o no con el viaje". Se ofrece el servicio de acceder a un servicio web, pero la prestación realmente realizada es la intermediación entre usuarios a través de dicha página web.

También Amazon "disfraza" el contrato de licencia: Amazon o sus proveedores de contenidos le conceden una licencia limitada no exclusiva, no transferible y no sublicenciable, de acceso y utilización, a los Servicios de Amazon para fines personales no comerciales. Dicha licencia no incluye derecho alguno de reventa ni de uso comercial de los Servicios de Amazon ni de sus contenidos, ni derecho alguno a compilar ni utilizar lista alguna de productos, descripciones o precios. Tampoco incluye el derecho a realizar ningún uso derivado de los Servicios de Amazon ni de sus contenidos, ni a descargar o copiar información de cuenta alguna para el beneficio de otra empresa, ni el uso de herramientas o robots de búsqueda y extracción de datos o similar". Sin embargo, los contratos son los que son, y no lo que las partes dicen que son. El servicio que prestan las plataformas es de clara intermediación y no de uso de un programa informático.

${ }^{183}$ Así lo entiende T. Rodríguez de las Heras ballell, op. cit., p. 456. A su juicio es irrelevante que tal software fomente la interacción entre los usuarios, que la plataforma cobre la comisión en función del contrato perfeccionado. El carácter técnico y no material de la actividad realizada por la plataforma aleja el contrato de la mediación.

${ }^{184}$ No han faltado quienes han defendido el carácter plurilateral del contrato de mediación, del que formaría parte también el otro contratante (mediatario) con el que contrata el oferente a través del mediador. El contrato de mediación se perfecciona en el momento en el que el corredor encuentra a algún sujeto interesado en contratar con el oferente, y comienza las gestiones de conciliación entre ellos. En este sentido, J. GARCíA-VALDECASAS y ALEX, La mediación inmobiliaria..., cit., p. 54 y 55. Esta doctrina parte del carácter unilateral del contrato de mediación, que hoy puede considerarse superada.

185 Como señalan J.L., Argudo Périz, y Sesma sánchez. op. cit., p. 594, “el mediatario no tiene vinculación contractual con el corredor, aunque llegue a concluirse el negocio previsto, pero si también le confiere al mismo mediador el encargo de la gestión, surge un segundo contrato de mediación o corretaje, con su propio contenido aunque ambos contratos confluyan en un mismo objeto, en el que el mediatario ocupa la posición del oferente, y es cuando queda vinculado con el mediador y quedaría obligado a remunerar al corredor si el contrato se concluye". En el mismo sentido, M.D.ÁlvVAREZ GARCíA, "El contrato de mediación y corretaje", en Los contratos de gestión, Consejo General del Poder Judicial, 1995, p. 239.

${ }^{186}$ Así se establece en el art. 1755 del Código civil italiano:" El mediador tiene derecho a una comisión de cada una de las partes, si el asunto se concluye como resultado de su intervención.

La cuantía de la comisión y la proporción que se cobrará a cada una de las partes, a falta de acuerdo, de tarifas profesionales o de costumbre, serán determinadas por el tribunal de manera equitativa". Traducción propia. La plataforma Airbnb cobra a ambos grupos de usuarios, tal y como se señala en sus condiciones de uso: "Airbnb podrá cobrar tarifas a los Anfitriones ("Tarifas de Anfitrión") y/o a los Huéspedes ("Tarifas de Huésped") (en adelante, conjuntamente, las "Tarifas de Servicio") en contrapartida por el uso de la Plataforma Airbnb". https://www.airbnb.es/terms\#sec7

El Artículo 545-3 del Anteproyecto de Código Mercantil permite que el mediador pueda cobrar la retribución de ambos contratante aunque solo haya celebrado el contrato con uno de ellos. Señala que "La retribución del mediador consistirá en una comisión que, salvo pacto en contrario, percibirá de ambas partes". 
cual significa que el otro contrato de mediación no sería oneroso, ya que el comprador o, prestatario del servicio, no asume ningún coste por la intermediación que obtiene de la plataforma. Cosa distinta es que el proveedor le repercuta la comisión al otro contratante aumentando el precio. Pero formalmente, en las plataformas multilaterales puede suceder que un grupo de usuarios no abone comisión alguna, lo cual no supone un obstáculo a seguir considerando el contrato como mediación, por tratarse la onerosidad de un elemento natural del contrato ${ }^{187}$. Con todo, a pesar de que un grupo de usuarios (proveedores o clientes) abone la comisión y el otro no, no priva de onerosidad a la operación en un sentido global.

158. A pesar de que, eventualmente, la remuneración la abone un grupo de usuarios (generalmente los proveedores), ello no significa que la plataforma pueda favorecer a este colectivo en detrimento de los clientes. La neutralidad o imparcialidad ${ }^{188}$ se erige en criterio determinante del contrato de mediación cuando el mediador recibe el encargo de varias partes ${ }^{189}$, que es lo que sucede en la contratación a través de plataformas ${ }^{190}$. Ello es necesario para que se genere confianza entre los usuarios ${ }^{191} \mathrm{y}$, a su vez, justifica que cuando hay dos contratos de mediación independientes, pueda la plataforma cobrar comisiones de ambas partes. Entiendo que tal deber es una exigencia de la buena fe (art. $1258 \mathrm{CC}$ ) y es fruto de la independencia que caracteriza la mediación, nota característica de la actuación de las plataformas y necesaria para su operatividad, dado que presta servicio a multitud de usuarios de manera simultánea.

159. De asimilarse el contrato de acceso a un contrato de mediación o corretaje, el derecho a la comisión por parte de la plataforma deriva de la puesta en contacto de los usuarios y de la perfección del contrato y no de su consumación ${ }^{192}$, tal y como ya se ha explicado. Por lo tanto, celebrado el contrato entre los usuarios, se devenga el derecho a la comisión a favor de la plataforma, al margen de que tal contrato se cumpla o no correctamente. Así, cuando un usuario adquiere, por ejemplo, a través de la plataforma eBay un bien y no resulta conforme con el mismo, una vez recibido, podrá resolver el contrato con el vendedor, pero no por ello, la plataforma deberá devolver la comisión cobrada. Y ello porque no es la consumación del contrato el hecho generador de la comisión, sino su perfección. Cosa distinta es que pueda pactarse que la comisión se devengue cuando se consume la venta ${ }^{193}$.

160. El contrato de acceso comparte con la mediación su carácter de contrato autónomo y no vinculado ni accesorio al contrato celebrado entre los usuarios. Las vicisitudes de este no afectan a la

${ }^{187}$ C. Cuadrado Pérez, Consideraciones sobre el contrato de mediación o corretaje». RCDI No 704, p. 2507 y doctrina allí citada.

${ }^{188}$ G. Macanás, El contrato de mediación o corretaje. (Carencias y posibilidades), Wolters kluwer, Madrid, 2015, p. 300. El deber de imparcialidad tiene dos posibles vertientes: de un lado, no debe el mediador buscar el beneficio de su comitente más allá de las instrucciones objetivas o marco contractual transmisible al mediatario, a costa de este último. De otro, no deberá tampoco buscar su propio provecho más allá de la retribución pactada por su actuación diligente, por encima de los intereses que su mediación pretende aunar un un consentimiento común. En los supuestos en los que la remuneración dependa del quantum que perciba el comitente, la infracción del deber de imparcialidad será conjunta.

189 E. Villa Vega, "El contrato de corretaje", en Bercovitz Rodríguez -Cano, A., (Dir.), Contratos mercantiles, T. I, Thomson Reuters, 2009, p. 683. Por el contrario, cuando el contrato de mediación se ha celebrado a instancia de una sola de las partes, se ha negado la nota de imparcialidad. En este sentido, A. Bonet Correa, "El contrato de corretaje o mediación. Conclusiones críticas...,cit.,p. 324, para quien el mediador no tiene ningún deber de imparcialidad para el mediatario como no sea el de su contrayente, es más, en la práctica de los negocios se puede constatar todos los días que el mediador unilateral no es jamás imparcial. El mediador permanece con su cualidad de mediador, tanto se comporte con espíritu de parcialidad como que opere imparcialmente respecto de una de las dos partes que le hayan encargado un negocio.

${ }^{190}$ Como señala M. SAnPons Delgado, "El contrato de corretaje, Ed. Montecorvo, Madrid, 1965, p. 140, la imparcialidad no es un rasgo esencial del contrato de corretaje y no opera cuando el mediador ha recibido el encargo de una de las partes del contrato futuro.

${ }^{191}$ M.I. Grimaldos García, op. cit., p. 382.

${ }_{192}$ Así, por ejemplo, la plataforma Airbnb que oferta un servicio de intermediación de alojamiento, establece una obligación de pago de la comisión a ambos grupos de usuarios "cuando se completa la reserva": para los anfitriones (arrendadores), quienes deben pagar un 3\% del subtotal bruto de la reserva y para los huéspedes (arrendatarios) entre un $0 \%$ y un $20 \%$ del subtotal bruto de la reserva. La concreción de la comisión se determina antes de que el huésped confirme la reserva, pero se abona una vez producida ésta. https://www.airbnb.es/help/article/1857/what-are-airbnb-service-fees

${ }^{193}$ En este sentido se pronuncia la sentencia del TS de 15 de noviembre de 2010 (2010/8874). 
eficacia del contrato celebrado entre la plataforma y los usuarios. Aunque la mayoría de las plataformas establecen en sus condiciones de uso el cobro de comisión cuando se perfecciona la venta ${ }^{194}$, algunas cargan también comisiones por publicar anuncios de venta en la plataforma o incluso una cuota mensual fija por ser el vendedor profesional ${ }^{195}$. Conforme las plataformas van ganando cuota de mercado y cuentan con un número importante de usuarios, se avanza hacia un cobro de remuneración que no depende del número de contratos que consiguen perfeccionar los usuarios. Ello no aleja la naturaleza del contrato de la mediación, aunque también perciba una remuneración al margen del éxito de la interacción, ya que podría considerarse que se retribuyen gastos derivados de la actividad mediadora y se trata de una comisión auxiliar a la principal.

161. Sí me parece esencial para la calificación del contrato como mediación, la falta de intervención del mediador en el contrato y en que su actividad se centre en favorecer la interacción. Por ello, a mi juicio, sí desnaturalizaría el contrato el que el mediador prestara el servicio subyacente o impusiera condiciones contractuales a los usuarios, como puede ser el precio. Respecto a este último extremo, no es infrecuente que la plataforma oriente, por ejemplo, sobre precios o gastos de envío, pero sin que vincule a los usuarios ${ }^{196}$.

162. También hemos visto que la plataforma puede prestar otros servicios (sistema de reputación, servicios de pago, orientación sobre condiciones contractuales) que son accesorios de la prestación principal que es la intermediación. La especificidad radica en cómo se presta este servicio que es electrónico, a través de un software que permite la búsqueda y case de las transacciones según los intereses concretos de cada usuario. El consentimiento contractual se presta por medio electrónico, tratándose de un contrato a distancia. Pero estas particularidades no desnaturalizan, a mi juicio, la calificación del contrato como mediación y sí provocarán el solapamiento de la regulación específica en materia de contratación electrónica y contratos a distancia. A ello hay que añadir, como ya he señalado, la aplicación de la regulación en materia de condiciones generales de los contratos, así como todo el bloque normativo de las normas de protección de consumidores cuando el usuario tiene tal carácter.

\subsection{Derechos y obligaciones de las partes}

163. La configuración del contrato de acceso a la plataforma como un contrato de mediación implica que desde su perfección emergen obligaciones para ambas partes contratantes. La plataforma al permitir el acceso del usuario a la plataforma mediante la cumplimentación de un formulario de registro al sistema que incluye la aceptación de condiciones generales del contrato. En tal formulario el usuario aporta los datos relevantes, no solo personales, sino también los relativos al bien y servicio que oferta, caso de ser proveedor ${ }^{197}$. La plataforma deberá, como responsable del tratamiento de los datos personales, cumplir los deberes establecidos en el Reglamento General de protección de datos ${ }^{198}$.

\footnotetext{
${ }^{194}$ En el caso de eBay, expresamente se dice que "Cuando tu artículo se vende o finaliza con una puja ganadora, se carga una comisión por venta realizada a tu cuenta de vendedor cuyo importe depende del precio de venta final y de la categoría del artículo". http://pages.ebay.es/help/sell/fvf.html

195 Es el caso de Amazon que distingue dos tipos de vendedores. El vendedor individual solo paga cuando vende el producto. El denominado "vendedor Pro", que es el que vende más de 40 productos al mes, paga una comisión mensual de 39 euros además de la comisión por venta de producto. https://services.amazon.es/servicios/vender-por-internet/planes-y-precios. html\#account-pro-anchor

${ }^{196}$ Así se establece, por ejemplo, en las condiciones de uso de eBay: "Podemos orientar acerca de precios, gastos de envío, y otras cuestiones en nuestros Servicios, si bien dichas orientaciones se realizan a título informativo, por lo que puedes optar por no seguirlas". http://pages.ebay.com/es/help/policies/user-agreement.html

${ }^{197}$ Sobre el proceso de formación del contrato y las características del formulario de acceso, vid. T. RoDRíGUEZ DE LAS HERAS BALLELl, El régimen jurídico de los mercados electrónicos cerrados...cit., pp. 285 y ss.

${ }^{198}$ Reglamento (UE) 2016/679 del Parlamento Europeo y del Consejo, de 27 de abril de 2016, relativo a la protección de las personas físicas en lo que respecta al tratamiento de datos personales y a la libre circulación de estos datos y por el que se deroga la Directiva 95/46/CE (Reglamento general de protección de datos). Los datos que almacenan las platafor-
} 
164. Permitido el acceso, la plataforma pone a disposición del usuario la infraestructura tecnológica para favorecer la interacción. La obligación de medios que corresponde a la plataforma como mediadora se cumple permitiendo el uso de las herramientas técnicas que permiten dicha interacción. Como acontece en el contrato de mediación, la plataforma no asume ninguna responsabilidad en el caso de que la perfección del contrato entre los usuarios no se logre. Su obligación es de medios, no de resultado en relación con la formalización del contrato entre los usuarios.

Sí puede considerarse de resultado su obligación de permitir el acceso al entorno electrónico, pero los clausulados a menudo la "disfrazan" de obligación de medios ya que ni siquiera se garantiza el acceso continuado al servicio, dada la frecuente presencia de cláusulas exoneradoras de responsabilidad en este punto ${ }^{199}$.

165. Puesto que en las plataformas de intermediación todos los usuarios que en ellas participan celebran el contrato de acceso, se produce una pluralidad de contratos de mediación con los usuarios, lo que exige que la plataforma actúe con imparcialidad, de forma que no beneficie a una contraparte sobre la otra ${ }^{200}$.

166. Como contrato bilateral, las obligaciones del usuario con la plataforma y viceversa nacen antes de que los usuarios contraten entre sí. En relación con la obligación de la plataforma, al permitir el acceso a la web y poner a disposición de los usuarios los medios tecnológicos, cumple su obligación de medios de facilitar la contratación entre usuarios. La "materialidad" de los actos de mediación no es imprescindible, a mi juicio, para descartar la naturaleza de contrato de mediación a la actividad de las plataformas ${ }^{201}$.

mas constituyen un importante activo. Como se ha puesto de relieve en el informe elaborado por la Comisión EuRopeA, «Exploratory study of consumer issues in online peer to peer platform markets. Final report», cit., p. 130, la utilización y reutilización de datos es común entre las plataformas y es una parte esencial de su modelo de negocio. La información que las plataformas facilitan con respecto a la utilización, reutilización, intercambio y venta, en muchos casos, no es plenamente transparente y no está claro si respetan las normas nacionales de protección de datos. Todas ellas indican que comparten datos con terceros, pero no siempre mencionan que lo hacen únicamente con el consentimiento del usuario. Por ello se sugiere que las medidas de acompañamiento destinadas a facilitar la aplicación del Reglamento General de protección de datos incluyan medidas específicas que se centren en las implicaciones para las plataformas en línea P2P. La preocupación por el respeto adecuado a la legislación de protección de datos ha sido puesta de relieve en la «Propuesta de Resolución del Parlamento Europeo sobre las plataformas en línea y el mercado único digital» de 31 de mayo de 2017 (2016/2276): «con frecuencia se incentiva a los usuarios para que compartan sus datos personales con las plataformas en línea; destaca la necesidad de informar a los usuarios sobre la naturaleza exacta de los datos recopilados y la forma en que se utilizarán; subraya que es imprescindible que los usuarios puedan controlar la recopilación y utilización de sus datos personales; insiste en que también debería existir la opción de no compartir los datos personales; observa que la norma del «derecho al olvido» también se aplica a las plataformas en línea; pide a las plataformas en línea que garanticen la protección del anonimato cuando los datos personales sean tratados por terceros». Por su parte, la Comisión de Asuntos Jurídicos, en el mismo informe resalta

«la importancia de garantizar la portabilidad de los datos para todos los usuarios, y en particular para los trabajadores de las plataformas, así como de garantizar la transferibilidad y la acumulación de sus puntuaciones y reseñas en las distintas plataformas, sobre la base del respeto de las normas de la Unión vigentes en materia de protección de datos y de la privacidad de las demás partes implicadas». https://www.europarl.europa.eu/doceo/document/A-8-2017-0204_ES.html (Consultado el 31 de mayo de 2020). Con todo, no creo que sea necesaria una intervención normativa en relación con la protección de datos de los consumidores en las plataformas en línea. Basta que se respete la regulación contenida en el Reglamento General de Protección de datos.

199 Así, en el caso de Amazon, se dispone en sus condiciones de uso que "Realizaremos nuestros mejores esfuerzos para asegurar la disponibilidad, sin interrupciones, de los Servicios de Amazon, así como la ausencia de errores en cualquier transmisión de información que pudiera tener lugar. No obstante, y debido a la naturaleza misma de Internet, no es posible garantizar tales extremos. Asimismo, su acceso a los Servicios de Amazon pudiera ocasionalmente verse suspendido o restringido a efectos de la realización de trabajos de reparación o mantenimiento, o la introducción de nuevos productos o servicios. Procuraremos limitar la frecuencia y duración de tales suspensiones o restricciones". https://www.amazon.es/gp/help/customer/display.html?nodeId=200545940

${ }^{200}$ I. Rodríguez Martínez, El servicio de mediación electrónica ..., cit., p. 156. I. Grimaldos García, "El contrato de intermediación ..., cit., p. 381.

${ }^{201}$ Esta es la calificación que, a juicio del Working Group ont the collaborative eConomy, , "Impulse paper on specific liability issues raised by the collaborative economy in accomodation sector. Paris, Amsterdam, Barcelona, University of Groningen, p. 96, merece el contrato que vincula a los usuarios con las plataformas en línea en España. 
167. Dado que la plataforma tiene la condición de empresario, al contrato que celebre con los usuarios que tengan la condición de consumidores ${ }^{202}$ le será de aplicación la normativa de protección de consumidores contenida en el Texto refundido de la Ley de Consumidores y Usuarios (TRLCU) ${ }^{203}$, particularmente la regulación en materia de contratos a distancia contenida en los arts. 92 y ss. TRLCU y las disposiciones sobre cláusulas abusivas. Cosa distinta es que, como se ha señalado, sea difícil en ocasiones determinar si nos encontramos ante un prosumer o un empresario. A esta regulación hay que sumar la contenida en la Ley 7/1998 de 13 de abril, de condiciones generales de la contratación, dado que en el contrato de acceso se lleva a cabo a través de contrato de adhesión e incorporadas a una pluralidad de contratos.

168. Puesto que, como se ha señalado, las plataformas son prestadores de servicios de la sociedad de la información, les resultan de aplicación las obligaciones establecidas en los arts. 9-12 bis LSSICE. Desde el punto de vista de la responsabilidad de la plataforma, predicado su carácter de mediador electrónico que no contrata directamente con los usuarios la prestación del servicio subyacente, del incumplimiento contractual por parte de cualquiera de los usuarios, de la falta de conformidad del bien o servicio, no se podrá derivar responsabilidad a la plataforma ${ }^{204}$. El deber de transparencia de las condiciones generales se erige en determinante pues es necesario que los usuarios conozcan que no existe ninguna relación de dependencia entre los proveedores y la plataforma de manera que pudiera desencadenar un régimen de responsabilidad civil por el hecho ajeno (art. 1903 CC).

169. De ahí que uno de los principales deberes del gestor de las plataformas sea el deber de información precontractual derivada de la normativa de protección del consumidor antes citada y de su consideración de contrato electrónico (art. 27 LSSICE 60.1 y 97.1. a) TRLCU) donde debe quedar clara su función de mediación y no de prestadora del servicio subyacente, así como de todas las condiciones contractuales (comisiones, cancelaciones, instrumentos de pago y responsabilidades de las partes).

170. En el art. 13 del Borrador de propuesta de directiva sobre plataformas intermediarias en línea se insiste en este deber de información precontractual que compete al gestor de la plataforma ${ }^{205}$ que deberá informar:

a) que el proveedor suministrará bienes, servicios o contenidos digitales en virtud de contratos con clientes y no con el operador de la plataforma,

b) sobre las tarifas debidas al operador de la plataforma y cómo se calculan;

${ }^{202}$ Según el art. 3 TRLCU A efectos de esta norma y sin perjuicio de lo dispuesto expresamente en sus libros tercero y cuarto, son consumidores o usuarios las personas físicas que actúen con un propósito ajeno a su actividad comercial, empresarial, oficio o profesión.

Son también consumidores a efectos de esta norma las personas jurídicas y las entidades sin personalidad jurídica que actúen sin ánimo de lucro en un ámbito ajeno a una actividad comercial o empresarial.

${ }^{203}$ Real Decreto Legislativo 1/2007, de 16 de noviembre, por el que se aprueba el texto refundido de la Ley General para la Defensa de los Consumidores y Usuarios y otras leyes complementarias.

${ }^{204}$ Este aspecto es resaltado en las condiciones de uso que publican las plataformas. Así lo expresa Airbnb: "En calidad de proveedor de la Plataforma Airbnb, Airbnb no posee, crea, vende, revende, suministra, controla, gestiona, ofrece, entrega ni presta ningún Anuncio ni Servicio de Anfitrión. Los Anfitriones son responsables en exclusiva de sus Anuncios y Servicios de Anfitrión. Cuando los Miembros realizan o aceptan una reserva, suscriben un contrato directamente entre ellos. Airbnb no es ni pasará a ser una parte ni un participante en ninguna relación contractual entre Miembros, ni tampoco constituye un agente inmobiliario ni de seguros. Airbnb no actúa como agente en capacidad alguna para ningún Miembro, excepto conforme a lo dispuesto en los Términos de pago". https://www.airbnb.es/terms

Tambien se aclara este extremo en las condiciones de uso de Wallapop: "wallapop no es propietaria de ninguno de los artículos en venta o vendidos a través de su plataforma y no es parte en la transacción de compraventa llevada a cabo exclusivamente entre compradores y vendedores ni revisa o valida los productos que los Usuarios ofrecen a través del Servicio, por lo que wallapop no será responsable, ni directa ni indirectamente, ni subsidiariamente, de los daños y perjuicios de cualquier naturaleza derivados de la utilización y contratación de los contenidos y de las actividades de los Usuarios ylo de terceros a través del Servicio así como de la falta de licitud, fiabilidad, utilidad, veracidad, exactitud, exhaustividad y actualidad de los mismos". https://es.wallapop.com/toc

${ }^{205}$ Research Group on the law of digital Services, "Discussion Draft of a Directive on Online Intermediary Platforms", Journal of European Consumer and Market Law, n 4/2016. 
c) sobre cualquier mecanismo de pago que el operador de la plataforma prevea para los contratos entre proveedor y cliente;

d) sobre cualquier método de transferencia de comunicaciones entre el proveedor y sus clientes,

e) si el operador de la plataforma selecciona clientes para el proveedor y si el proveedor tiene derecho a rechazar a un cliente propuesto.

171. Insiste BPDPL en los deberes de información en el art 11: El operador de la plataforma debe informar al cliente antes de la celebración de un contrato proveedor-cliente de que el cliente celebrará un contrato con un proveedor y no con el operador de la plataforma. En su apartado segundo del art. 11 del BPDPL se establece una obligación que considero novedosa y relevante: El operador de la plataforma debe garantizar que el proveedor informa al cliente de que actúa como comerciante. Este aspecto es sumamente relevante en la medida de que como veremos seguidamente, el régimen jurídico de los contratos celebrados entre los usuarios, está condicionado por la condición de comerciante del proveedor. Dado que en el ámbito de la contratación con plataformas intermediarias es factible que un consumidor actúe como proveedor (prosumer), puede ser difícil determinar cuándo estamos ante una u otra categoría. Con este deber de información se aporta seguridad jurídica a las relaciones contractuales entre los usuarios. La obligación de información pesa sobre el usuario-proveedor, pero es el operador de la plataforma el encargado de garantizar que tal obligación se cumple. De hecho, en muchas plataformas el procedimiento de registro es distinto para empresas y particulares ${ }^{206}$.

172. También corresponde a la plataforma, fruto de su obligación principal de intermediación, el deber de informar al cliente de las condiciones específicas del contrato que va a celebrar con el otro usuario y sobre la marcha de la negociación. Así, deberá remitir las comunicaciones del proveedor al cliente y viceversa. Este aspecto ha sido especialmente contemplado en el BPDPL que dispone en su art. 7 que "cuando la plataforma de intermediación en línea ofrezca facilidades para la comunicación entre el cliente y el proveedor en relación con la conclusión o ejecución de contratos proveedor-cliente, el proveedor de la plataforma deberá remitir las comunicaciones sin demora injustificada. 2. En relación con las comunicaciones entre un proveedor y un cliente, la recepción de la comunicación por parte del sistema de comunicación del operador de la plataforma se considerará como recepción por parte del destinatario si la comunicación ha sido realizada por un consumidor o por un cliente en un contrato entre empresarios".

173. Cabe plantearse si el operador de la plataforma tiene la obligación de controlar la licitud de la información difundida. Si observamos las condiciones de uso de las plataformas comprobamos que la respuesta es negativa ${ }^{207}$. Como acertadamente se ha señalado, los entes gestores tratan de encontrar

\footnotetext{
${ }^{206}$ Así lo hacen, por ejemplo, eBay https://centroparavendedores.ebay.es/anuncios-articulos-ley y Amazon https://services. amazon.es/servicios/vender-por-internet/como-funciona-pro.html\#benefits (Consultado el 10 de junio de 2020).

${ }^{207}$ Así se dice en la plataforma Amazon Marketplace: "No somos responsables de examinar o calificar, ni en ningún caso garantizamos, las ofertas de ninguna de tales empresas o personas fisicas, ni el contenido alojado en sus respectivos sitios web. No asumimos responsabilidad alguna por las acciones, productos y contenidos de ninguna de tales empresas o individuos o cualesquiera otros terceros. El cliente siempre estará informado sobre si un tercero participa en su operación y podremos compartir con dicho tercero cualquier información relativa a dicha operación. Le sugerimos que revise detenidamente las declaraciones de privacidad y demás condiciones de uso de tales terceros". https:/www.amazon.es/gp/help/customer/display. html?nodeId=200545940 En el caso de Airbnb encontramos una cláusula en parecidos términos: "Aunque podremos ayudar a facilitar la resolución de disputas, Airbnb no tiene control sobre, ni garantiza (i) la existencia, calidad, seguridad, idoneidad o legalidad de ningún Anuncio o Servicio de Anfitrión, (ii) la veracidad o exactitud de las descripciones de ningún Anuncio ni de las Evaluaciones, Comentarios y demás Contenido del Miembro (conforme a lo definido a continuación) o (iii) la actuación o la conducta de ningún Miembro o tercero. Airbnb no avala a ningún Miembro, Anuncio o Servicio de Anfitrión. Toda referencia a un Miembro "verificado" (u otro término similar) únicamente indica que ese Miembro ha completado el proceso de verificación o identificación correspondiente, pero no significa nada más. Este tipo de descripción no supone un aval, una certificación ni una garantía por parte de Airbnb acerca de Miembro alguno, incluida la identidad o antecedentes del Miembro o el hecho de que el Miembro sea fiable, seguro o adecuado. Usted debe siempre ejercer la diligencia y atención debidas al decidir si pernocta en un Alojamiento, participa en una Experiencia o Evento o utiliza otros Servicios de Anfitrión, acepta una petición de reserva de un Huésped o comunica e interactúa con otros Miembros, ya sea en línea o en persona. Las Imágenes
} 
convencionalmente un equilibrio entre dos extremos de difícil compatibilidad: generación de confianza y limitación de la responsabilidad ${ }^{208}$. Con ello, los gestores de las plataformas pretenden convertirse en simples albergadores de datos y beneficiarse de las exenciones de responsabilidad previstas en el art. 16 LSSICE, a las que me he referido anteriormente. Sin embargo, como ha señalado el TJUE en sentencia de 12 de julio de 2011 (C-324/09-L'Oreal), tendrán la consideración de prestadores de servicios de la sociedad de la información y, por lo tanto, podrán acogerse a tales exenciones de responsabilidad cuando la actividad de la plataforma sea meramente pasiva, técnica y automática. "Cuando el operador presta una asistencia consistente, entre otras cosas, en optimizar la presentación de venta en cuestión o en promover tales ofertas, cabe considerar que no ha ocupado una posición neutra entre el cliente vendedor correspondiente y los potenciales compradores, sino que ha desempeñado un papel activo que le permite conocer los datos relativos a esas ofertas". Por lo tanto, al margen de lo dispuesto en el clausulado, habrá que enjuiciar el caso concreto para valorar esa capacidad de supervisión y control. Como ya he señalado anteriormente, el concepto de prestador de servicio de intermediación en que estaba pensando la LSSICE y la DCE, era el de un prestador de servicios meramente técnico de acceso a red de comunicación. Las plataformas intermediarias, tal y como he tratado de justificar llevan a cabo una actividad de mediación a través de una infraestructura electrónica, lo cual es distinto de considerar que su actuación es de pura transmisión de datos, mere condiut, como señala el Considerando 43 DCE.

174. De hecho, muchas plataformas hacen público en sus condiciones de uso la existencia de condiciones de eligibilidad de los usuarios ${ }^{209}$, con el objeto de generar confianza en el sistema, lo cual evidencia la existencia de un posible control y supervisión ${ }^{210}$ que tiene consecuencias por mucho que se aclare que no asumen ningún tipo de responsabilidad. En cualquier caso, como digo habrá que atender al caso concreto y examinar la actividad desarrollada por la plataforma a los efectos de determinar su régimen de responsabilidad.

175. Respecto de la información engañosa, el BPDPL establece en su art. 17 la obligación del gestor de la plataforma de eliminar la información engañosa facilitada por los proveedores:

1. Si un proveedor presenta información engañosa en el formulario, y esto se comunica mediante una notificación dirigida al operador de la plataforma, el operador de la plataforma es responsable de los daños causados por la información engañosa, a menos que el operador de la plataforma tome las medidas apropiadas para eliminar o rectificar la información engañosa.

2. Si el operador de la plataforma utiliza un sistema de retroalimentación de reputación para rectificar la información engañosa proporcionada por el proveedor, el operador de la plataforma asume la carga de la prueba de que la información engañosa presentada por el proveedor fue contrarrestada eficientemente a través del sistema de retroalimentación de reputación.

Verificadas (conforme a lo definido a continuación) tienen como intención únicamente indicar una representación fotográfica de un Anuncio en el momento en que la fotografia haya sido realizada, y no suponen, por lo tanto, un aval por parte de Airbnb respecto a Anfitrión o Anuncio alguno". https://www.airbnb.es/terms

${ }^{208}$ T. Rodríguez de las Heras Ballell, 22 El régimen jurídico de los mercados electrónicos cerrados...cit.,p. 394.

${ }^{209}$ Así lo hace Airbnb: “Airbnb podrá supeditar el acceso y uso de la Plataforma Airbnb, o de ciertas áreas o funciones de la misma, a determinadas condiciones o requisitos, como realizar un proceso de verificación, cumplir cualidades concretas o criterios de elegibilidad, satisfacer umbrales de Evaluaciones o Comentarios o un determinado histórico de reservas y cancelaciones". https://www.airbnb.es/terms (Consultado el 12 de junio de 2020).

${ }^{210}$ En el caso de eBay, se establecen una serie de requisitos que deben cumplir los usuarios y también unas consecuencias: "Si consideramos que, de cualquier manera, haces un mal uso de eBay y/o de nuestros Servicios, tendremos derecho, a nuestra entera discreción y sin perjuicio de otros recursos, a limitar, suspender o cancelar tu cuenta o tus cuentas de usuario y el acceso a nuestros Servicios, retrasar o retirar los contenidos, remover cualquier estatus especial asociado a tu cuenta o tus cuentas, eliminar, no mostrar anuncios y/o bajarlos de categoría, reducir o eliminar cualquier descuento y tomar medidas técnicas y/o legales para impedir que utilices nuestros Servicios". https://pages.ebay.com/co/es-co/help/policies/user-agreement.html 
176. En este punto se centra la preocupación de la Comisión Europea: en los riesgos para el consumidor de la información engañosa publicada en la plataforma y en la generalizada falta de transparencia ${ }^{211}$, que se evidencia en varios extremos.

177. En primer lugar, en relación con la falta de información que ofrecen las plataformas respecto de la condición del proveedor del bien o servicio, si tiene la condición de empresario o no ${ }^{212}$. Es el caso, por ejemplo, de las plataformas Airbnb, Peerby, Wallapop, UberPop. Como veremos a continuación, el régimen jurídico aplicable a los contratos entre los usuarios depende y mucho de la condición o no de empresario del proveedor.

178. En segundo lugar, en relación con el precio del bien o servicio, se ha detectado falta de transparencia en cuanto en muchas plataformas no se desglosa el precio del bien del coste de transacción y de otros cargos como pueden ser seguros y gastos de entrega. En muchos casos los resultados de las búsquedas en múltiples plataformas no dan el precio total y las comisiones de las plataformas solo se añaden en la fase de reserva ${ }^{213}$

179. Por último, la extensión de las condiciones de uso y su prolijo lenguaje se ha considerado poco transparente. No se aclaran cuáles son los derechos de los consumidores y quién es responsable de los daños ocasionados. La mayoría de las plataformas se limitan a establecer su exención de su responsabilidad $^{214}$, a pesar de establecer condiciones de uso que afectan directamente a las relaciones entre los usuarios (por ejemplo, gastos de cancelación, devoluciones, gestión de pagos). Como se ha señalado, ello puede hacer creer al usuario que la plataforma asume algún tipo de responsabilidad en caso de falta de cumplimiento del contrato por alguno de los usuarios ${ }^{215}$.

180. Resumiendo, la contratación a través de plataformas intermediarias en línea, respecto a la protección del consumidor, se caracteriza por la falta de transparencia y exenciones de responsabilidad de la plataforma por el incumplimiento de las obligaciones por parte de los usuarios y por la veracidad de la información aportada por éstos y por las opiniones vertidas en el sistema de reputación que normalmente incluyen. Este último aspecto es sumamente relevante. El control de los sistemas de reputación y la capacidad de supervisión de la plataforma sobre el contenido son claves para una eficiente protección del consumidor. Las plataformas se presentan como entes generadores de confianza, pero a su vez, disfrazan jurídicamente su posición de intermediarios de servicios de la sociedad de la información con objeto de beneficiarse de las exenciones de responsabilidad que para estos prevé la LSSICE.

181. En relación con las obligaciones de los usuarios respecto de la plataforma, ya sean proveedores o clientes, la formalización del contrato de acceso a través de la cumplimentación del oportuno formulario de inscripción, les obliga a proporcionar los datos personales y los del bien y servicio ofertado, en el caso de que se trate de proveedores. La falta de conformidad del bien o servicio prestado en relación con el ofertado no implica ningún tipo de responsabilidad con la plataforma, sino con el otro usuario (cliente) que es con el que realmente contratan.

182. En su vinculación con la plataforma, la obligación principal de los usuarios será la de abonar la comisión o tarifa establecida, que normalmente es un porcentaje sobre el precio de venta o prestación del servicio en el momento de la perfección del contrato con el otro usuario.

\footnotetext{
${ }^{211}$ Así lo ha puesto de manifiesto la Comisión Europea en un informe, "Exploratory study of consumer issues in online peer to peer platform markets. Final report" 12/06/2017, http://ec.europa.eu/newsroom/just/item-detail.cfm?item_id=77704,p. 78, en el que analiza los clausulados de varias plataformas, destacando las diferencias entre ellas.

${ }^{212}$ Hay plataformas como BlaBlaCar y easyCar Club que solo permiten el acceso a particulares. Otras permiten el acceso a ambos tipos de usuarios (empresarios y particulares) y exigen que el proveedor aclare si es empresario o no (así lo hacen eBay, Windu y Yoopies).

${ }^{213}$ Comisión EuropeA, "Exploratory study of consumer issues in online peer to peer platform markets. Final report", cit., 80.

${ }^{214}$ COMISIÓN EuRopea,, "Exploratory ... cit., p. 80.

215 COMISIÓn EuropeA, , "Exploratory ... cit., p. 82.
} 


\section{Régimen jurídico aplicable a los contratos celebrados entre los usuarios a través de plataformas intermediarias en línea. En particular, la posición jurídica del prosumidor}

183. El régimen jurídico aplicable a los contratos celebrados entre usuarios, vendrá determinado por su naturaleza. Así, se pueden celebrar contratos entre empresarios (B2B), entre consumidores entre sí $(\mathrm{C} 2 \mathrm{C})$, entre empresario y consumidor $(\mathrm{B} 2 \mathrm{C})$ y entre consumidor (proveedor) y empresario $(\mathrm{C} 2 \mathrm{~B})$.

184. En primer lugar, al margen de la condición de empresario o no del usuario, hay que tener en cuenta que el proveedor que proporciona el bien o servicio no tiene la condición de prestador de servicio de la sociedad de la información. La contratación se realiza a través de la plataforma que es la que tiene tal consideración y su funcionalidad radica precisamente en favorecer el comercio electrónico ${ }^{216}$. Será la plataforma la encargada de que se cumplan, por ejemplo, los deberes precontractuales de información que prevé el art. 27 LSSICE, ya que el proveedor no tiene tal carácter cuando actúa a través de una plataforma intermediaria.

185. Como ya he señalado, la normativa específica de protección del consumidor está diseñada para relaciones verticales, entre empresarios proveedores y consumidores. De esta forma, cuando se trate de contratos entre consumidores (C2C), la normativa de aplicación será el Código Civil, en función del tipo contractual celebrado. Sin embargo, a pesar de que se trate de un contrato entre particulares, lo cierto es que las mismas no se conocen físicamente, la identidad de las partes no es clara, no negocian los términos del contrato que en muchas ocasiones están predispuestos por la propia plataforma que incluye condiciones relativas a los contratos entre particulares ${ }^{217}$. De ahí que la Comisión Europea estime que la regulación contenida en los Códigos civiles no sea adecuada para transacciones entre consumidores concluidas online a través de plataformas de intermediación ${ }^{218}$. Francia ha sido pionera en la adaptación del Código Civil en este punto. La reciente reforma del Código Civil ${ }^{219}$ ha modificado el art. 1171 del Código Civil introduciendo un criterio que estaba hasta la fecha presente en los contratos celebrados con consumidores y empresarios. Según el nuevo art. 1171, los tribunales tienen la facultad de anular las cláusulas "abusivas" que crean "un desequilibrio significativo en los derechos y obligaciones de las partes" en los contratos de adhesión (cláusulas no negociadas). Los términos que pueden ser anulados son aquellos que no tienen relación con el objeto del contrato o su precio. Anteriormente, con arreglo al Derecho francés codificado, este principio sólo era aplicable en el caso de los contratos de consumo. Se traslada la regulación en materia de cláusulas abusivas a los contratos entre consumidores.

186. La particularidad de régimen que presentan los contratos $\mathrm{C} 2 \mathrm{C}$ celebrados a través de plataformas es que se rigen en muchos casos por cláusulas que predispone la propia plataforma que no es parte en el contrato. No se puede olvidar que la Ley 7/1998, de 13 de abril, sobre Condiciones Generales de la Contratación (LCGC) y los mecanismos de protección allí establecidos para la protección del adherente están diseñados para los supuestos es los que una de las partes contratantes es el predisponente (al margen de la autoría material de las cláusulas) ${ }^{220}$ y otra parte contractual es la adherente. Ninguna de

${ }^{216}$ El problema de la calificación que merecen los servicios prestados por un proveedor cuando se limita a recibir los servicios de comercio electrónico de un tercero, es planteado por S. CAVANILLAS, "La conclusión del contrato en internet" en Cavanillas, S., y Meoro, C., Responsabilidad civil y contratos en internet, Granada, 2003, Ed., Comares, p. 131. A su juicio, no queda claro quién es en este caso el prestador de servicios de la sociedad de la información que realiza la actividad de contratación electrónica a través de un tercero.

${ }^{217}$ El estudio realizado por la Comisión Europea ("Exploratory study of consumer issues in online peer to peer platform markets. Final report”, cit., p. 80) abarca el análisis de 485 plataformas de las cuales el $35 \%$ prevén reglas en sus condiciones de uso que afectan a los contratos entre particulares. Así sucede, por ejemplo, con las plataformas Airbnb, BlaBlaCar, eBay, UberPop. Destacan las reglas relativas a las políticas de cancelación https://www.blablacar.es/conoce-blablacar/condiciones-generales-de-uso

${ }^{218}$ COMISIÓN EUROPEA, "Exploratory study of consumer issues in online peer to peer platform markets. Final report", cit., p. 102.

${ }^{219}$ Ordinance ${ }^{\circ} 2016-131$, de 10 de febrero de 2016.

${ }^{220}$ Como señala R. Bercovitz Rodríguez-Cano, "Comentario al art. 1 LCGC” en R. Bercovitz Rodríguez-Cano (Dir.), Comentario a la Ley de Condiciones Generales de la contratación, Thomson Aranzadi, 1999, p. 26, "son CGC las cláusulas ya 
las partes contractuales predispone las condiciones generales presentes en el contrato entre los usuarios, sino que ambos se adhieren a un contrato predispuesto por un tercero que no es parte. El ámbito subjetivo de aplicación de la LCGC son los contratos que contengan condiciones generales celebrados entre un profesional -predisponente- y cualquier persona física o jurídica -adherente-. Hay aquí otro agujero regulatorio que merece especial atención ${ }^{221}$.

187. La inaplicación de las normas de protección de los consumidores, deja huérfanos de solución los desequilibrios que pueden producirse en la contratación entre "iguales". Para que podamos hablar de contratos $\mathrm{C} 2 \mathrm{C}$, es necesario que una de las partes sea proveedora, la cual, si no tiene la condición de empresaria, será considerado "prosumidor", no aplicándose la normativa en materia de protección de consumidores $^{222}$. Baste un ejemplo para "visualizar" las consecuencias. Si se tratara de una compraventa en línea, si el vendedor es un particular, se aplica el Código Civil y la responsabilidad por vicios ocultos será la contemplada en los arts. 1484 CC: 6 meses para reclamar al vendedor a contar desde la entrega de la cosa. de conformidad que se manifiesten en un plazo de dos años desde la entrega del bien, en el caso de bienes nuevos, pudiendo pactar, en los productos de segunda mano, un plazo menor, que no podrá ser nunca inferior a un año desde la entrega (art. 123 TRLGDCU) ${ }^{223}$

188. No puede exigirse a un particular proveedor no profesional que tenga las habilidades y recursos técnicos, legales y organizativos de los que disponen los comerciantes y las empresas profesionales. Como se ha señalado, mientras que un productor profesional de automóviles o máquinas de café puede reparar o reemplazar fácilmente un producto defectuoso, este requisito exigido por la regulación en materia de garantías de bienes de consumo (arts. 118 y ss. TRLCU) puede plantear dificultades para un prosumer que ha vendido su coche o máquina de café. Del mismo modo, cumplir con el extenso catálogo de deberes de información puede ser un reto importante para los particulares proveedores, que pueden no poseer toda la información requerida. Si se aplican de manera inapropiada, los requisitos legales mal adaptados podrían constituir un desincentivo para que los proveedores y consumidores se involucren en plataformas de pares en primer lugar ${ }^{224}$.

189. Más dudas se plantean en si cabe considerar como relación de consumo la entablada $\mathrm{C} 2 \mathrm{~B}$ siendo el consumidor es el proveedor del bien o servicio (prosumidor) en un contrato con un empresario. Efectivamente, cuando el proveedor actúa con un propósito ajeno a su actividad empresarial o profesional (prosumer) se plantea el problema general de si puede ser considerado consumidor cuando es proveedor de servicio de financiación a un empresario que actúa en el ámbito de su actividad profesional o empresarial. El Derecho de consumo parte de la necesidad de corregir los desequilibrios e información asimétrica que tienen lugar entre prestadores profesionalizados que imponen sus condiciones contractuales y consumidores con escasos conocimientos que carecen de margen en la contratación. La protección del consumidor es una protección frente al empresario, frente a quien se dedica a comercializar en el mercado los bienes y servicios que él adquiere y/o utiliza o disfruta. Se trata de compensar esta

preparadas previamente, predispuestas por un profesional para ser utilizadas en la contratación propia de su actividad profesional o empresarial. La predisposición no implica autoría, que normalmente corresponderá a un tercero o incluso será anónima. Debe entenderse la "autoría material" del Texto legal como autoría a secas. Por ello carece de sentido indagar en la finalidad perseguida por el autor de las cláusulas contractuales". En nuestro caso, el promotor de la financiación no utiliza las cláusulas redactadas por la plataforma, sino que se "ve obligado" a utilizar las cláusulas materialmente redactadas por la PFP en su contrato con el inversor. Por eso, parece ciertamente injusto que se pueda ver afectado por acciones de nulidad o no incorporación.

${ }^{221}$ Trato este problema para los contratos de préstamo a través de plataformas de financiación participativa, en mi trabajo, "Las FinTech de prestamos..., cit., pp- 262 y ss.

${ }^{222}$ S. CÁmara Lapuente, "El concepto legal de "consumidor" en el Derecho privado europeo y en el Derecho español: aspectos controvertidos o no resueltos", Cuadernos de Derecho Transnacional (marzo,2011), Vol. 3, No 1, p. 114. https://erevistas.uc3m.es/index.php/CDT/article/viewFile/1068/387 (Consultado el 29 de mayo de 2020).

${ }^{223}$ Pone de relieve esta disfunción M.F., MarTín Moral, "Economía colaborativa y protección del consumidor Revista de Estudios Europeos No 70, julio-diciembre, 2017-185-203

${ }^{224}$ OCDE, "Protecting consumers in peer platform markets. Exploring the issues, $2016 \mathrm{http} / /$ unctad.org/meetings/es/Contribution/dtl-eWeek2017c05-oecd_en.pdf (Consultado el 30 de mayo de 2020), p. 21. 
desventaja del consumidor frente al empresario. Se parte de que el consumidor es un sujeto cautivo en su relación con el mercado, puesto que no tiene más remedio que consumir bienes y servicios ${ }^{225}$.

190. La definición de consumidor contemplada en el art. 3 TRLCU no atiende a la posición que éste tiene en la relación jurídica ${ }^{226}$ es decir, si es o no proveedor del bien o servicio ${ }^{227}$. Tal precepto se limita a señalar que son consumidores o usuarios las personas físicas que actúen con un propósito ajeno a su actividad comercial, empresarial, oficio o profesión. Un criterio de interpretación literal no permite privar al consumidor de su condición de tal por el mero hecho de que sea proveedor del bien o servicio. De ahí que se haya estimado "sigue existiendo una relación entre un consumidor y un profesional, donde el fundamento de la desigualdad jurídica, negociadora y económica seguirá vigente y no existe exclusión legal de este tipo de relaciones" y normalmente la contratación se realizará a través de un contrato de adhesión $^{228}$. Aunque el fundamento de la regulación europea, y la nacional española que es su consecuencia, es la posición de desequilibrio contractual en la que se encuentra, la conceptuación de consumidor no atiende a la vulnerabilidad, sino a la extraprofesionalidad. Nos guste o no, este es el criterio impuesto legalmente.

191. Por tanto, el proveedor consumidor encaja en el concepto del art. 3 y en el art. 2 TRLCU ${ }^{229}$ y no se puede obviar que se trata de un concepto normativo, no valorativo. No es preciso entrar a enjuiciar en cada caso si se dan los presupuestos que justificaron, desde un planteamiento teleológico, la protección de los consumidores. Entiendo que sí se produce una relación de consumo en los contratos $\mathrm{C} 2 \mathrm{~B}$, siendo aplicables los deberes de información precontractual, derecho de desistimiento y normas sobre cláusulas abusivas ${ }^{230}$.

192. No hay duda de que, en relación con los contratos B2C, sí será de aplicación la normativa en materia de protección del consumidor recogida en el Texto Refundido de la Ley de Consumidores y Usuarios (Real Decreto Legislativo 1/2007, de 16 de noviembre), así como la Ley de Condiciones Generales de la Contratación (Ley 7/1998, de 13 de abril) y el Código Civil. El proveedor debe proporcionar, cuando perfecciona su contrato de acceso a la plataforma, toda la información sobre el bien o servicio requerida por la normativa de protección de consumidores.

${ }^{225}$ R. Bercovitz Rodríguez-Cano, R., "Comentario al art. 2 TRlCU” en Bercovitz, R., (Coord.) Comentario del Texto Refundido de la Ley General para la defensa de los Consumidores y Usuarios y otras leyes complementarias, Thomson Reuters Aranzadi, 2015, p. 50 y 55.

${ }^{226}$ Sí era claro en este punto el art. 2 de la Ley 26/1984, de 19 de julio, General para la Defensa de los Consumidores y Usuarios: "A los efectos de esta Ley, son consumidores o usuarios las personas fisicas o jurídicas que adquieren, utilizan o disfrutan como destinatarios finales, bienes muebles o inmuebles, productos, servicios, actividades ofunciones, cualquiera que sea la naturaleza pública o privada, individual o colectiva de quienes los producen, facilitan, suministran o expiden".

${ }^{227}$ Sí se ha atendido a esta cuestión en varias normas comunitarias, como es el caso de la Directiva 2011/83 UE del Parlamento Europeo y del Consejo de 25 de octubre de 2011 sobre los derechos de los consumidores, por la que se modifican la Directiva 93/13/CEE del Consejo y la Directiva 1999/44/CE del Parlamento Europeo y del Consejo y se derogan la Directiva 85/577/CEE del Consejo y la Directiva 97/7/CE del Parlamento Europeo y del Consejo. En su art. 2.5 relativo al contrato de compraventa, posiciona al consumidor como comprador. En el art. 2.6 relativo a la prestación de servicios, el proveedor es el comerciante. No se aplica tal regulación al supuesto en que el proveedor es consumidor. También la Ley 22/2007, de 11 de julio, sobre comercialización a distancia de servicios financieros destinados a los consumidores, delimita su ámbito de aplicación a los supuestos en los que el consumidor es el receptor de la financiación.

${ }^{228}$ S. CÁmara Lapuente, "El concepto legal de consumidor en el Derecho privado europeo y en el Derecho español: aspectos controvertidos o no resueltos", Cuadernos de Derecho Transnacional (marzo, 2011), Vol. 3, No 1, https://e-revistas.uc3m. es/index.php/CDT/article/viewFile/1068/387 p. 113. L. ARnau Raventós, “ La noció de consumidor i la incorporació de les normes en materia de contractació amb consumidors al Llibre sisè del Codi Civil de Catalunya", p. 40, Revista Catalana de Dret Privat, Vol. 9, 2008, p. 41. Desde el punto de vista del Derecho de la UE, cf. E. MONTERO, « Régime juridique des sites de ventes aux enchères sur Internet », Droit de la consommation n ${ }^{\circ}$ 90, 2011, p.80.

${ }^{229}$ En este sentido, R. Bercovitz Rodríguez-Cano, op., cit., p. 55. No obstante, entiende que en el caso del consumidor que esporádicamente suministra bienes y servicios, no se trata de un sujeto cautivo en su relación con el mercado y, consiguientemente, cliente cautivo de los empresarios como colectivo. En esto es en lo que radica, principalmente la desigualdad entre empresarios y consumidores, y la consiguiente conveniencia de proteger a éstos frente a aquéllos. Desaparecida esta circunstancia, la conveniencia de proteger a éstos frente a aquéllos se desvanece.

${ }^{230}$ S. Cámara Lapuente, op. cit., p. 114. 


\section{Recapitulación. Retos jurídicos que plantea la economía de la plataforma}

193. Son muchos los problemas que plantea la contratación de bienes y servicios a través de plataformas intermediarias en línea. El aspecto principal que creo que compete aclarar es el de la responsabilidad, habida cuenta que el desarrollo tecnológico ha hecho que emerjan nuevos intermediarios que no parecen encajar en el concepto de prestador de servicios de intermediación de servicios de la sociedad de la información. La confusión al respecto está generando una importante litigiosidad en relación con la aplicación o no de las exenciones de responsabilidad previstas en el art. 14 DCE. Este aspecto parece será objeto de inminente regulación a nivel europeo ${ }^{231}$. Ha nacido un nuevo modelo de prestador de servicio de la sociedad de la información, que tiene una posición activa y muy protagonista en las transacciones que debe reflejarse en su régimen de responsabilidad no estando justificados para estos operadores los puertos seguros o exenciones de responsabilidad previstas en la DCE ${ }^{232}$

194. El establecimiento de criterios claros conceptuales que permitan determinar cuándo se considera que la plataforma presta o no el servicio subyacente, la necesaria transparencia sobre su papel en la contratación y unas adecuadas reglas para el diseño de los sistemas de reputación son aspectos claves que deben regularse desde una norma general que aborde esta modalidad de contratación a través de plataformas y no tanto por sectores de actividad. Debe huirse de la ploriferación normativa de una misma actividad, incoherente y solapada, algo que ya hemos padecido con la regulación europea en materia de protección de consumidor.

195. La posición del prosumer, la regulación de las relaciones entre consumidores cuando contratan a través de plataformas exige una adaptación de las normas contenidas en el Código Civil. Dicha contratación se realiza a través de contratos de adhesión, siendo en algunas ocasiones cláusulas predispuestas por la propia plataforma que, no obstante, no se convierte en parte de dicho contrato. Por más que los consumidores acepten en el contrato de acceso tales reglas contractuales, el contrato de compraventa o prestación de servicios se produce entre particulares, contrato al que no es de aplicación la regulación contenida en la LSSICE en materia de contratación electrónica no es aplicable a contratos entre consumidores ${ }^{233}$.

196. A mi juicio, es necesaria una intervención legislativa europea que aborde de manera general la problemática que encierra la contratación a través de intermediarios en línea. La Directiva 2019/2161 ${ }^{234}$ de 27 de noviembre sobre la mejora de la aplicación y la modernización de las normas de protección de los consumidores de la UE resuelve algunos problemas, pero deja fuera un tratamiento más completo

${ }^{231}$ En este sentido, el Parlamento Europeo, "Propuesta de resolución del PE sobre las plataformas en línea y el mercado único digital" de 31 de mayo de 2017 (2016/2276)", hace hincapié en este aspecto: "debe aclarase en mayor medida el régimen de responsabilidad, dado que se trata de un pilar crucial para la economía digital de la Unión; considera que se requieren unas orientaciones de la Comisión sobre la aplicación del marco de responsabilidad de los intermediarios para que las plataformas en línea puedan cumplir sus obligaciones y las normas sobre responsabilidad, reforzar la seguridad jurídica y aumentar la confianza de los usuarios; pide a la Comisión que adopte nuevas medidas a tal fin, recordando al mismo tiempo que las plataformas que no desempeñen un papel neutro, tal como se define en la Directiva sobre el comercio electrónico, no pueden acogerse a la exención de responsabilidad".

${ }^{232}$ Como señala G. Frosio, "Reforming Intermediary Liability in the Platform Economy: A European Digital Single Market Strategy" (6 de febrero de 2017). 112 Northwestern University Law Review 19 (2017). SSRN: https://ssrn.com/abstract $=2912272$ (Consultado el 13 de junio de 2020), la reforma debe llevarse a cabo desde la DCE, y no por sectores de actividad, una reforma con cautela para evitar que los prestadores de servicios de intermediación se conviertan en "policías de internet". Sin duda habrá que buscar un punto de equilibrio para que estos agujeros regulatorios inviten a convertir la red en un terreno propicio para la violación de los derechos. Buen ejemplo de ello es el ejemplo de los sistemas de reputación online y la impunidad que alimentan cuando se lesiona el honor y la reputación de los proveedores.

${ }^{233}$ S. Cavanillas, "La conclusión del contrato en internet" en Cavanillas, S., y Meoro, C., Responsabilidad civil y contratos en internet, Granada, 2003, Ed., Comares, p. 132.

${ }^{234}$ Directiva del Parlamento Europeo y del Consejo de 27 de noviembre de 2019 por la que se modifican la Directiva 93/13/ CEE del Consejo, de 5 de abril de 1993, la Directiva 98/6/CE del Parlamento Europeo y del Consejo, la Directiva 2005/29/CE del Parlamento Europeo y del Consejo y la Directiva 2011/83/UE del Parlamento Europeo y del Consejo, en lo que atañe a la mejora de la aplicación y la modernización de las normas de protección de los consumidores de la UE. 
de los sistemas de reputación online y no hay mecanismos sancionadores adecuados al respecto, los cuales se dejan en manos de los Estados miembros. La posibilidad de operaciones transfronterizas es mayor en esta modalidad de contratación y debe avanzarse en la armonización en el terreno sancionador.

197. Falta una regulación detallada de la ordenación de los resultados de búsqueda en las plataformas de las ofertas de los productos y servicios lo que pone en cuestión el esquema tradicional de deber de información precontractual al consumidor. Efectivamente, en la contratación a través de plataformas intermediarias en línea, sobre todo en los mercados electrónicos, las ofertas se basan en el uso de algoritmos que proporcionan a los consumidores una experiencia de compra personalizada. Gracias a la gran gestión de datos, muchas tareas y decisiones se confían a sistemas basados en la toma de decisiones algorítmicas (inteligencia artificial). La información del producto se dirige específicamente a los consumidores en función de un perfil diseñado por algoritmos, hasta el punto de que el precio del producto se determina en función del perfil del consumidor (precio personalizado) ${ }^{235}$. La oferta personalizada dificulta la comparación con otras ofertas y la clasificación de las ofertas puede ser opaca y los algoritmos pueden ser manipulables. Los consumidores deben estar capacitados para comprender cómo se organizan y presentan la información y las ofertas. La transparencia se torna fundamental.

198. La Directiva 2019/2161 citada, introduce en el nuevo art. 6 bis de la Directiva 2011/83 una mención muy general a esta cuestión señalando que la obligación el mercado en línea facilitará

${ }^{235}$ Se destaca este extremo el informe elaborado por EUROPEAN CONSUMER ORGANIZATION, "Ensuring consumer protection in the platform economy", 2/10/2018 https://www.beuc.eu/publications/beuc-x-2018-080_ensuring_consumer_protection_in_ the platform_economy.pdf (Consultado el 20 de mayo de 2020), p. 5. El precio de los productos en las plataformas también se fija en función de algoritmos personalizándolo para el usuario. Así, por ejemplo, Amazon, utiliza el algoritmo Dynamic Pricing que toma automáticamente decisiones de cambio de precio en función del a competencia, de las ventas de dicho producto y de las características del cliente. Hay que distinguir los "precios dinámicos", del precio personalizado. En los primeros, se cambia el precio de un producto de una manera muy flexible y rápida en respuesta a las demandas del mercado. Muy típico en medios de transporte, un billete de tren o de avión es distinto en función del día en que se hace la reserva.

Por el contrario, en los precios personalizados el precio para el cliente concreto es distinto en función de su historial de compras, el tiempo que has estado buscando el producto incluso en otras páginas web (datos que recaba gracias a las famosas cookies).

Se crean 'perfiles de compra' basados en compras anteriores de sus clientes en línea, lo que permite al comerciante adaptar sus precios. La amplia disponibilidad de datos personales en internet y en los dispositivos del internet de las cosas, así como la capacidad de hacer correlaciones y crear vínculos puede permitir determinar, analizar y predecir ciertos aspectos de la personalidad o el comportamiento, los intereses y los hábitos de una persona. Un cliente clasificado como de "mayor poder adquisitivo" podría ser reconocido por la dirección IP del ordenador o por otros medios, como una cookie, cuando el consumidor visita el sitio web del comerciante desde su ordenador de origen. Los precios propuestos a este cliente podrían ser, por ejemplo, por término medio un $10 \%$ superiores a los de un nuevo cliente o a los de un cliente clasificado como de "menor poder adquisitivo".

En definitiva, como señala J. ALFARO, "se trata de cobrarle al cliente el precio máximo que está dispuesto a pagar". https:// www.elconfidencial.com/tecnologia/2018-05-13/precios-personalizados-webs-viajes_1562301/ (Consultado el 20 de febrero de 2019). Tales datos son procesados a través de técnicas de inteligencia artificial y los algoritmos predicen la capacidad económica y el precio es personalizado. Vid. SANCHEZ, J., "La muerte del precio fijo: por qué tú y yo no compraremos lo mismo por el mismo precio". https://www.revistagq.com/noticias/tecnologia/articulos/big-data-algoritmos-fin-del-precio-fijo/25953 (Consultado el 20 de febrero de 2019). La "locura" de la fijación de precios a través de algoritmos puede conducir a resultados sorprendentes como que un libro se venda a 35 dólares un día y dos días más tarde a \$1,730,045.91, M. EISEN, “Amazon's $\$ 23,698,655.93$ book about flies" http://www.michaeleisen.org/blog/?p=358 (Consultado el 20 de marzo de 2019). En cuanto al impacto en el consumidor de esta modalidad de fijación de precios se ha señalado que, debido al efecto de transferencia de riqueza asociado a la personalización de los precios de un producto o servicio, los consumidores son menos capaces de gastar en otros productos o servicios. Por lo tanto, el efecto de expansión de la producción para el producto o servicio en particular sujeto a precios personalizados se produce a expensas de la producción (consumo) de otros productos y servicios.

En segundo lugar, el efecto de expansión de la producción es limitado en situaciones en las que la producción es limitada. En el caso de los servicios digitales con costes marginales casi nulos, en la práctica la producción es casi ilimitada. Pero en el caso del comercio electrónico de productos tangibles, es probable que la producción sea limitada. En tales casos, cabría esperar que la empresa vendiera su producción limitada a los clientes más ricos como una cuestión prioritaria, sin dejar nada para los clientes menos acomodados. Este escenario constituye una excepción a la idea de que los consumidores menos acomodados podrán comprar un producto que de otro modo no habrían podido permitirse.

Cfr. DIRECTORATE FOR FINANCIAL AND ENTERPRISE AFFAIRS COMPETITION COMMITTEE (OCDE), "Personalised Pricing in the Digital Era - Note by the European Union" 20 de noviembre de 2018. https://one.oecd.org/document/ DAF/COMP/WD(2018)128/en/pdf (Consultado el 23 de mayo de 2020). 
al consumidor información sobre "los principales parámetros que determinan la clasificación de las ofertas presentadas al consumidor como resultado de su consulta en el mercado en línea". Lo decisivo es el peso que tiene cada criterio para que las ofertas se presenten al consumidor. Así, como ha puesto de relieve en un informe la Organización de Consumidores Europeos "los consumidores podrían pensar que las ofertas que ven en las plataformas de reserva en línea para servicios de viajes como Booking. com se basan en el valor y la relevancia de cada oferta y se evalúan sobre la base de los comentarios de los usuarios. La realidad es que a menudo los proveedores de servicios específicos han pagado para que sus ofertas sean promovidas, o que las ofertas promovidas son las que dan a la plataforma el mayor margen de beneficio. Todo esto no se revela y explica adecuadamente. De las principales plataformas de reservas online en Alemania, sólo Booking.com menciona en sus términos y condiciones que su clasificación por defecto está influenciada por la comisión que pagan los hoteles. Pero esta información no se divulga adecuadamente, sino que se oculta en los términos y condiciones. Esto conduce a una situación muy engañosa para los consumidores ${ }^{236 "}$.

199. Debe informarse a los consumidores sobre el hecho de que se usan algoritmos para presentar ofertas o determinar precios, sus criterios y cuáles son los que prevalecen, los datos que se utilizan y si se personaliza la fijación de los precios. El consumidor debe conocer si los proveedores de servicios específicos han pagado para que sus ofertas sean promovidas, es decir, las ofertas promovidas son las que dan a la plataforma el mayor margen de beneficio. Y ello sin olvidar el derecho que corresponde al usuario a oponerse al uso de sus datos para finalidades distintas para las que fueron recopilados, como le autoriza la regulación en materia de protección de datos personales ${ }^{237}$. Con todo, la Directiva 2019/2161 modifica el art. 6 de la Directiva 2011/83 sobre derecho de los consumidores dedicado a los deberes de información precontractual en contratos a distancia. Dispone el nuevo apartado e) bis del art. 6 que el comerciante debe informar "cuando corresponda, que el precio ha sido personalizado basándose en la toma de decisiones automatizada". Tal y como se establece en el Considerando 45, la personalización del precio no está prohibida, sino que tan solo hay deber de informar sobre ello, sin que queden claros qué datos se utilizan para la personalización de los precios.

${ }^{236}$ EUROPEAN CONSUMER ORGANISATION "Ensuring consumer protection in the platform economy", 2/10/2018 https://www. beuc.eu/publications/beuc-x-2018-080_ensuring_consumer_protection_in_the_platform_economy.pdf (Consultado el 20 de mayo de 2020), p.5.

${ }^{237}$ No hay que olvidar que el art. 22 RGPD dispone que "todo interesado tendrá derecho a no ser objeto de una decisión basada únicamente en el tratamiento automatizado, incluida la elaboración de perfiles, que produzca efectos jurídicos en él o le afecte significativamente de modo similar". Se excepciona la regla cuando es necesaria para la celebración o la ejecución de un contrato entre el interesado y un responsable del tratamiento b) está autorizada por el Derecho de la Unión o de los Estados miembros que se aplique al responsable del tratamiento y que establezca asimismo medidas adecuadas para salvaguardar los derechos y libertades y los intereses legítimos del interesado, c) se basa en el consentimiento explícito del interesado.

Como se señala en documento elaborado por el GRUPO DE TRABAJO SOBRE PROTECCIÓN DE DATOS DEL ARTículo 29, "Directrices sobre decisiones individuales automatizadas y elaboración de perfiles a los efectos del Reglamento" 2016/67917/ES WP251 rev.01, https://ec.europa.eu/newsroom/article29/item-detail.cfm?item id=612053 (consultado el 22 de mayo de 2020), señala que "la elaboración de perfiles y las decisiones automatizadas pueden plantear riesgos importantes para los derechos y libertades de las personas que requieran unas garantías adecuadas. Estos procesos pueden ser opacos y puede que las personas no sean conscientes de que se está creando un perfil sobre ellas y que no entiendan lo que implica. La realización de perfiles puede perpetuar los estereotipos existentes y la segregación social. Así mismo, puede encasillar a una persona en una categoría específica y limitarla a las preferencias que se le sugieren. Esto puede socavar su libertad a la hora de elegir, por ejemplo ciertos productos o servicios como libros, música o noticias. A veces las predicciones son inexactas. Las decisiones automatizadas que provoquen diferencias de precios sobre la base de datos o características personales también podrían tener un efecto significativo si, por ejemplo, unos precios prohibitivamente elevados impiden que una persona acceda a determinados bienes o servicios. Según este informe, la elaboración de perfiles automatizados para diseñar un precio personalizado no tiene como título de legitimación el que sea necesario para la celebración del contrato. Normalmente estos datos se usan para elaboración de perfiles con base en el consentimiento para el procesamiento de los datos de navegación a través de las cookies. Con todo, según la normativa contenida en el RGPD, los responsables del tratamiento deben garantizar que explican a las personas de forma clara y sencilla el funcionamiento de la elaboración de perfiles o las decisiones automatizadas. El Considerando 60 RGPD establece que facilitar información acerca de la elaboración de perfiles forma parte de las obligaciones de transparencia del responsable del tratamiento según el art. 5.1a). El interesado tiene derecho a ser informado por el responsable del tratamiento, en determinadas circunstancias acerca de su derecho de oposición a la elaboración de perfiles, independientemente de si se han producido decisiones individuales basadas únicamente en el tratamiento automatizado sobre la base de la elaboración de perfiles. 
200. Resulta sorprendente que este aspecto no haya sido más desarrollado en la Directiva 2019/2161 citada $^{238}$ que afecta a las relaciones de la plataforma con los consumidores y sí lo sea con mayor intensidad en el Reglamento 2019/1150 sobre el fomento de la equidad y la transparencia para las empresas que utilizan servicios de intermediación en línea de 20 de junio de 2019. El Reglamento se centra en las relaciones entre las plataformas que prestan servicios de intermediación en línea y motores de búsqueda con los proveedores de bienes y servicios a consumidores. Que una empresa aparezca antes o después en los motores de búsqueda puede influir de manera significativa en el éxito comercial. Como se señala en el Considerando tercero, "la clasificación de los sitios web que elaboran los proveedores de motores de búsqueda electrónicos, incluida la de los sitios web donde las empresas ofrecen sus bienes y servicios a los consumidores, tiene un impacto significativo en la posibilidad de elección de los clientes y en los resultados comerciales de tales usuarios de sitios web corporativos. Incluso a falta de una relación contractual con estos usuarios, los proveedores de motores de búsqueda en línea pueden, por consiguiente, actuar en la práctica de una manera unilateral que puede ser injusta y perjudicar a los intereses legitimos de los usuarios de los sitios web corporativos y, de modo indirecto, también de los consumidores europeos".

201. Por esta razón, el art. 5 del Reglamento se ocupa de regular la necesaria transparencia de los parámetros principales que rigen la clasificación y los motivos por los que aquellos cuentan con una importancia relativa superior a la de otros parámetros. Este último aspecto es clave, así como la referencia a la posible remuneración por parte de las empresas a la plataforma para priorizar su aparición en los motores de búsqueda. No parece razonable que el nivel de protección de los consumidores sea menor que el de los empresarios sobre este extremo que me parece decisivo. Los motores de búsqueda desempeñan un papel fundamental en el comportamiento de los consumidores en línea como guardianes de la web, por lo que es imprescindible una total transparencia en cuanto a su funcionamiento.

202. En suma creo que debe diseñarse una regulación general de la contratación a través de plataformas intermediarias en línea que proteja a los usuarios del sistema con las especificaciones que correspondan en función de su consideración como empresarios o consumidores. Ambos tipos de usuarios tienen problemas comunes (sistemas de reputación, parámetros de clasificación en motores de búsqueda) y hay que huir de la doble regulación de una misma realidad.

203. Francia ha sido uno de los países pioneros en abordar una regulación específica de la contratación a través de plataformas intermediarias en línea. La Ley n ${ }^{\circ}$ 2016-1321 de 7 de octubre de 2016 pour une Repúblique numérique ${ }^{239}$, modifica entre otras normas el Código de Consumo introduciendo normas específicas para esta modalidad de contratación. Concretamente, la sección tercera se titula "Lealtad de las plataformas y protección del consumidor".

204. Se modifica el art. 111-7 del Código de Consumo que define al operador de la plataforma como toda persona física o jurídica que ofrezca, con carácter profesional, remunerado o no, un servicio público de comunicación en línea basado en:

$1^{\circ}$ La clasificación o referenciación, mediante algoritmos informáticos, de contenidos, productos o servicios ofrecidos o puestos en línea por terceros;

$2^{\circ} \mathrm{O}$ la vinculación de varias partes con el fin de vender un bien, prestar un servicio o intercambiar o compartir contenido, un bien o un servicio.

Se incluyen pues, de manera expresa, los motores de búsqueda online.

${ }^{238}$ Hay que decir que también dicha directiva modifica la Directiva sobre competencia desleal (2005/29). El nuevo Art. 7 , apartado 4 bis, dispone que el titular de una plataforma tiene que facilitar información general relativa a los principales parámetros que determinan la clasificación. Pero no se especifica el contenido de la obligación sobre todo cuando afecta a consumidores.

${ }^{239} \mathrm{https}$ ://www.legifrance.gouv.fr/affichTexte.do?cidTexte=JORFTEXT000033202746\&categorieLien=id (Consultado el 3 de junio de 2020). 
205. La necesidad de transparencia en la contratación se pretende lograr con el cumplimiento por parte del operador de la plataforma quien debe proporcionar a los consumidores información justa, clara y transparente sobre el papel de la plataforma debiendo declarar "las condiciones generales de uso del servicio de intermediación que ofrece y sobre las modalidades de referenciación, clasificación $y$ descentralización de los contenidos, productos o servicios a los que este servicio permite el acceso".

206. Deben aclararse los parámetros de clasificación de los proveedores de servicios. La información es más detallada que la contenida en la Directiva 2019/2161 que modifica la Directiva 2011/83. La norma francesa exige que se informe sobre "la existencia de una relación contractual, de un vínculo de capital o de una remuneración en su beneficio, en cuanto influyan en la clasificación o referenciación de los contenidos, bienes o servicios ofrecidos o puestos en línea". De esta forma, el consumidor tendrá conocimiento de que las ofertas que aparecen mejor posicionadas no necesariamente son las mejor valoradas por los clientes, sino, en su caso, por ser especialmente remuneradas por el proveedor a la plataforma.

207. Es el operador de la plataforma el que tiene que informar de si el proveedor es comerciante o no y además especificar el contenido obligacional. Así, se dispone que deberá informar de "la calidad del anunciante y los derechos y obligaciones de las partes en materia civil y fiscal, cuando se pone en contacto a los consumidores con profesionales o no profesionales".

208. Se establece una remisión a desarrollo reglamentario del precepto y se especificará para cualquier operador de una plataforma en línea cuya actividad consista en proporcionar información que permita comparar los precios y las características de los bienes y servicios ofrecidos por los profesionales, la información comunicada a los consumidores sobre los elementos de esta comparación y lo que constituye publicidad en el sentido del artículo 20 de la Ley $N^{o}$ 2004-575, de 21 de junio de 2004, sobre la confianza en la economía digital.

209. Este decreto establece las modalidades según las cuales, cuando los profesionales, vendedores o prestadores de servicios se pongan en contacto con los consumidores, el operador de la plataforma en línea les proporcionará un espacio que les permita comunicar a los consumidores la información prevista en los artículos L. 221-5 y L. 221-6". Estos preceptos se refieren a los deberes precontractuales de información que deben cumplir los profesionales que contratan con consumidores.

210. Se prevé así mismo la posibilidad de la autoridad administrativa competente evaluará y comparará las prácticas de los operadores de plataformas en línea mencionados en el párrafo primero del presente artículo. A tal fin, podrá recabar de estos operadores la información necesaria para el cumplimiento de esta tarea y difundirá periódicamente los resultados de estas evaluaciones y comparaciones y publicará la lista de las plataformas en línea que no cumplen las obligaciones que les incumben en virtud del artículo L. 111-7. Como se puede apreciar, la sanción más eficiente para una plataforma es su desprestigio online.

211. Y, por último, establece una regulación de los sistemas de reputación online en el art. 111-72 del Código de Consumo: "Sin perjuicio de las obligaciones de información previstas en el artículo 19 de la Ley no $2004-575$ de 21 de junio de 2004 sobre la confianza en la economía digital y en los artículos L. 111-7 y L. 111-7-1 del presente Código, toda persona física o jurídica cuya actividad consista, como actividad principal o secundaria, en recabar, moderar o difundir opiniones en línea de los consumidores está obligada a proporcionar a los usuarios información justa, clara y transparente sobre la forma de publicar y tratar las opiniones publicadas en línea. Debe especificarse:

- Si las opiniones están o no sujetos a control y, en caso afirmativo, indica las principales características del control realizado.

- La fecha de la opinión y las actualizaciones 
Se deberá informar a los consumidores cuyo anuncio en línea no haya sido publicado de los motivos de su rechazo.

Los proveedores de bienes y servicios tienen derecho a advertir al operador de la plataforma sobre la autenticidad de la notificación, debiendo indicar el motivo de la alerta.

212. Como se puede apreciar de la regulación francesa, la misma opera para toda plataforma al margen de la naturaleza del bien o servicio que se ofrezca. Se abordan los aspectos clave: transparencia sobre el papel de la plataforma, condición de los usuarios, parámetros de clasificación de ofertas y sistemas de reputación. A ello hay que añadir la reforma citada del art. 1171 del Código Civil francés sobre la aplicación de la normativa sobre cláusulas abusivas a contratos entre particulares a la que ya he hecho mención.

213. Es clara, a mi juicio, la necesidad y oportunidad de abordar esta regulación antes de que la contratación a través de plataformas intermediarias en línea se convierta en foco de conflicto para los consumidores, usuarios y proveedores. La Comisión Europea inició la consulta pública para recabar opiniones sobre una norma europea sobre servicios digitales y que afectará a las plataformas intermediarias en línea. El tema está encima de la mesa y esperemos que la regulación vaya en la dirección correcta https:// ec.europa.eu/commission/presscorner/detail/es/ip_20_962 (Consultado el 2 de septiembre de 2020). 